\title{
Description of Calligenethlon watsoni based on computed tomography and resulting implications for the phylogenetic placement of embolomeres
}

\author{
by
}

Gabrielle Ruth Adams

A thesis submitted to the Faculty of Graduate and Postdoctoral Affairs in partial fulfillment of the requirements for the degree of

Master of Science

in

Earth Sciences

Carleton University

Ottawa, Ontario

(C) 2020, Gabrielle Ruth Adams 


\begin{abstract}
Although Calligenethlon watsoni, an enigmatic embolomere from Joggins, Nova Scotia, has been known since 1934, an in-depth description of its anatomy and taxonomic diagnosis is missing from the literature, resulting in subsequent specimen referrals to be based largely on the nondiagnostic trait of small body size. Here, an exquisitely preserved Calligenethlon specimen is described in detail using micro-computed tomography. The anatomical knowledge gained here allowed for the re-evaluation of all referred specimens and creation of the first ever, robust morphological diagnosis of Calligenethlon. This anatomical data was then used to test the recent hypothesis that braincase characters unite embolomeres in a stem tetrapod position. A series of analyses, using the most up-to-date sampling of characters and relevant tetrapod taxa, resulted in the conclusion that embolomeres do group together in a stem tetrapod position, but braincase characters are seemingly uninfluential in this placement, and taxon sampling may be of greater significance.
\end{abstract}




\section{Acknowledgements}

Firstly, I would like to thank my supervisor, Dr. Hillary Maddin for the continued support, advice, and belief that this project would work against all odds. Thanks must also extend to the Redpath Museum for loaning the specimen for study. Thank you also to my committee members, Danielle Fraser and Emily Standen, for their careful reading of this thesis and their insightful comments and suggestions. Thank you to Carleton University, the Earth Science Department, and the Maddin Lab for their wonderful support through all the technical difficulties and especially Misha, Jade, and Bassel for creating the army of computers necessary to complete my phylogenies. To all the amazing friends I've made through my years at Carleton University, you're the bestest and I couldn't have done it without you! Special thanks go to my brilliant Mum and Dad for the love, endless support, and free meals. To Raphael and Nathanael, thanks for the awful music recommendations along the way. 


\section{Table of Contents}

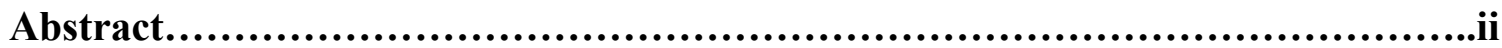

Acknowledgements.....................................................................ii

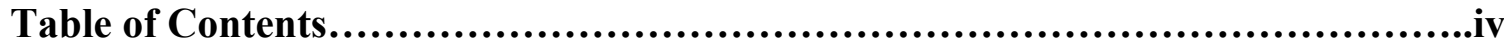

List of Tables.....................................................................vii

List of Illustrations...................................................................viii

List of Appendices...................................................................ii

Chapter 1: An overview of geological and paleontological research at the Joggins

Fossil Cliffs with a focus on the Embolomeri..........................................1

The Joggins Fossil Cliffs................................................

Description of the Joggins Formation Geology ................................4

The Vertebrate Fauna of the Joggins Fossil Cliffs.............................

Statement of Research................................................... 12

Chapter 2: Computed Tomography (CT) analysis of the anatomy of NSM 994GF1.1 and the implications for the taxonomic validity of Calligenethlon watsoni Steen.....14

Introduction.............................................................. 14

Problems with Calligenethlon........................................43

Institutional Abbreviations.........................................44

Anatomical Abbreviations.............................................44

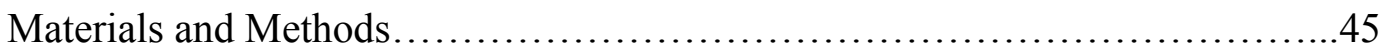

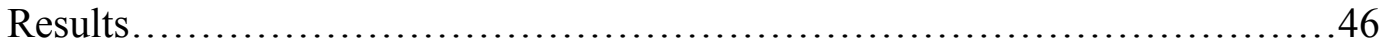

The Skull Table............................................................50 
The Cheek Margin..............................................54

The Braincase ....................................................57

The Lower Jaw.................................................61

The Dentition.................................................64

The Atlas-Axis Complex.........................................64

The Vertebral Column..............................................68

The Neural Arches..................................................71

The Ribs....................................................... 72

The Pectoral Girdle................................................73

The Forelimb.................................................. 77

Discussion............................................................ 81

Referral of NSM 994GF1.1 to Calligenethlon watsoni..................81

Reassessment of specimens referred to Calligenethlon.................83

The Diagnosis of the genus Calligenethlon ...........................88

Further questions regarding Calligenethlon morphology...............89

Implications for embolomere diversity at Joggins ...................91

Chapter 3: A phylogenetic analysis of NSM 994GF1.1 to determine the placement of embolomeres in the tetrapod tree........................................................93

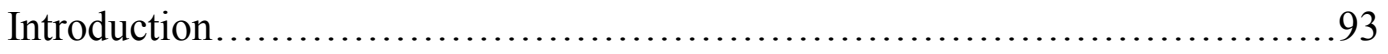

Methods.......................................................... 98

Results........................................................... 100

Discussion...................................................... 108 
The role of braincase characters in determining the phylogenetic position of embolomeres.

The role of taxon sampling in determining the phylogenetic position of embolomeres................................................110

Insights into embolomere interrelationships......................111

The surprising position of Calligenethlon ..........................113

Chapter 4: Conclusions and further research..................................117

The 3D description of NSM 994GF1.1 ...............................117

The revision of the genus Calligenethlon .................................118

Embolomere taxonomy............................................ 119

The placement of Calligenethlon .......................................120

Directions for further research...................................... 120

Final Remarks....................................................122

Appendices...........................................................................124

Appendix A....................................................... 124

Appendix B......................................................... 125

Appendix C........................................................ 145

References...............................................................................148 


\section{List of Tables}

Table 1.1: An overview of all specimens previously attributed to Calligenethlon

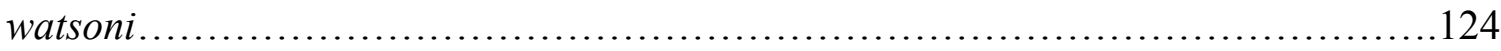




\section{List of Illustrations}

Figure 1.1: Map of Nova Scotia, Canada. Red dot shows the placement of the Joggins Fossil Cliffs

Figure 1.2: Map of the Joggins Fossil Cliffs, showing the arrangement of the formations

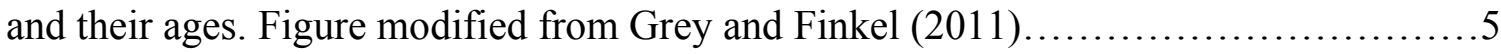

Figure 1.3: Detail of NSM 994GF1.1. Skull table in dorsal view................... 10

Figure 2.1: A, RM 2.1122, the type specimen of Calligenethlon watsoni. B-C, pelvic girdles associated with RM 2.1122 in medial view. Grey represents the impression of bone. Figure modified from Carroll (1967), scale unspecified in original publication....18

Figure 2.2: A-B, RM 2.1193a, counterparts of the type of “Atopotera moneres”, which was later referred to Calligenethlon watsoni (Carroll, 1967). Grey represents the impression of bone. Figure modified from Carroll (1967), scale unspecified in original

publication

Figure 2.3: RM 12115, may be associated with RM 2.1193a. The pterygoid (A), interclavicle (B), radius (C) and scapulocoracoid (D) referred to Calligenethlon by Carroll (1967). Grey represents the impression of bone. Figure modified from Carroll (1967), scale unspecified in original publication.

Figure 2.4: NMC 10050. The right femur in A, dorsal; B, ventral; C, anterior; and D, posterior views. B1, the right tibia in extensor view; B2, the right tibia in flexor view. The pleurocentrum in B1, lateral and B2, posterior views. C, the intercentrum in lateral view. Grey represents the impression of bone. Figure modified from Carroll (1967), scale unspecified in original publication........................................... 24 
Figure 2.5: NMC 10096. Basioccipital in ventral view. Grey represents the impression of bone. Figure modified from Carroll (1967), scale unspecified in original publication...26

Figure 2.6: NMC 10119. A clavicle and interclavicle in ventral view. Figure modified from Carroll (1967), scale unspecified in original publication......................28

Figure 2.7: DMSW B.224. A left humerus in ventral view. Figure modified from Carroll (1967), scale unspecified from in original publication. 30

Figure 2.8: $\mathrm{BM}(\mathrm{NH})$ R.442. Clavicle, limb elements and scales. Figure modified from Carroll (1967), scale unspecified in original publication. .32

Figure 2.9: $\mathrm{BM}(\mathrm{NH})$ R.4553. Grey represents the impression of bone. Figure modified from Carroll (1967), scale unspecified in original publication........................ 34

Figure 2.10: NSM 988GF70.1. An articulated series of trunk vertebrae in left lateral view. Figure modified from Godfrey et al. (1991)..................................

Figure 2.11: RM 20.4984. A series of articulated presacral vertebrae with pelvic and limb elements in left lateral view. Figure modified from Godfrey et al. (1991)...........38

Figure 2.12: NSM 994GF1.1. An articulated anterior half of an embolomerous skeleton in dorsal view .40

Figure 2.13: Detail of NSM 994GF1.1 showing the articulated skull table, cheek margin and cervical vertebrae in dorsal view..... .41

Figure 2.14: NSM 994GF1.1 as it was originally found in ventral view. Photo courtesy of the Nova Scotia Museum in Nova Scotia, Canada.

Figure 2.15: The full skeleton of NSM 994GF1.1 as revealed by segmentation of the CT data. A, dorsal; B, ventral; and C, left lateral view. Anterior to the left in A and B and to the top in C. Scale bar is $1 \mathrm{~cm}$ 49 
Figure 2.16: The skull table of NSM 994GF1.1 in A, dorsal; B, lateral; and C, posterior view

Figure 2.17: The left cheek margin of NSM 994GF1.1 in A, lateral view as preserved; and $\mathrm{B}$, in lateral view with the jugal removed to show the postorbital.................55

Figure 2.18: The skull of NSM 994GF1.1 in ventral view.........................58

Figure 2.19: Isolated prearticular, surangular, and articular of NSM 994GF1.1 in A, left lateral and B, medial view. C, isolated surangular and dentary teeth in left lateral view..62 Figure 2.20: Isolated elements of the atlas-axis complex of NSM 994GF1.1. A-C, articulated complex in anterior, left lateral, and posterior view. D-E, right atlas arch in anterior and medial view. F, left proatlas in dorsal view. G, atlas pleurocentrum in anterior view. $\mathrm{H}$, atlas intercentrum in anterior view. Scale bars equal $1 \mathrm{~cm} \ldots \ldots \ldots \ldots . . .66$

Figure 2.21: Isolated vertebral elements of NSM 994GF1.1. A, articulated neural arch, pleurocentrum, and intercentrum. B-C, pleurocentrum in anterior and left lateral view. D$\mathrm{E}$, intercentrum in anterior and left lateral view. $\mathrm{F}$, neural arch in anterior view..........70

Figure 2.22: Isolated ribs in NSM 994GF1.1. Note the elongated and curved morphology of the posterior ribs compared to the short straight morphology of the anterior ribs.....73

Figure 2.23: Isolated left of the pectoral girdle of NSM 994GF1.1 in A, left lateral; B, ventral; and $\mathrm{C}$, medial view 74

Figure 2.24: Isolated articulated right forelimb of NSM 994GF1.1 in A, dorsal and B, ventral view............................................................ 78

Figure 2.25: Isolated forelimb elements of NSM 994GF1.1. A-D right humerus in anterior, dorsal, posterior, ventral view. Note the extremely well developed ectepicondylar process. E-H right radius in anterior, dorsal, posterior, ventral view. I-L, 
right ulna in anterior, dorsal, posterior, ventral view. Note the well developed olecranon

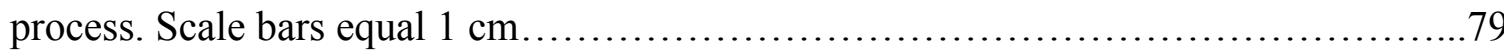

Figure 3.1: The two prevailing theories of embolomere placement within the tetrapod tree. A, embolomeres considered reptiliomorphs on the amniote stem; and B, embolomeres considered stem tetrapods. Figure modified from Vallin and Laurin (2004).

Figure 3.2: The strict consensus tree of Analysis 2 showing embolomeres in a stem tetrapod position

Figure 3.3: The majority rule consensus tree of Analysis 2 showing embolomeres in a stem tetrapod position. Branch labels indicate the percentage of parsimonious trees that recovered this node.

Figure 3.4: The strict consensus tree of the analysis that added more characters showing embolomeres in a stem tetrapod position. .104

Figure 3.5: The majority rule consensus tree of the analysis that added more characters showing embolomeres (boxed in red) in a stem tetrapod position. Nodes of interest are labelled: A, the characters that unite embolomeres to a stem tetrapod position (characters listed in Appendix C1); B, characters that exclude embolomeres from a more derived position (characters listed in Appendix C2). Branch labels indicate the percentage of parsimonious trees that recovered this node.................................... 105

Figure 3.6: The strict consensus tree of the analysis that added more stem tetrapod taxa showing embolomeres in a more crownward position within the stem tetrapods.... 106

Figure 3.7: The majority rule consensus tree of the analysis that added more stem tetrapod taxa showing embolomeres (boxed in red) in a more crownward position within 
the stem tetrapods. Nodes of interest are labelled: A, the characters that unite embolomeres in a more crownward position (characters listed in Appendix C3). Branch labels indicate the percentage of parsimonious trees that recovered this node.................107 


\section{List of Appendices}

Appendix A: An overview of all specimens previously attributed to Calligenethlon

watsoni

Appendix B: Phylogenetic character list, modified from Pardo et al. (2017a) and Clack

et al. (2016).

125

Appendix C: Synapomorphy lists describing nodes of interest in the analyses that added

more characters and more stem tetrapod taxa.

C1: Characters uniting embolomeres in a stem-tetrapod position in the analyses that added more embolomeres taxa and more characters (describing Figure 3.5, Node A)

C2: Characters excluding embolomeres from a more derived position within the tetrapod tree in the analyses that added more embolomeres taxa and more characters (describing Figure 3.5, Node B)

C3: Characters uniting embolomeres in a more crownward position in the analysis that added more stem tetrapod taxa (describing Figure 3.7, Node A)...147

C4: Characters uniting Calligenethlon and Tulerpeton in the analysis that added more stem tetrapod taxa (describing Figure 3.7, Node B).... 


\section{Chapter 1: An overview of geological and paleontological research at the Joggins Fossil Cliffs with a focus on the Embolomeri}

\subsection{THE JOGGINS FOSSIL CLIFFS}

The importance and significance of the cliffs of the Bay of Fundy near the town of Joggins, Nova Scotia (Figure 1.1), known as the Joggins Fossil Cliffs (JFC), have only grown since their first description in 1826 by Richard Brown. Brown had been hired by the General Mining Association of London to assess the possibility of coal mining in Nova Scotia (Falcon-Lang, 2006). His mention of successive horizons of upright, fossilized trees (Brown and Smith, 1826) caught the attention of British geologist Sir Charles Lyell, who had been trying to understand whether coal originated from driftwood or was formed in situ beneath forest ecosystems (Falcon-Lang, 2006). Lyell felt that studying the coal seams preserved in successive beds with the forest profiles at Joggins would allow him to prove their connection and thereby confirm the latter hypothesis (Lyell, 1845). This interest resulted in the confirmation that coal is created autochthonously and also led to the first thorough description of the Joggins fossil record (Lyell, 1845). Lyell returned to Joggins in 1852 with Sir William Dawson to study the fossilized trees, look for additional fossils within them, and measure the stratigraphic section (Dawson, 1853). Dawson went on to publish over 19 major papers on the JFC over the course of his career, but after his death much of the research at this locality dropped off (Falcon-Lang, 2006), aside from a few publications based on the study of Dawson's pre-existing faunal collections (e.g. Steen, 1934; Copeland, 1957). 
Walter Bell, from the Geological Survey of Canada, renewed interest in fieldbased research at the JFC with the development of a Joggins field guide (Bell, 1913) and

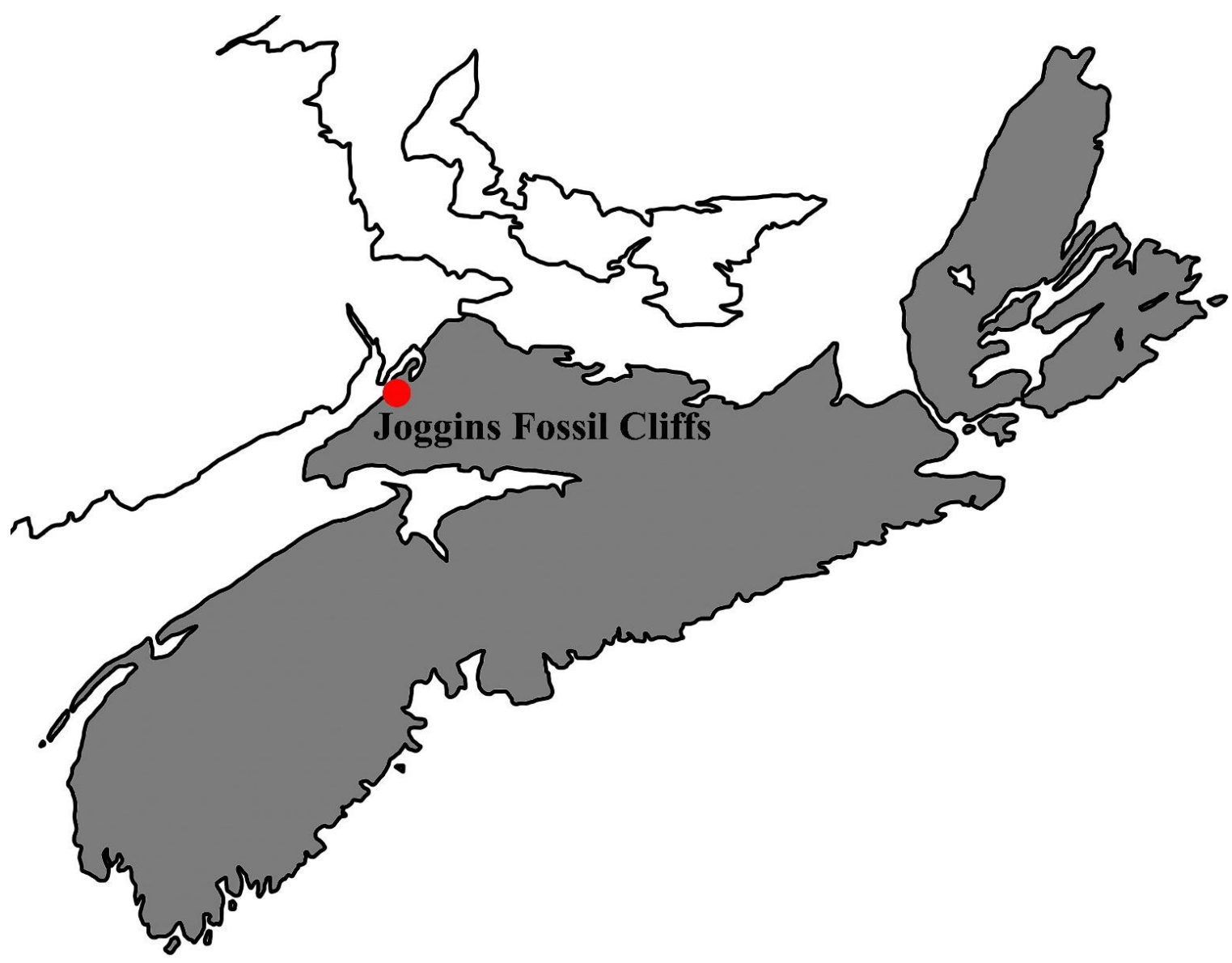

Figure 1.1: Map of Nova Scotia (in grey), Canada. Red dot indicates the location of the Joggins Fossil Cliffs. Scale bar equals $50 \mathrm{~km}$. 
a new paper on the Pennsylvanian flora at the site (Bell, 1943). Bell's works inspired a second wave of interest in field work at Joggins, including teams led by Charles Sternberg of the Geological Survey of Canada, who described tetrapod trackways (Sternberg, 1933) and body fossils (Sternberg, 1948), a team from Harvard University led by William Dawson, who described a new tetrapod species, "Baphetes" minor (Dawson, 1870), and a team from Princeton University, led by Don Baird, who recovered the earliest representative of the extinct fish family Haplolepidae (Baird, 1962; 1978). Continued field work at Joggins led to several more publications on temnospondyl remains (Baird, 1982; Godfrey et al., 1987; Milner, 1996; Holmes et al., 1998; Robinson et al., 2005), the 'microsaur' fauna (e.g. Carroll, 1963; 1966; Stevenson and Stevenson, 1966; Stevenson, 1967; Reisz and Modesto, 1996), embolomerous tetrapods (Godfrey et al., 1991; Holmes and Carroll, 2010) and tetrapod trackways (Matthew, 1903; 1905; Sarjeant and Mossman, 1978; Mossman and Grantham, 1996; Prescott et al., 2013). Soon after this new wave of interest in the JFC, sedimentologist Martin Gibling from Dalhousie University and his graduate student John Calder began a long-term research group, which has continued the geological and paleontological study of the cliffs to this day (Falcon-Lang, 2006). Calder involved local amateur paleontologist Brian Hebert, who has contributed significantly to the current knowledge of the faunal assemblage and geology at the JFC (e.g. Hebert and Calder, 2004; Falcon-Lang et al., 2004). Fossil collection at Joggins is ongoing today, primarily led by a collaborative effort between Carleton University, the Nova Scotia Museum, Saint Mary’s University and the Joggins Fossil Institute. 


\subsection{DESCRIPTION OF THE JOGGINS FORMATION GEOLOGY}

The Joggins Fossil Cliffs (JFC), inscribed on the UNESCO World Heritage Site list in 2008, include a $14.7 \mathrm{~km}$ section along the shores of the Cumberland Basin of Chignecto Bay, which is part of the Northern extension of the Bay of Fundy (Calder, 2012). The JFC make up part of the Cumberland Group, which resides within the Cumberland Basin as part of the larger scale Maritimes Basin (Allen et al., 2013). The protected section extends from Downing Cove to Ragged Reef Point (Calder, 2012). It exposes strata of the Pennsylvanian Period, as well as several million years prior (Calder, 2012). The outcrop comprises six formations representing a time frame spanning $325 \mathrm{Ma}-305 \mathrm{Ma}$ : the Shepody Formation, the Boss Point Formation, the Little River Formation, the Joggins Formation, the Spring Hill Mines Formation, and the Ragged River Formation, from base to top (Calder, 2012; Figure 1.2). The Joggins Formation, which makes up a part of the JFC, is exposed along Chignecto Bay for about 2.8 kilometers (Davies et al., 2005) between Lower Cove and the old Joggins Wharf and is traceable inland for about 35 kilometers (Falcon-Lang et al., 2006). The type section is 915.5 meters thick and is interpreted as being deposited around 313.4-314.5 Ma, or Langsettian stage, based on palynological analysis (Falcon-Lang et al., 2006). The Joggins Formation was deposited near the equator within Pangea during Pennsylvanian times (Falcon-Lang et al., 2006; Calder, 1998). The Joggins Formation displays three facies associations: an open-water brackish bay, a poorly drained floodplain, and a well-drained floodplain (Rygel and Gibling, 2006). 


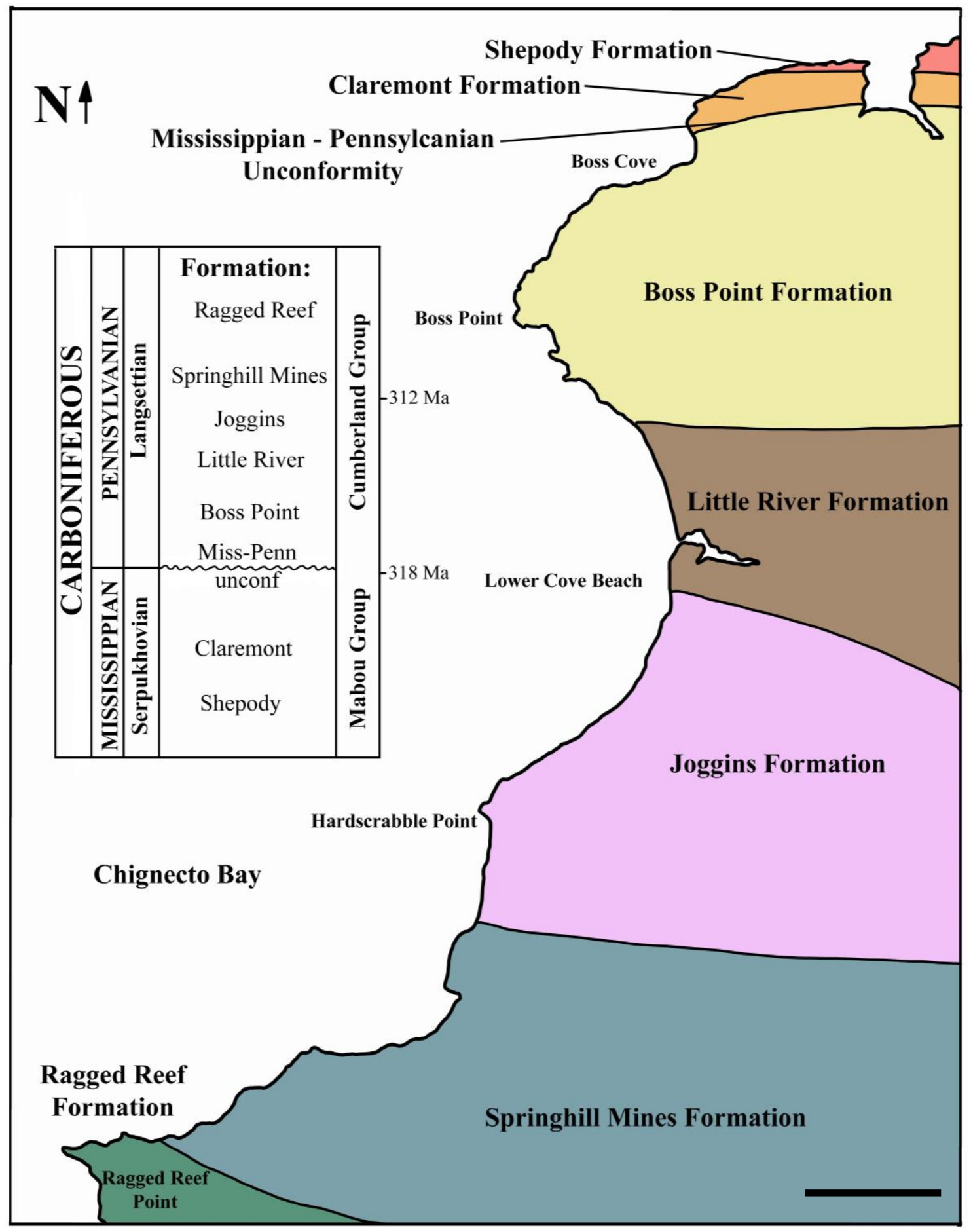

Figure 1.2: Map of the Joggins Fossil Cliffs in aerial view, showing the arrangement of the formations and their relative ages. Coloured portions indicate land exposures. White portion indicates tidal flats and ocean. Figure modified from Grey and Finkel (2011). Scale bar equals 1 $\mathrm{km}$. 
The open-water brackish bay associations consist of coal beds overlain by fossiliferous limestones or fossiliferous siltstones containing bivalves, ostracods, gastropods, fish, insects, and arthropods (Davies and Gibling, 2003). These are interpreted as representing periodic flooding events that would have covered much of the basin (Rygel and Gibling, 2006). The rapid increase in water level during this phase reduced the deposition of clastic material into the basin while the limestones were being deposited, and the siltstones that follow represent a return of the deposition of clastic material into standing water (Davies and Gibling, 2003). The poorly drained floodplain facies comprises over $50 \%$ of the Joggins Formation and represents a period of progradation during which time the bays became infilled by wetland delta environments (Rygel and Gibling, 2006; Falcon-Lang et al., 2006). Included in this association are mudrock, channel sandstones, coal layers, and lacustrine limestones (Rygel and Gibling, 2006). Davies and Gibling (2006) further split the sandstones into a sand-poor subgroup and sand-rich subgroup, where the sand-poor subgroup represents a period of low sediment input and low channel activity and the sand-rich group represents the main fluvial channels. The presence of fossilized charcoal within the coal seams indicates periodic wildfires (Davies and Gibling, 2003).

The poorly drained floodplain association is followed by a well drained floodplain facies association (Davies and Gibling, 2003). This facies is characterized by a lack of coal seams, as well as distinctive red-coloured siltstones and sandstones and calcareous nodules, which indicate good drainage of the environment (Davies and Gibling, 2003). An anastomosing fluvial system is indicated by several channel bodies at the same level 
(Davies and Gibling, 2003). The sandstones of this facies preserve tetrapod footprints (Davies and Gibling, 2003).

The open-water bay, poorly drained floodplain, and well-drained floodplain facies are repeated over 14 cycles, each cycle ranging from 16 to 212 meters in thickness (Rygel and Gibling, 2006). These cycles are interpreted as being related to the rapid subsidence

of the entire Cumberland Basin between the Namurian and the Early Westphalian (Rygel and Gibling, 2006; Davies and Gibling, 2003). This ongoing movement would have created a lot of accomodation within the basin, but the high deposition rates at this time balanced out this effect, allowing the basin to remain as a coastal depositional setting (Davies and Gibling, 2003). The glacioeustatic fluctuations in sea level seen at Joggins are not as obvious as temporally equivalent basins in Europe and the United States, but this is thought to be because the rapid subsidence exaggerated the sea level rises and masked the sea level falls (Davies and Gibling, 2003).

\subsection{THE VERTEBRATE FAUNA OF THE JOGGINS FOSSIL CLIFFS}

The JFC is considered an eco-lagerstätte, meaning the locality preserves an exceptionally rich record of the paleoenvironment, including a diverse faunal assemblage of terrestrial and aquatic members (Falcon-Lang et al., 2006). This includes over 95 genera (and over 140 species) of protists, animals, and plant fossils, and about 20 inchogenera, making the JFC one of the richest Pennsylvanian-aged assemblages currently known (Falcon-Lang et al., 2006). 
The high abundance of small vertebrates is likely due to the unusual mode of preservation found at the locality (Holmes et al., 1998). The large "trees" that initially attracted the attention of Lyell and Dawson were found to contain numerous tiny bones. It was hypothesized that these lycopsids would have been hollow in the Pennsylvanian, and that small animals either lived, became trapped, or were washed into the stump cavities, subsequently protecting and fossilizing their delicate remains (Holmes et al., 1998). The first animal remains to be discovered within one of these "trees" were those of the tetrapod Dendrerpeton acadianum (Lyell and Dawson, 1853), now understood to be a non-amniote, temnospondyl tetrapod (Carroll, 1967; Godfrey et al., 1991). Subsequent expeditions of the JFC led to one of the most significant fossil discoveries to come out of Joggins - the remains of an animal named Hylonomus lyelli (Dawson, 1859). Although originally thought to be an early amphibian (Steen, 1934), Hylonomus is now recognized as the earliest record of an amniote ever found (Gregory and Carroll, 1965; Carroll, 1964). Over the years, many other taxa have been found at this site, including members of the now paraphyletic 'Microsauria' - Trachystegos megalodon, Leiocephalikon problematicum, Hylerpeton dawsoni, and Ricnodon sp. (Carroll, 1966) - as well as early 'protorothyridid' reptiles, such as Archerpeton anthracos, and the putative pelycosaurgrade synapsid Protoclepsydrops haplous (Carroll, 1964). Several specimens have also been attributed to the enigmatic embolomere genus Calligenethlon (Steen, 1934; Carroll, 1967). In virtually all these cases, detailed taxonomic revision is necessary, if not currently underway, due to an almost 50-year hiatus in research on much of this fauna.

In addition to the famous "stump fauna", a few rare tetrapod specimens have been discovered outside the stumps. These are typically found as ex situ beach float on the 
tidal flats adjacent to the cliffs and, unlike the "stump fauna", are often exceptionally well preserved and articulated. The first of these was a three-dimensionally preserved skull of the temnospondyl Dendrerpeton acadianum, found in an overbank deposit, described by Godfrey and colleagues (1987). More recently, another articulated, nearly complete specimen of Dendrerpeton was found in an isolated boulder on the beach, described by Holmes et al. (1998). This discovery dramatically improved the morphological, taxonomic, and ecological knowledge of Dendrerpeton (Holmes et al., 1998). A large, embolomerous tetrapod ilium was reported as well by Hebert and Calder (2004) as possibly belonging to "Baphetes" minor, a tetrapod of unknown affinities, but may actually be an embolomere (Adams et al., in prep). The tail of another embolomere was found preserved in a siderite nodule, described by Holmes and Carroll (2010), and most recently, an articulated anterior half of an embolomerous skeleton (specimen NSM 994GF1.1) was also found in an isolated boulder and attributed to the genus Calligenethlon (Holmes and Carroll, 2010; Figure 1.3). The excellent preservation of this latter discovery is comparable to that of the specimen Holmes et al. (1998) used to revise Dendrerpeton. A similar revision for Calligenethlon is long overdue in embolomere literature, and the specimen described by Holmes and Carroll (2010) represents an excellent opportunity to do just that. Calligenethlon was first named and described by Steen (1934), and although it has since been well described in review papers (e.g. Carroll, 1967) and fairly well represented in the fossil record (Steen, 1934; Carroll, 1967; Godfrey et al., 1991; Holmes and Carroll, 2010), it remains one of the least understood embolomere taxa. The Calligenethlon literature does not contain a clear, unambiguous 


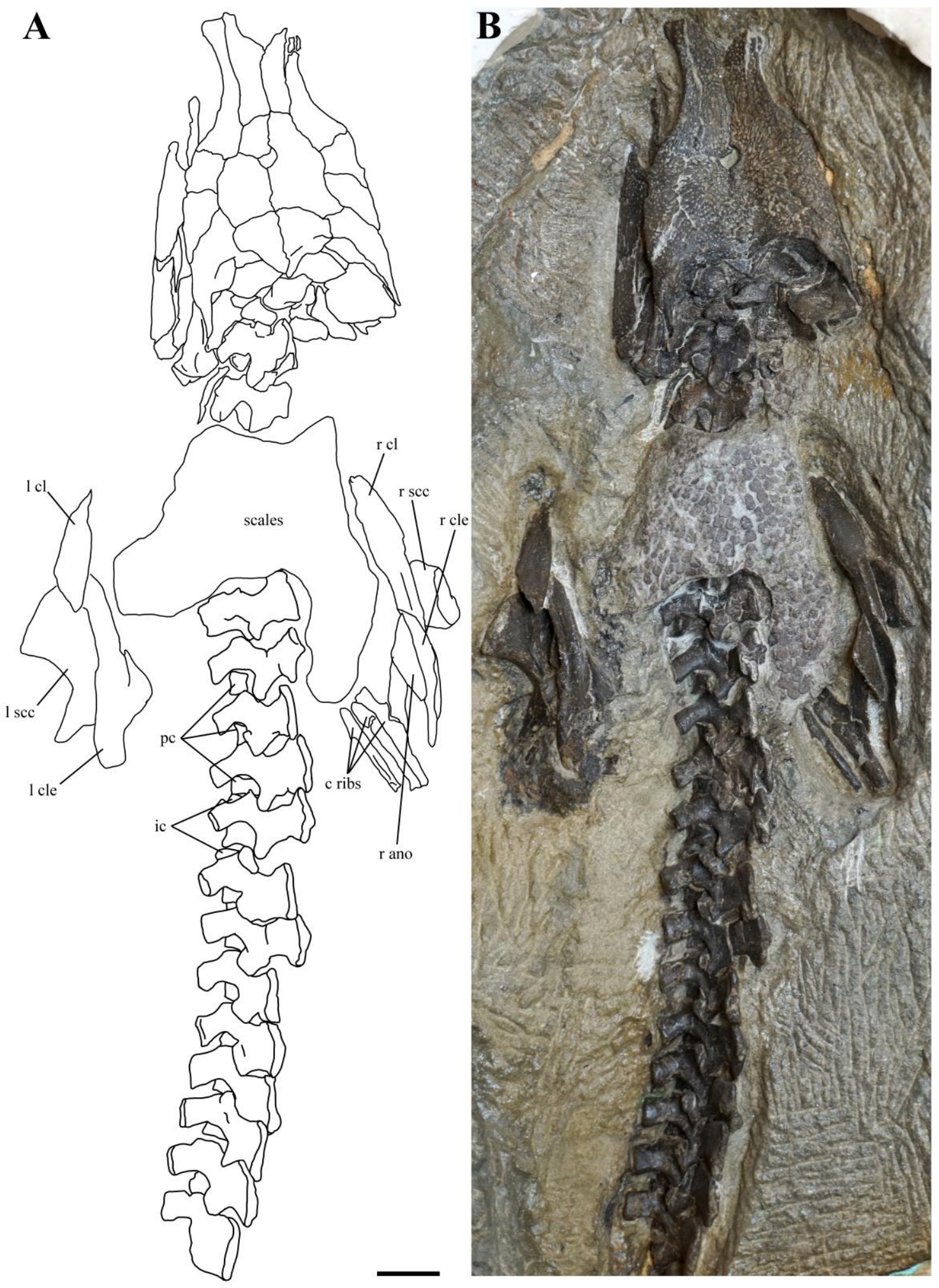

Figure 1.3: A, interpretive drawing and B, photograph of specimen NSM 994GF1.1, the anterior half of an embolomere skeleton in dorsal view tentatively attributed to Calligenethlon watsoni by Holmes and Carroll (2010). See Anatomical Abbreviations list below. Scale bar equals $1 \mathrm{~cm}$. 
definition of the taxon, and therefore attributions of other material to the taxon (see Appendix A for a complete list of all specimens currently attributed to Calligenethlon) have mainly been based on three vague characteristics: large tabulars, the presence of a gracile posterior process of the ilium and a small adult body size (Holmes and Carroll, 2010). As most Calligenethlon specimens are almost half the size of the other smallbodied embolomeres, body size became the taxon's most obvious distinguishing characteristic. However, the more recent discovery of a Proterogyrinus-sized ilium with the diagnostic Calligenethlon morphology (see Godfrey et al., 1991) has seriously challenged the idea that the small specimens previously described for Calligenethlon represent its maximum body size or even something similar to it (see Godfrey et al., 1991). This new discovery reveals the flaws in the existing definition of Calligenethlon and calls into question the accuracy with which specimens have been referred to the genus based primarily on body size and locality (Godfrey et al., 1991).

In addition to a much-needed synthesis of the known anatomy and establishment of a clear morphological diagnosis, ambiguity also surrounds the taxonomic placement of embolomeres within the tetrapod tree (Holmes and Carroll, 2010). Historically, embolomeres were considered to be relatively derived tetrapods, referred to as reptiliomorphs (i.e., animals more closely related to amniotes than to extant amphibians), on the amniote stem (Watson, 1929). This placement was recently challenged by Pardo et al. (2017a) in a broadly sampled analysis of early tetrapod relationships. There, embolomeres were recovered in a stem tetrapod position. Their study used a mix of characters from several different tetrapod studies, as well as 66 new braincase characters following the well-supported hypothesis that braincase characteristics are more 
phylogenetically informative than other parts of the skull because braincase morphology is less influenced by functional or environmental pressures (Olson, 1985; Lieberman et al., 2000; Cardini and Elton, 2008; Goswami and Polly, 2010; Maddin et al., 2012). The stemward placement of embolomeres has not been obtained in other recent studies (e.g. Clack et al., 2016), where embolomeres appear in their historical position on the amniote stem. An in-depth study of the placement of embolomeres on the tetrapod stem was not attempted by Pardo et al. (2017a) and thus remains an open question.

\subsection{STATEMENT OF RESEARCH}

The exquisite nature of the articulated specimen of Calligenethlon (NSM 994GF1.1) presents an opportunity to both revisit questions of the identity of material currently referred to the genus Calligenethlon and potentially aid in creating a more robust diagnosis for the genus, as well as provide new insights into the phylogenetic position of the group through the incorporation of additional anatomical details.

In the second Chapter of this thesis, I synthesize previous work done on Calligenethlon, including short descriptions of each specimen currently referred to the taxon. I then provide a detailed description of the well-preserved specimen NSM 994GF1.1 through the use of micro-computed tomography. A thorough comparison of the anatomy revealed by this analysis with that of the holotype specimen confirms that NSM 994GF1.1 is referable to Calligenethlon watsoni and provides a broader basis for the re-evaluation of all historically referred specimens. For the first time, I outline a clear anatomical diagnosis of the genus Calligenethlon, based on the anatomy shared between all confidently referred specimens and the autapomorphies they display. I conclude by 
briefly commenting on the implications of the new definition of Calligenethlon on the existing tetrapod fauna known at Joggins and on new embolomere discoveries.

The third Chapter of this thesis describes the convoluted taxonomic history of embolomeres since their discovery. In an attempt to address the new controversy surrounding the placement of embolomeres as stem tetrapods in a recent analysis by Pardo et al. (2017a), I conduct a series of analyses based on recently published datasets incorporating new data obtained here. This Chapter presents a novel analysis that combines the characters originally used by Pardo et al. (2017a) with non-overlapping characters used in another recent analysis by Clack et al. (2016). My new matrix also attempts to resolve biases in taxonomic sampling by adding twelve stem tetrapod taxa found in the analysis of Clack et al. (2016) from non-overlapping tetrapod groups, along with the extensive new anatomical data for Calligenethlon provided in Chapter Two and the three most completely known embolomere taxa besides those already included by Pardo et al. (2017a). The resulting analysis represents the most comprehensive character and taxon sample relevant to the issue of embolomere phylogeny to date. This Chapter then provides a series of analyses designed to determine the factors most involved in the phylogenetic placement of embolomeres and an examination of the results.

The fourth Chapter summarizes the new knowledge of Calligenethlon gained in the previous chapters and provides directions for further research into Calligenethlon, embolomeres in general, and their relationships to each other and the broader tetrapod tree. 


\section{Chapter 2: Computed Tomography (CT) analysis of the anatomy of NSM 994GF1.1 and the implications for the taxonomic validity of \\ Calligenethlon watsoni Steen}

\subsection{INTRODUCTION}

The Joggins Fossil Cliffs (JFC), located near the town of Joggins, Nova Scotia, Canada, have only gained fame and significance in the paleontological and geological communities since their discovery in 1826 . The site is placed within the Langstettian substage of the Bashkirian (about 315 Ma; Holmes and Carroll, 2010) and gained the status of a UNESCO World Heritage Site in 2008 for its exceptional preservation of a Pennsylvanian ecosystem and the early tetrapod community that lived within it (FalconLang et al., 2006). The unique mode of preservation of vertebrate material within the lithified infill of upright lycopsid "tree" trunks led to the discovery of the earliest amniote and reptile, Hylonomus lyelli (Dawson 1860; Carroll, 1966; 1964) and the earliest synapsids, Protoclepsydrops haplous (Carroll, 1964) and Asaphestera intermedia (Mann et al., 2020). Other significant discoveries include a variety of 'microsaur' tetrapods, the temnospondyl Dendrerpeton acadianum (Carroll, 1967; Godfrey et al., 1987; Holmes et al., 1998), the putative embolomere "Baphetes" minor (Dawson 1870, figured in Romer, 1963), and the embolomere Calligenethlon watsoni (Steen, 1934; Carroll, 1967; Godfrey et al., 1991; Holmes and Carroll, 2010). Of these various tetrapod groups, the embolomeres remain the least studied and therefore some of the most enigmatic.

Calligenethlon watsoni (Steen, 1934) was the first embolomere found in the Pennsylvanian of North America. It was first named and described from scattered tree 
stump remains in 1934 by Margaret Steen and has remained exclusively known from Joggins ever since (Holmes and Carroll, 2010). Although originally thought of as belonging to the embolomere family Archeriidae, Calligenethlon lacks the specialized dentition present in all archeriids (Holmes, 1989) and is now considered as part of the family Eogyrinidae (Panchen, 1970). To date, Calligenethlon is represented by fourteen specimens, each described below.

Specimen number: RM 2.1122, type specimen (Figure 2.1).

Original publication: Steen 1934.

Consists of: RM 2.1122 includes an articulated skull table which is incomplete anteriorly and a maxilla bearing teeth. Disarticulated postcrania include a scapulocoracoid, a possible clavicle, an interclavicle, a radius, rib fragments, and a broken femur. All elements are scattered and in various levels of completeness. RM 2.1122 represents a minimum of two individuals, based on the presence of four clavicles.

Comments: RM 2.1122 was found in an upright tree stump. The skull is distinguished by elongate, parallel-sided lateral margins and slender tabular horns that protrude posteriorly far beyond the posterior margin of the skull (Steen, 1934). The maxilla shows an undifferentiated dentition, like Archeria (Holmes, 1989), but the morphology is conical or peg-like, unlike the chisel-shaped teeth in Archeria (Holmes 1989) or the recurved apexes in Proterogyrinus (Holmes, 1984; Panchen 1970). The vertebral centra known from RM 2.1122 are deeply amphicoelous, distinguishing it from Dendrerpeton and other temnospondyls (Steen, 1934). Both single- and double-headed ribs are present (Steen, 
1934). There is no evidence of the forelimbs but the scapulocoracoid is preserved, as well as four clavicles (Carroll 1967). The pelvis present in the same block as RM 2.1122 was considered by Steen (1934) to be of unknown affinity, but Carroll (1967) associated it with Calligenethlon. An ilium (Figure 2.2) preserved on the same block as RM 2.1122 was not considered to be part of the embolomere by Steen (1934) but was attributed to Calligenethlon by Carroll (1967). It is diagnostically gracile and bears an extremely slender posterior process and a posteriorly leaning dorsal process. 
A
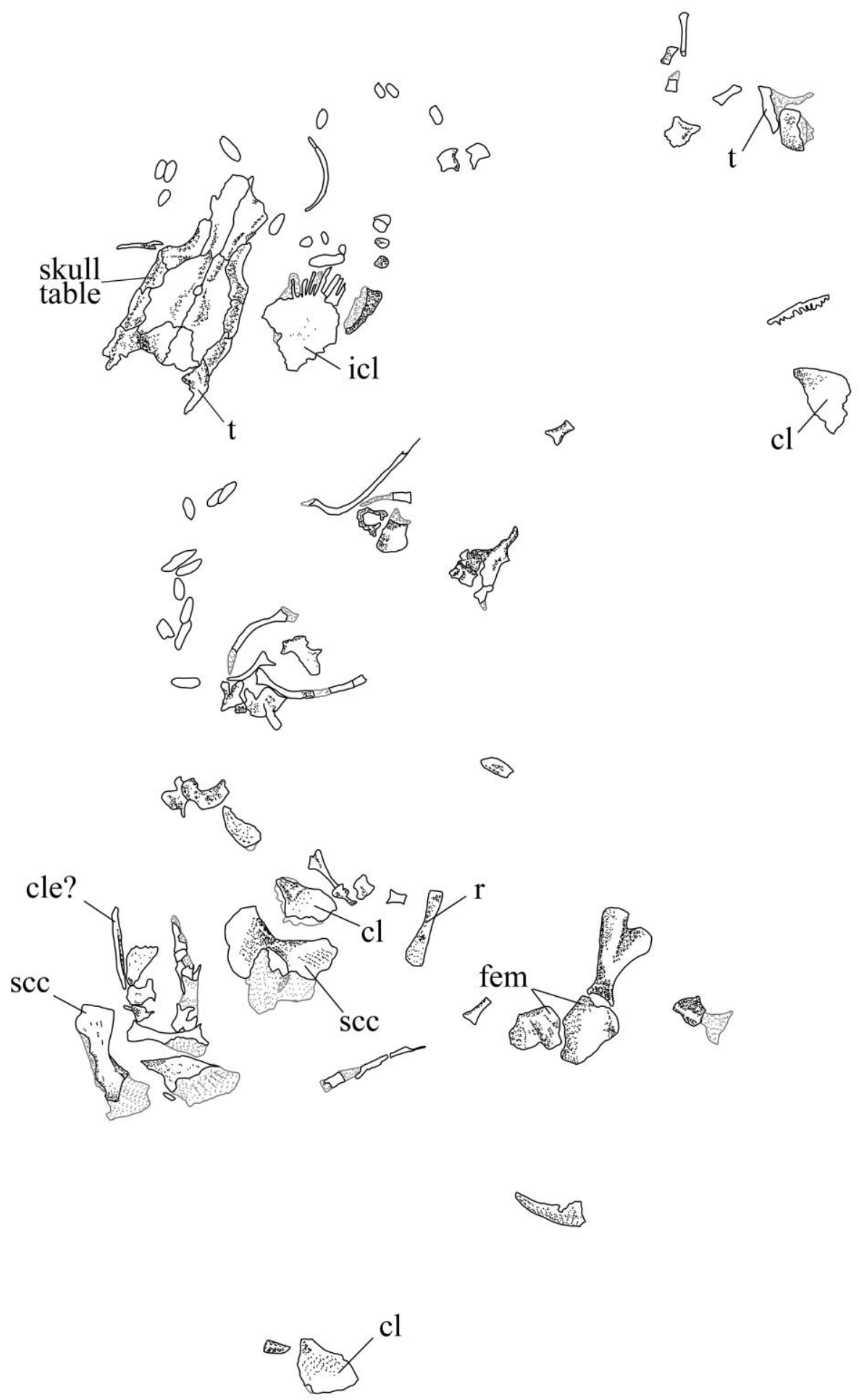


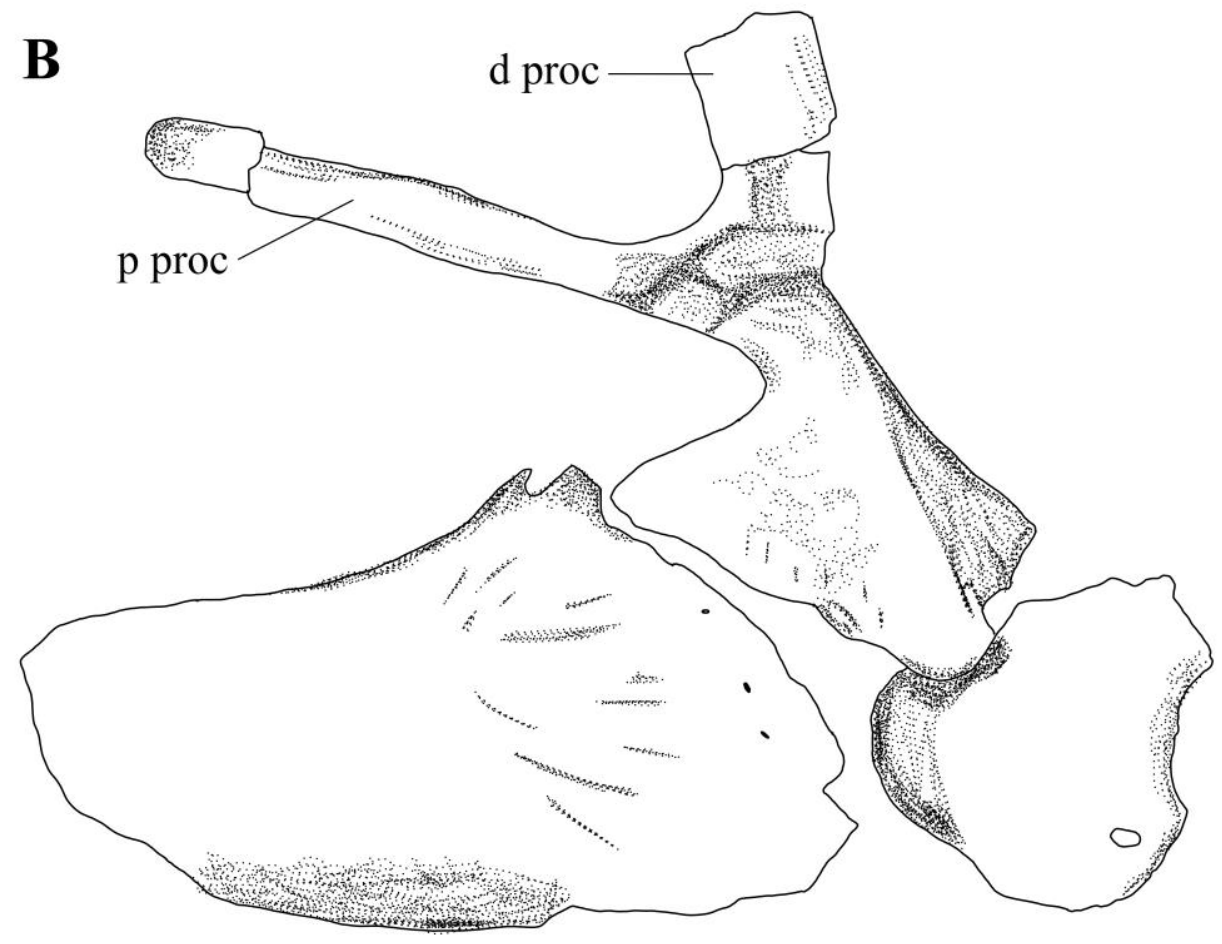

C

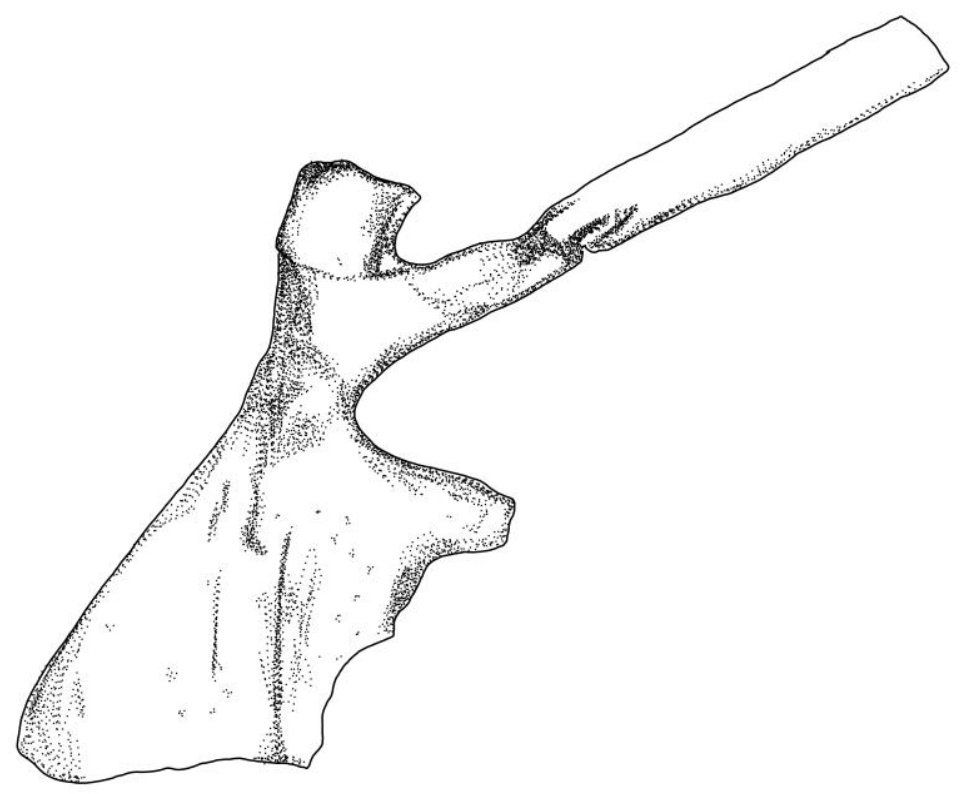

Figure 2.1: Drawing of RM 2.1122. A, the type specimen of Calligenethlon watsoni. Note the large tabulars and the parallel-sided skull table. B-C, pelvic girdles associated with RM 2.1122 in medial view. Note the gracile posterior process of the ilium. Figures modified from Carroll (1967). Scale unspecified in original publication. See Anatomical Abbreviations list below. 
Specimen number: RM 2.1193a, type specimen of Atopotera moneres Steen 1934, but was later referred to Calligenethlon watsoni (Carroll 1967) (Figure 2.2).

Original publication: Steen, 1934.

Consists of: Impressions of the interior surfaces of two skull tables. The first preserves a fragmentary parietal, elongate frontal, and the postfrontal, prefrontal, and lacrimal which surround the right orbital. The second impression preserves the right parietal, fragments of the postparietal, tabular, supratemporal, an elongate frontal and prefrontal of a skull table, as well as a squamosal, quadratojugal, and a narrow maxilla.

Comments: These skulls were found in upright lycopsid tree trunks at Joggins. RM 2.1193, originally named "Atopotera moneres" by Steen (1934) but was referred to Calligenethlon by Carroll (1967). Both skulls are clearly embolomerous and not significantly different from the type of Calligenethlon (Carroll, 1967). This referral added further knowledge of the anatomy of the cheek margin and anterior skull of Calligenethlon. In all instances, the cheek region was disarticulated from the skull table, possibly indicating a loose attachment in life (Carroll, 1967). 
A

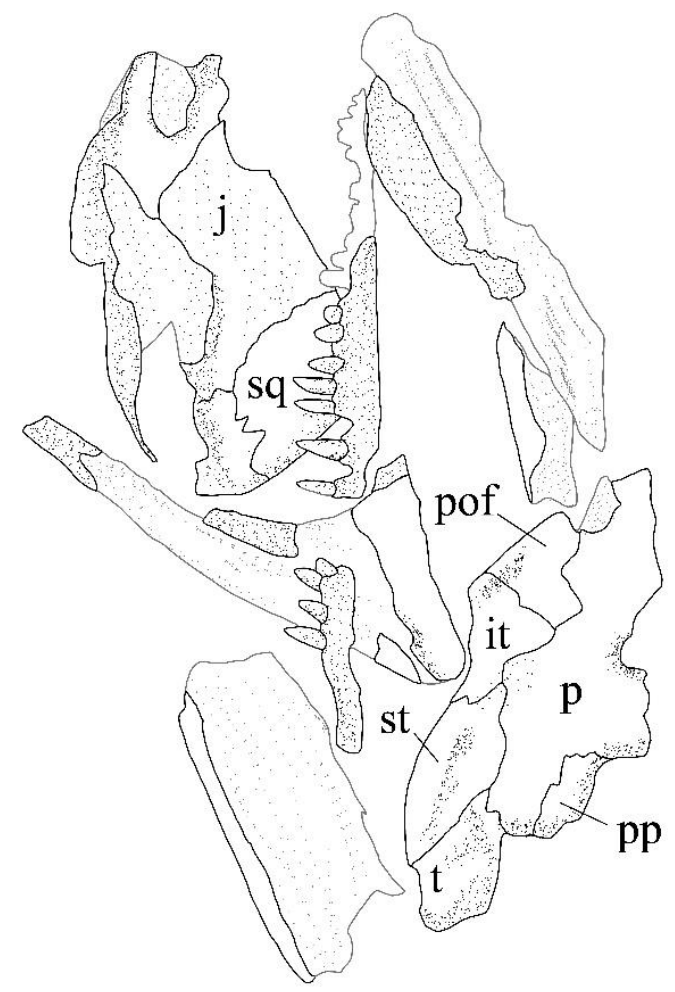

B

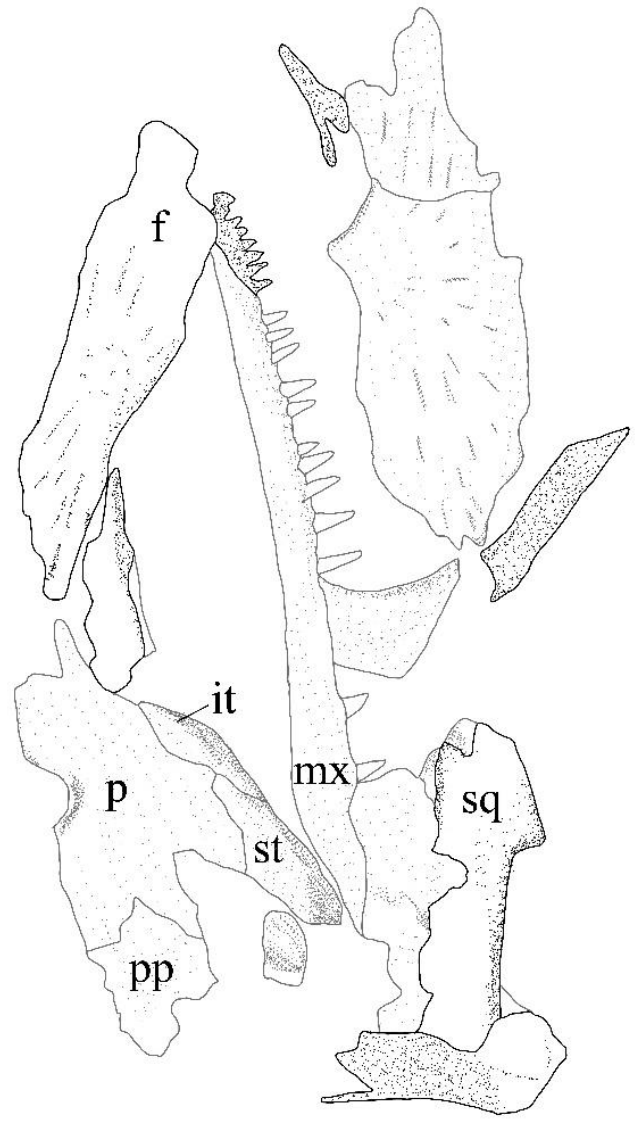

Figure 2.2: Drawing of RM 2.1193a, A-B, part and counterpart of the type of "Atopotera moneres", which was later referred to Calligenethlon watsoni (Carroll, 1967). Figure modified from Carroll (1967). Scale unspecified in original publication. See Anatomical Abbreviations list below. 
Specimen number: RM 12115 (Figure 2.3).

Original publication: Carroll, 1967.

Consists of: Pterygoid, interclavicle, radius, scapula.

Comments: Carroll (1967) tentatively included RM 12115 in the referral of "Atopotera moneres" to Calligenethlon, suggesting that it may have been associated with the other "Atopotera" material because of the similarity of the matrices. With this referral, part of the palate of Calligenethlon became known. Carroll (1967) describes the pterygoid as having a smooth medial margin and a denticulated ventral surface. This morphology has been noted in other Calligenethlon specimens, such as BM(NH) R.4553 (Carroll, 1967). The interclavicle was questionably associated with the rest of the "Atopotera" material but is consistent with other interclavicles referred to Calligenethlon, (see Figures 1 and 8). The interclavicle preserves a long posterior stem and an ovoid anterior plate, similar to the morphology seen in Gephyrostegus bohemicus Jaekel 1902 (Carroll, 1967). The anteriormost margin bears many thin projections, like the teeth of a comb (Carroll, 1967). This morphology is also seen in Archeria (Romer, 1957) to a lesser extent (Carroll, 1967). 

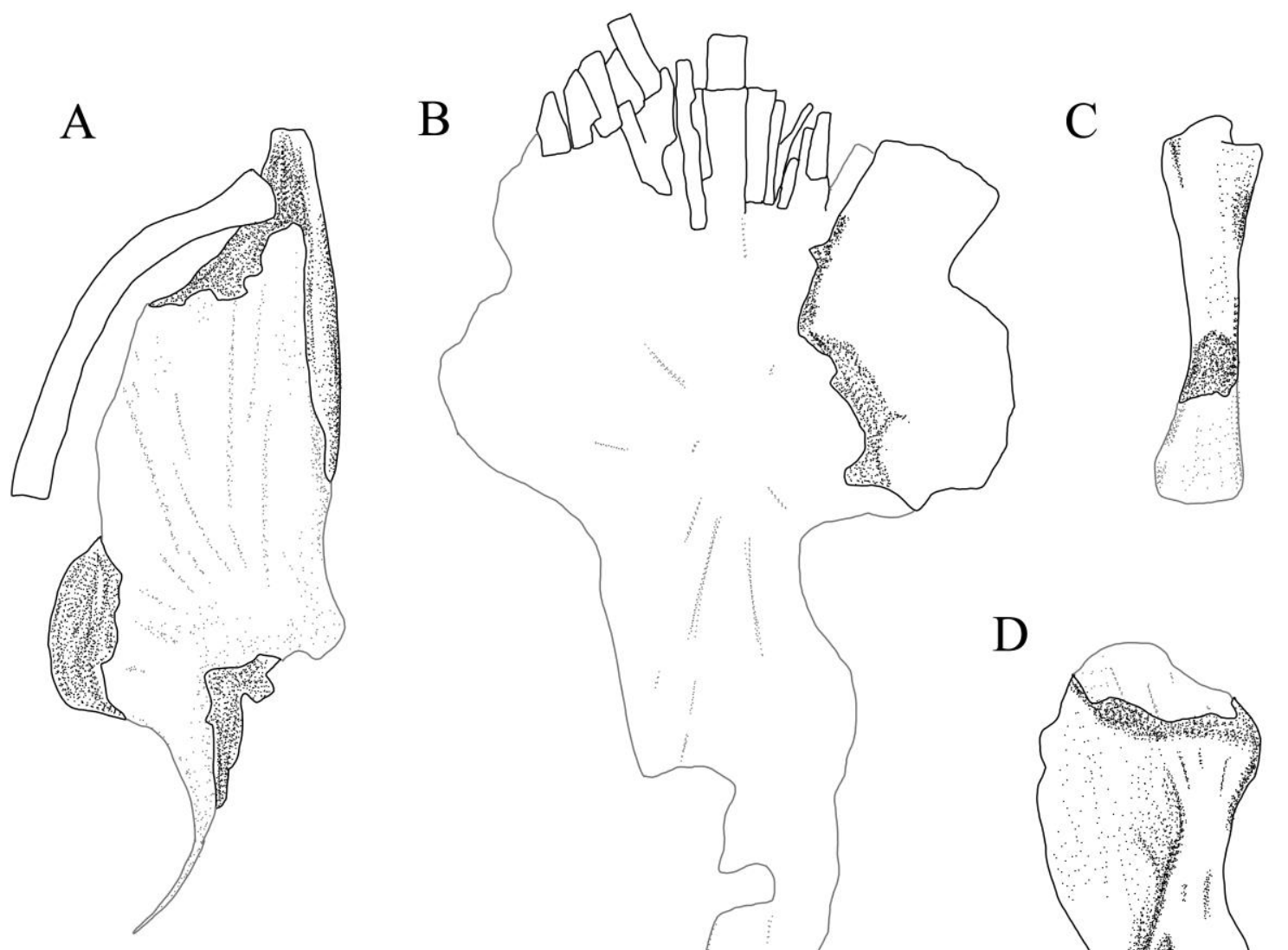

$\mathrm{D}$

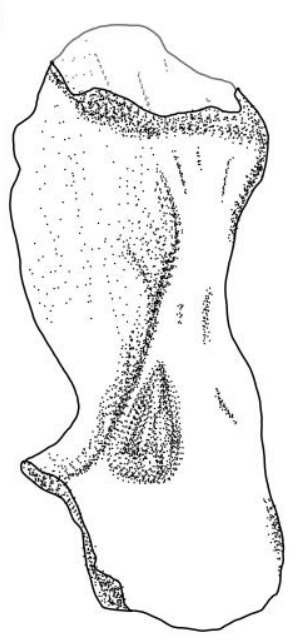

Figure 2.3: Drawing of RM 12115, may be associated with RM 2.1193a. The pterygoid (A), interclavicle (B), radius (C) and scapulocoracoid (D) referred to Calligenethlon by Carroll (1967). Figure modified from Carroll (1967). Scale unspecified in original publication. 
Specimen number: NCM 10050 (Figure 2.4).

Original publication: Carroll, 1967.

Consists of: Vertebrae, femur, tibia.

Comments: NMC 10050 shows dorsally complete and incomplete intercentra, but always fully embolomerous pleurocentra (Carroll, 1967). The femur of NCM 10050 preserves a longer shaft and is more gracile than that of Archeria (Romer, 1957).

Similarly, the tibia is smaller and more lightly built than that of Archeria (Romer, 1957) or other embolomeres. 


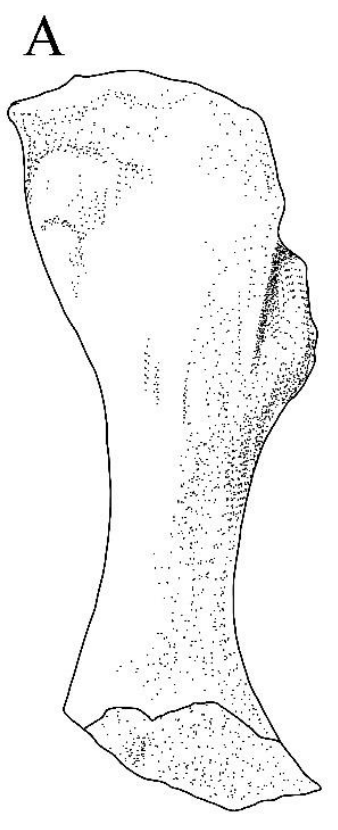

B

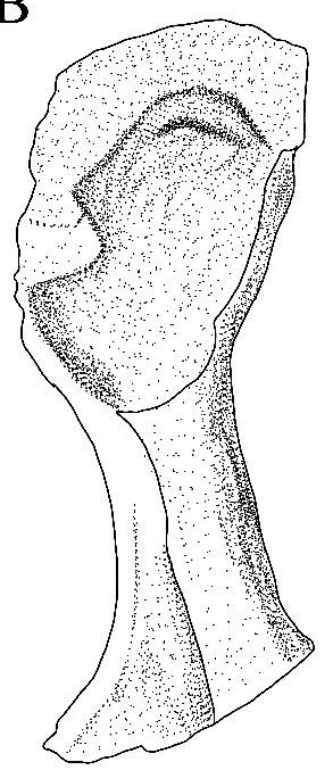

F

E

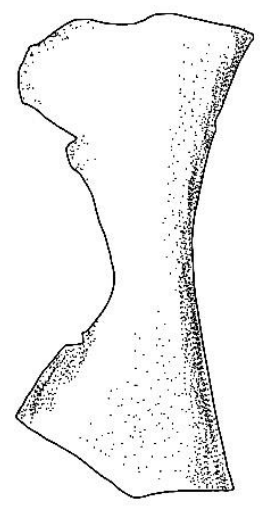

G

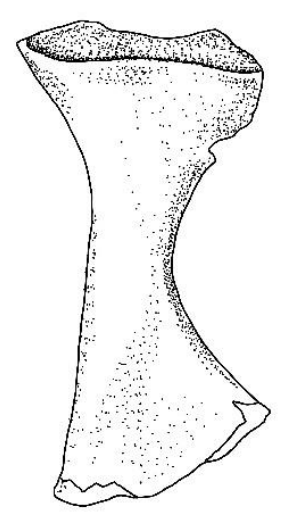

C

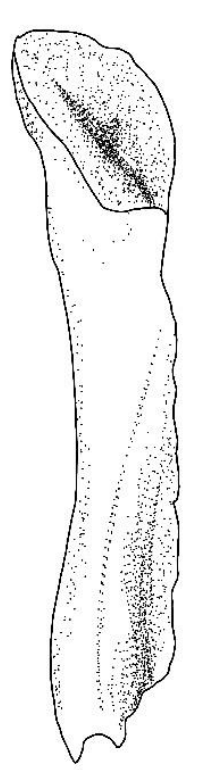

D

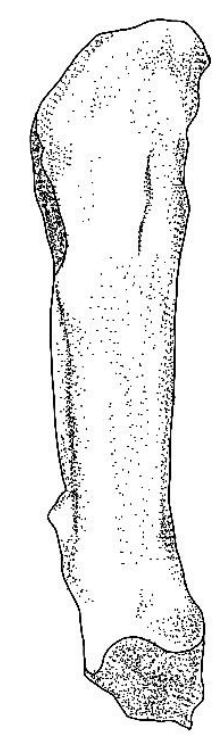

H
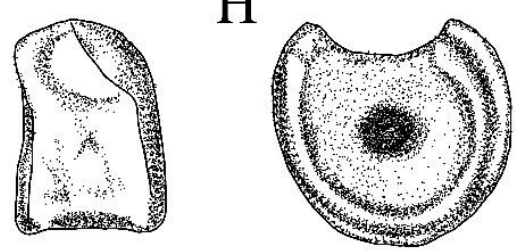

I

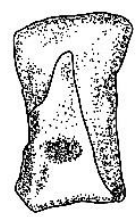

Figure 2.4: Drawing of NMC 10050. The right femur in A, dorsal; B, ventral; C, anterior; and $\mathrm{D}$, posterior views. The right tibia in $\mathrm{E}$, extensor view; and F, flexor view. The intercentrum in $\mathrm{G}$, lateral and $\mathrm{H}$, posterior views. I, the pleurocentrum in lateral view. Figure modified from Carroll (1967). Scale unspecified in original publication. 
Specimen number: NMC 10096 (Figure 2.5).

Original publication: Carroll, 1967.

Consists of: A basioccipital.

Comments: NMC 10096 may be associated with NMC 10050 Carroll (1967). This is the only braincase material known for Calligenethlon. The basioccipital is bullet-shaped, with a wide posterior width that tapers to a blunt point anteriorly. The element is incompletely preserved along most margins but there appears to be the base of a winglike process on the left lateral margin of the basioccipital, as is seen in Archeria (Clack and Holmes, 1988) and Pholiderpeton (Clack, 1987). 


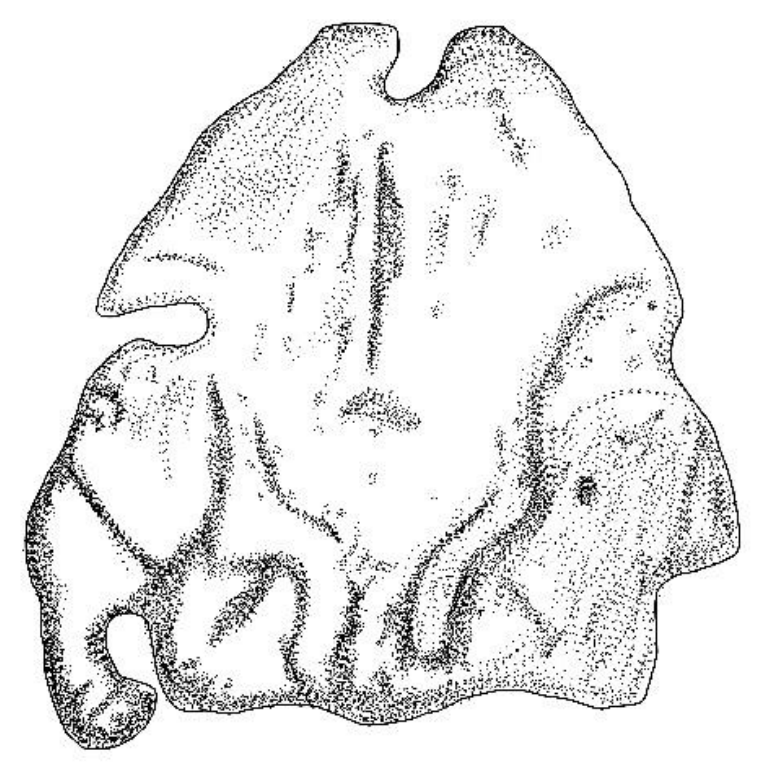

Figure 2.5: Drawing of NMC 10096. Basioccipital in ventral view. Figure modified from Carroll (1967). Scale unspecified in original publication. 
Specimen number: NMC 10119 (Figure 2.6).

Original publication: Carroll, 1967.

Consists of: Clavicle, interclavicle.

Comments: The interclavicle is known from the type specimen, RM 12115, and NMC 10119. These specimens show a broad, flat anterior plate with radiating grooves on the ventral surface. The element is diamond-shaped and NMC 10119 particularly shows thin, comb-like structures along the anterior margin. Similar structures are described for Archeria, but Calligenethlon displays them more extensively (Carroll, 1967). One clavicle is preserved in NMC 10119, but it is incomplete posteriorly. It shows a broad proximal head with radiating pits and grooves (Carroll, 1967). Other clavicles are known from BM(NH) R. 442, showing a narrow stem and distal head (Carroll, 1967). 


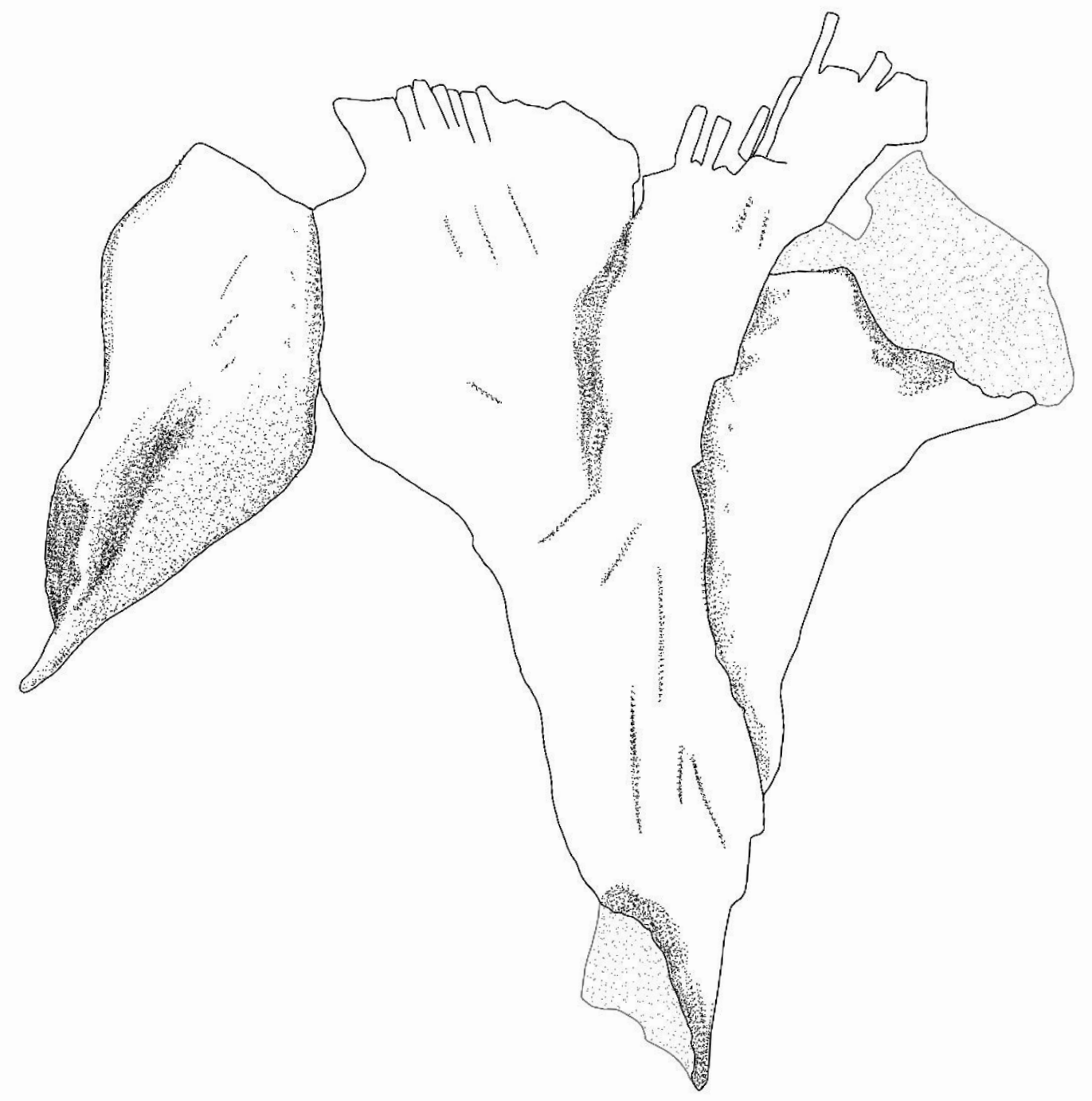

Figure 2.6: Drawing of NMC 10119. A clavicle and interclavicle in ventral view. Figure modified from Carroll (1967). Scale unspecified in original publication. 
Specimen number: DMSW B.224 (Figure 2.7).

Original publication: Carroll, 1967.

Consists of: Right humerus.

Comments: The humerus of Calligenethlon is also known from BM(NH) R. 4553 but is much more complete in DMSW B.224. The overall morphology of the element is similar to that in Archeria (Romer, 1957) in that it is lightly built and more elongated than those described for Pholiderpeton (Clack, 1987) or Proterogyrinus (Holmes, 1984). It preserves an entepicondylar foramen like Archeria (Romer, 1957), Proterogyrinus (Holmes, 1984), and other embolomeres. The entepicondylar region is flat and extends farther posteriorly than Pholiderpeton (Clack, 1987), but not as far as Proterogyrinus (Holmes, 1984). 


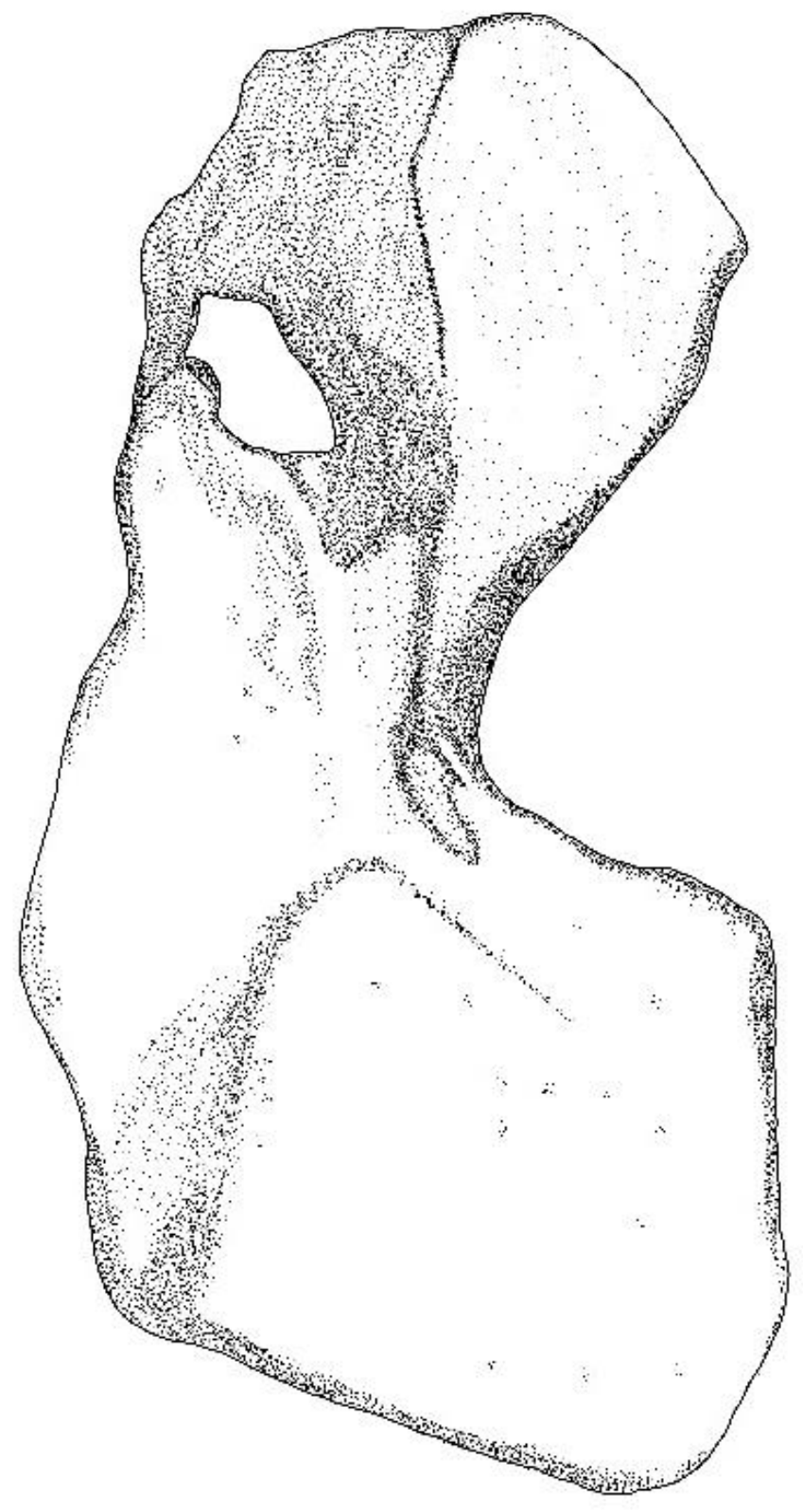

Figure 2.7: Drawing of DMSW B.224. A left humerus in ventral view. Figure modified from Carroll (1967). Scale unspecified from in original publication. 
Specimen number: BM(NH) R.442 (Figure 2.8).

Original publication: Carroll, 1967.

Consists of: Ulna, radius, clavicle.

Comments: Carroll (1967) notes again the similarity in the clavicles and ulna to the morphology of Archeria (Romer, 1957) based on this specimen. BM(NH) R.442 also reveals that Calligenethlon possesses a well-developed olecranon process of the ulna, similar to that seen in Pholiderpeton (Clack, 1987) and Archeria (Holmes, 1989), and quite different from that of Proterogyrinus (Holmes, 1984). The shaft of the ulna in $\mathrm{BM}(\mathrm{NH})$ R.442 is broken distally, but it preserves an elongate, parallel-sided shape, similar to that of Archeria (Romer, 1957). 


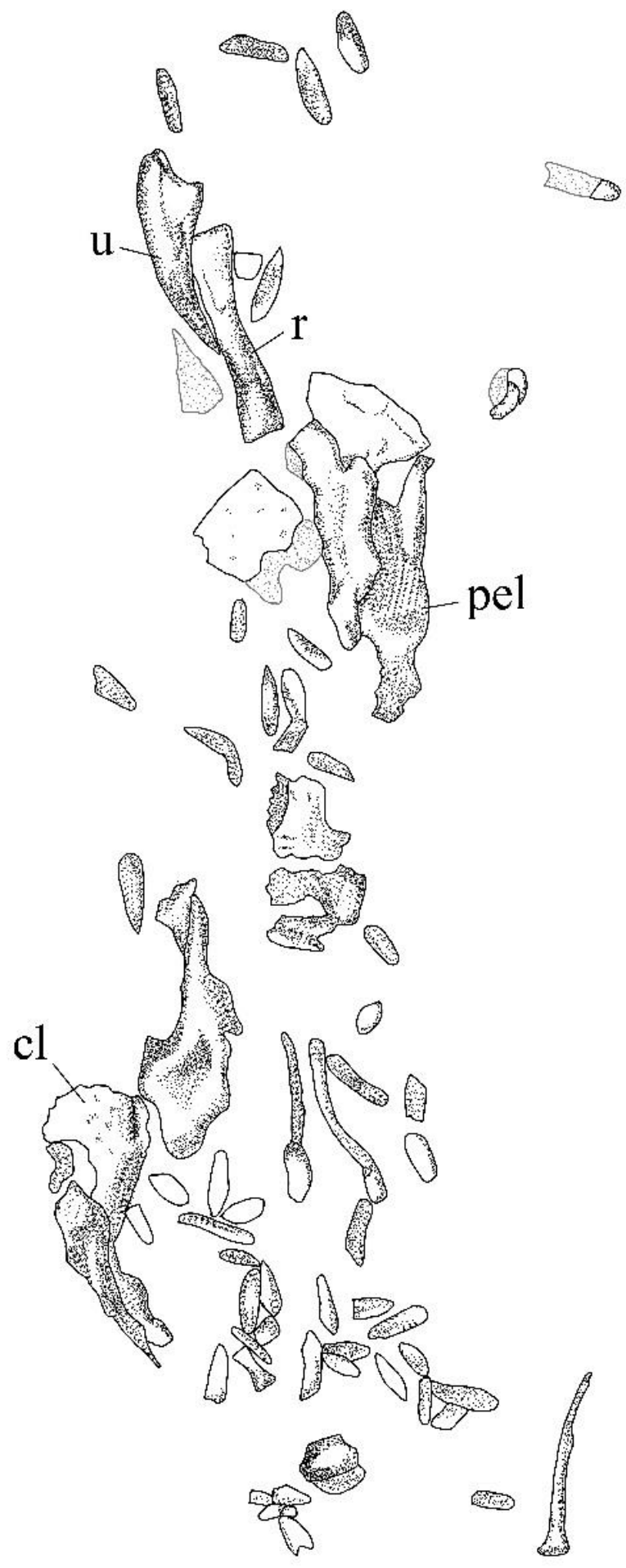

Figure 2.8: Drawing of BM(NH) R.442. Clavicle, limb elements and scales. Figure modified from Carroll (1967). Scale unspecified in original publication. See Anatomical Abbreviations list below. 
Specimen number: BM(NH) R.4553, type of Dendryazousa, now Calligenethlon

watsoni (Carroll, 1967). (Figure 2.9).

Original publication: Steen, 1934.

Consists of: Part and counterpart of the type skull, BM(NH) R.439. Includes the skull table and various disarticulated postcranial bones.

Comments: This specimen was named the type specimen of Dendryazousa by Steen (1934) but was later referred to Calligenethlon by Carroll (1967). The pleurocentra are complete rings and intercentra are incomplete dorsally, like the condition seen in NCM 10050. The ventral surface of the clavicles is wide and shaped similarly to RM 2.1122 and other Calligenethlon specimens. The ilium is preserved in articulation with the ischium and pubis. It displays the beginnings of a slender posterior process, but it is very incomplete. The morphology of the ischium is consistent with that of the type specimen in that its dorsal margin is slightly concave as it extends posteriorly (Carroll, 1967). This character is reminiscent of the ischium morphology described for Archeria (Romer, 1957). 


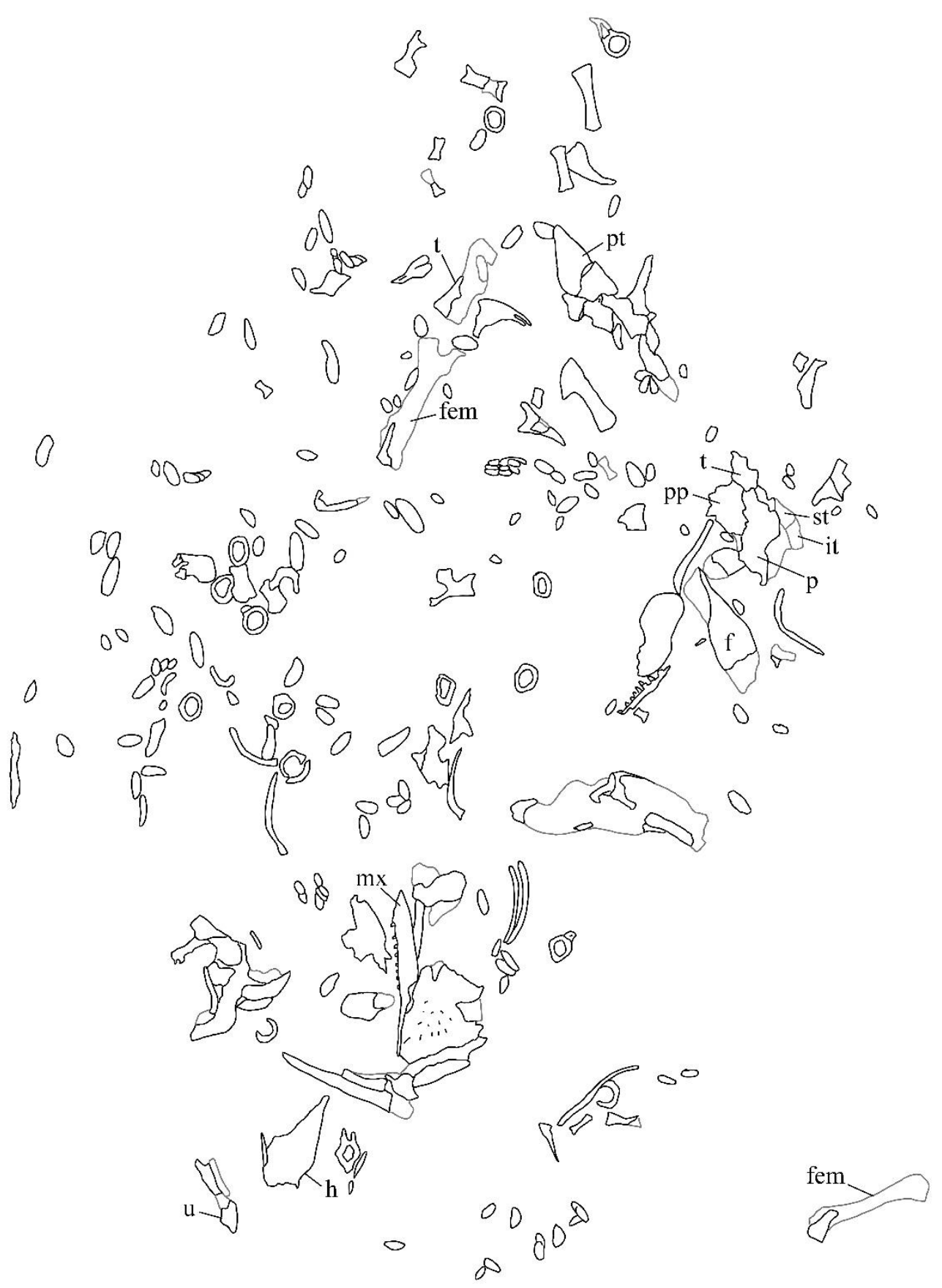

Figure 2.9: Drawing of $\mathrm{BM}(\mathrm{NH})$ R.4553. Scattered cranial and limb elements. Figure modified from Carroll (1967). Scale unspecified in original publication. See Anatomical Abbreviations list below. 
Specimen number: NSM 988GF70.1 (Figure 2.10).

Original publication: Godfrey, Holmes, and Laurin, 1991.

Consists of: A section of articulated trunk vertebrae, neural spines, and ribs.

Comments: The vertebral section preserved in NSM 998GF70.1 shows progressive ossification of the dorsal suture in the intercentra moving posteriorly down the vertebral column, from a ventral crescent to a fully fused, disc-shaped intercentrum (Godfrey et al., 1991). Both dorsally complete and dorsally incomplete intercentra have been preserved in specimen NCM 10050, but NSM 998GF70.1 is the first conclusive evidence of both morphologies within one individual. The neural spines are broad and similar in morphology to those of Proterogyrinus (Godfrey et al., 1991). This material also provides the first evidence of a larger embolomere at Joggins. 


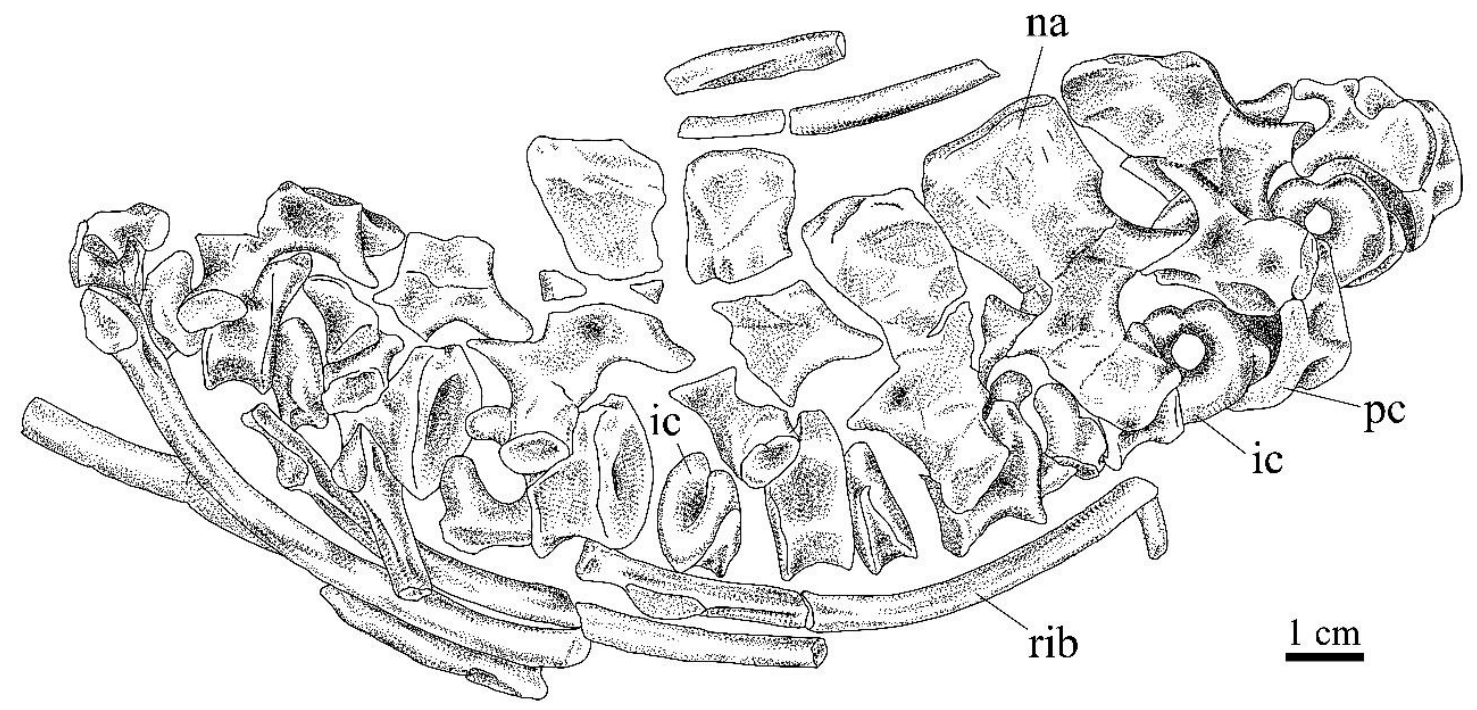

Figure 2.10: Drawing of NSM 988GF70.1. An articulated series of trunk vertebrae in left lateral view. Figure modified from Godfrey et al. (1991). See Anatomical Abbreviations list below. 
Specimen number: RM 20.4984 (Figure 2.11).

Original publication: Godfrey, Holmes, and Laurin, 1991.

Consists of: A series of articulated posterior presacral vertebrae, along with haemal arches and neural spines. Also preserved are an ilium, femur, and tarsal elements.

Comments: The morphology of the ilium in RM 20.4984 is markedly similar to that of the ilium in the Calligenethlon type specimen (Godfrey et al., 1991). However, the length of the posterior process in RM 20.4984 is $220 \%$ that of the type specimen, making the adult size of Calligenethlon more than twice as large as was previously thought. 


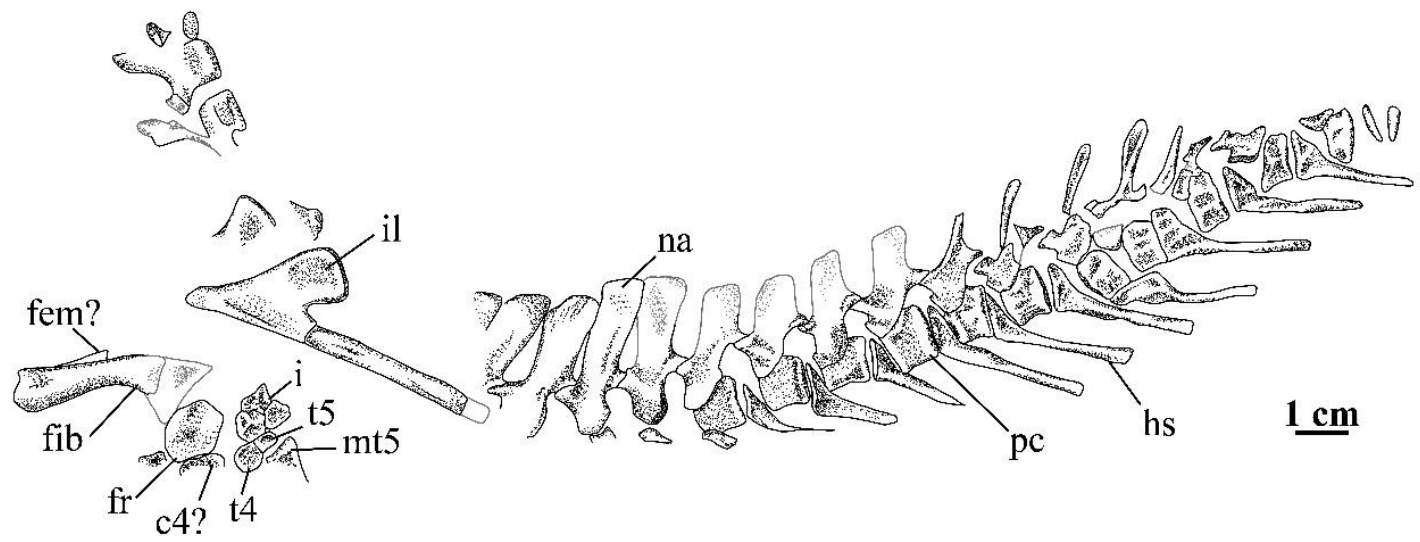

Figure 2.11: Drawing of RM 20.4984. A series of articulated presacral vertebrae with pelvic and limb elements in left lateral view. Figure modified from Godfrey et al. (1991). See Anatomical Abbreviations list below. 
Specimen number: NSM 994GF1.1 (Figures 2.12-2.14).

Original publication: Holmes and Carroll, 2010.

Consists of: Articulated anterior half of an embolomere skeleton.

Comments: NSM 994GF1.1 is one of very few tetrapod specimens found outside a stump at Joggins. In spite of exceptionally good preservation, the few diagnostic characters known for Calligenethlon were not preserved, making an unequivocal identification impossible (Holmes and Carroll, 2010). Because only one embolomere is currently known from Joggins, it was considered most plausible that NSM 944GF1.1 has some relation to Calligenethlon (Holmes and Carroll, 2010). 

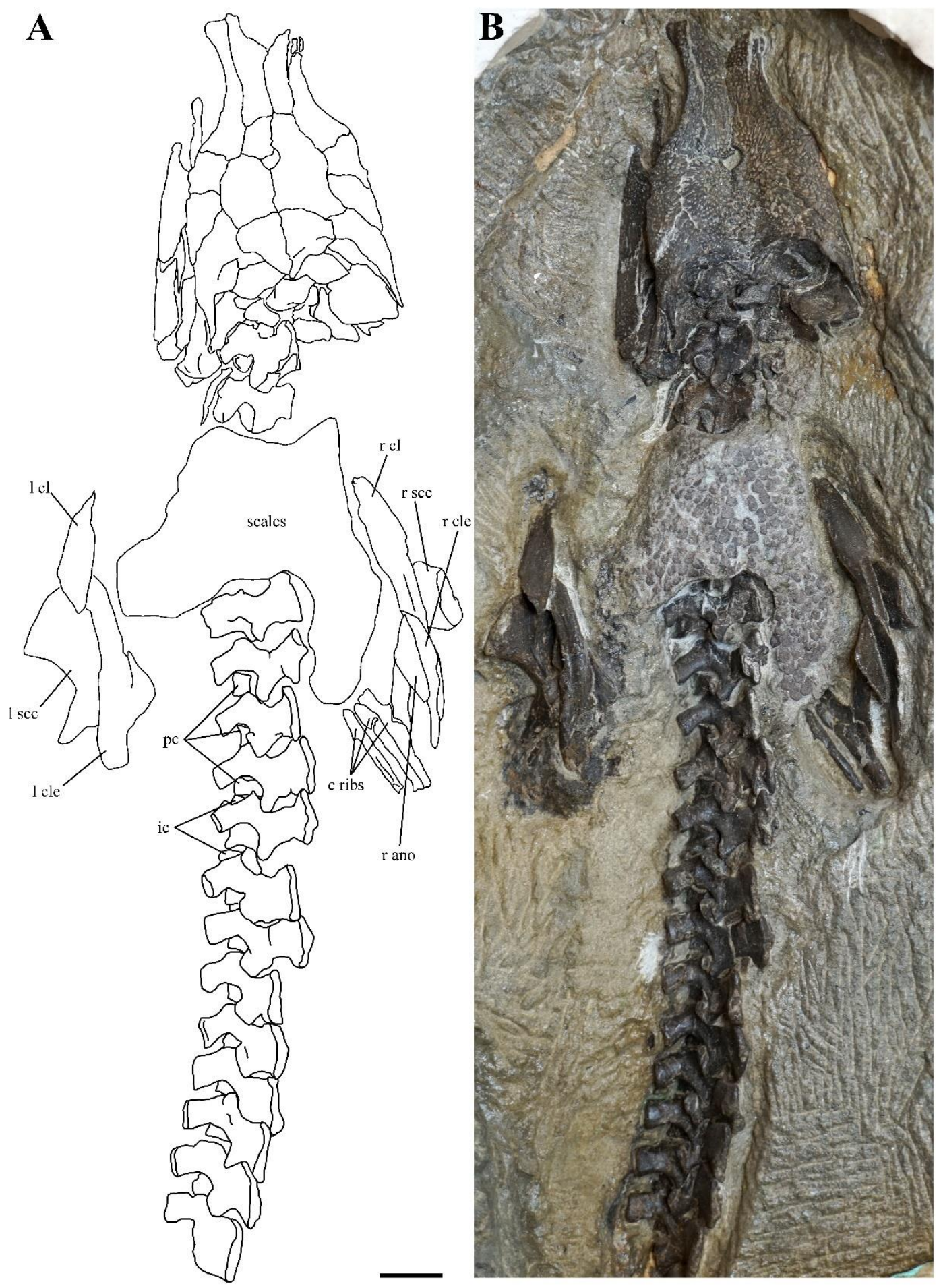

Figure 2.12: Drawing and photograph of NSM 994GF1.1, an articulated anterior half of an embolomerous tetrapod skeleton in dorsal view. A, interpretative drawing; B, photograph. See Anatomical Abbreviations list below. Scale bar equals $1 \mathrm{~cm}$. 

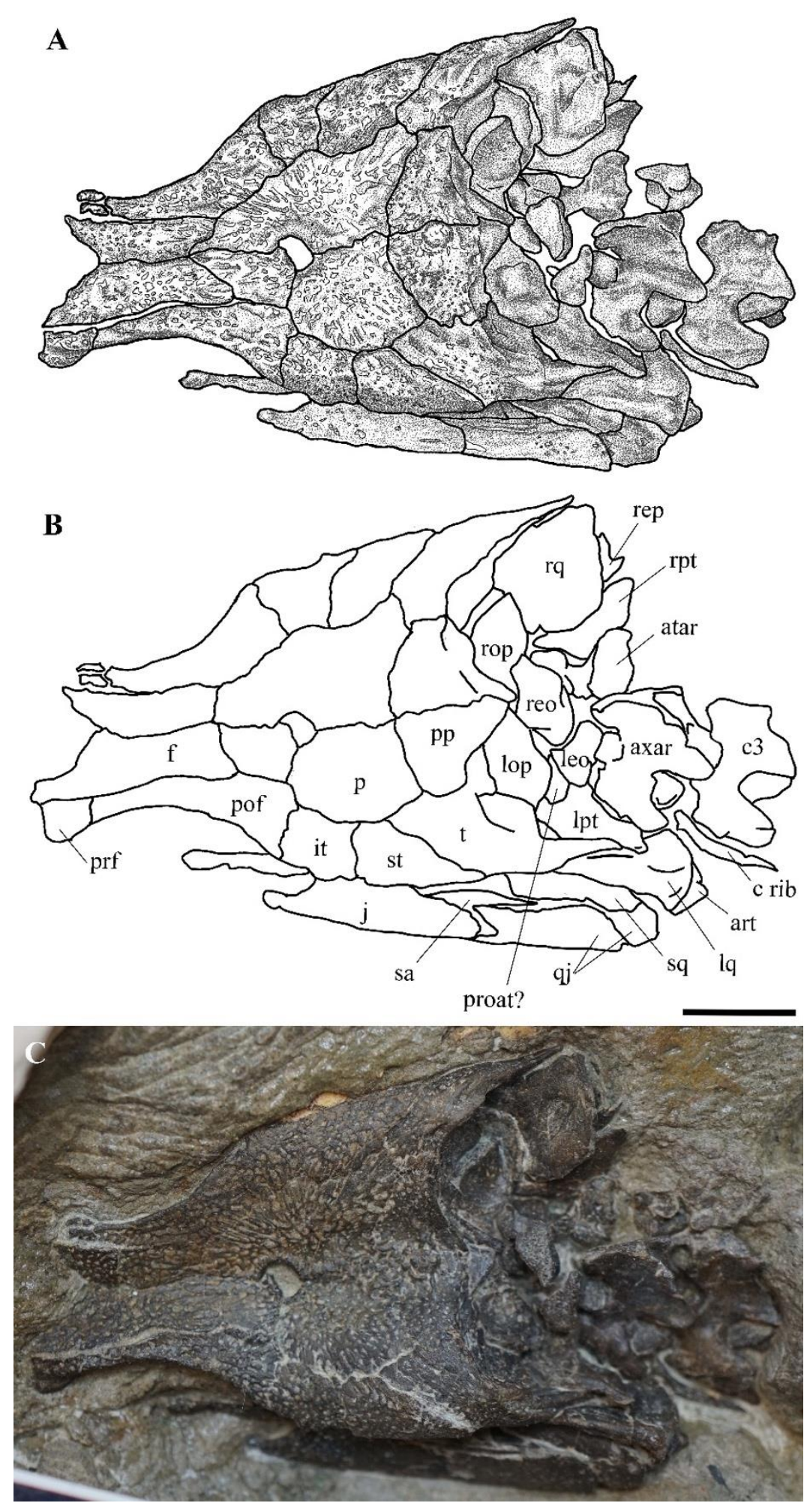

Figure 2.13: Detail of the skull of NSM 994GF1.1 showing the articulated skull table, cheek margin and cervical vertebrae in dorsal view. A, interpretive drawing; B, labelled cranial elements; and C, photograph. See Anatomical Abbreviations list below. Scale bar equals $1 \mathrm{~cm}$. 

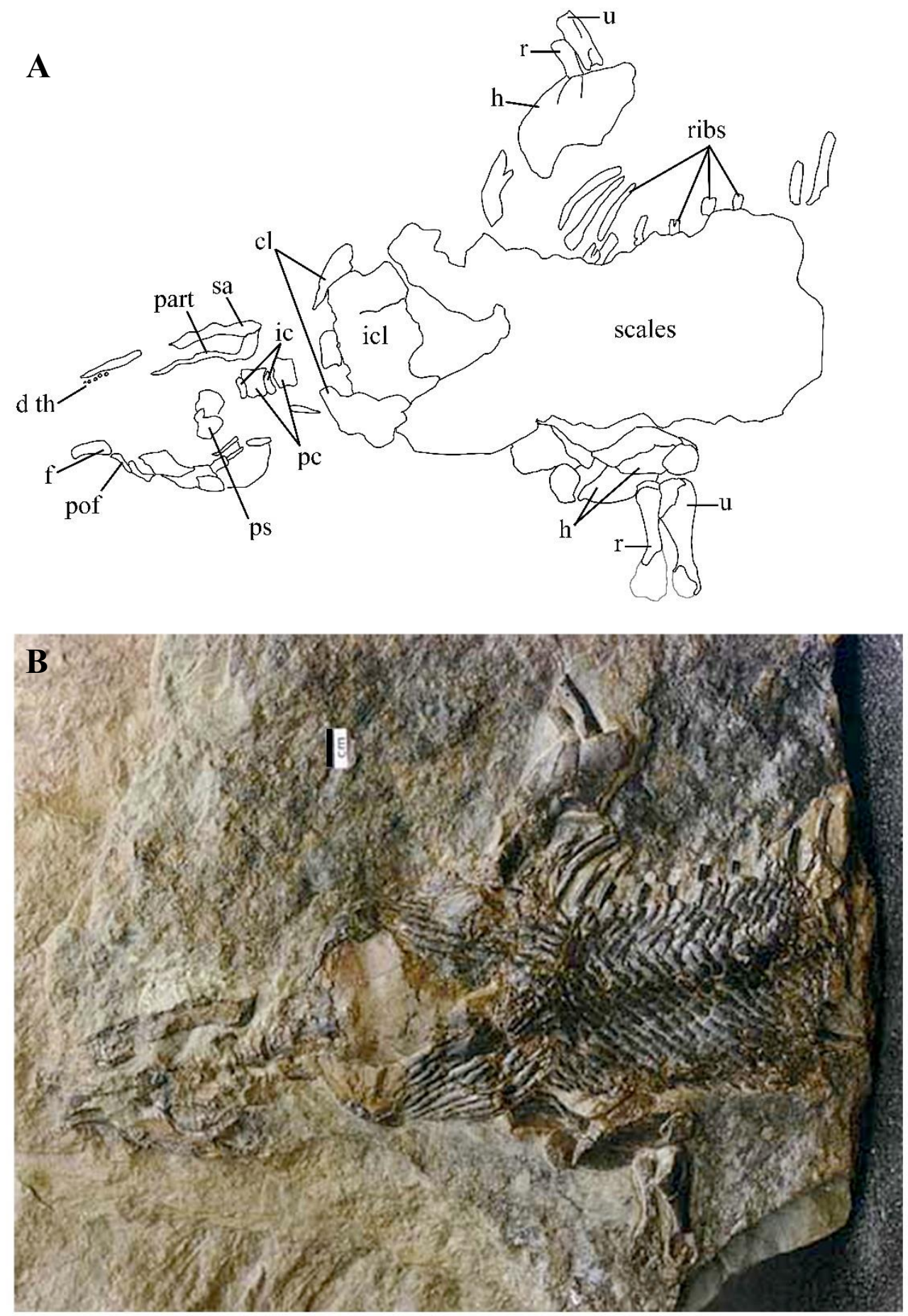

Figure 2.14: A, interpretive drawing and B, photograph of NSM 994GF1.1 as it was originally found in ventral view. Photo courtesy of the Nova Scotia Museum in Nova Scotia, Canada. See Anatomical Abbreviations list below. Scale bar equals $1 \mathrm{~cm}$. 


\section{Problems with Calligenethlon}

In spite of being fairly extensively known from multiple specimens, the genus remains poorly defined with only a few putative autapomorphies known, including large tabulars, a distinctively gracile posterior iliac blade, and a small adult size (Figure 2.1; Holmes and Carroll, 2010; Godfrey et al., 1991). Because of this, with the exception of the specimen referred to as "Baphetes" minor, all tetrapod discoveries with embolomere affinities from Joggins have been provisionally attributed to Calligenethlon (e.g., Carroll, 1967; Godfrey et al., 1991; Holmes and Carroll, 2010). Despite being quite fragmentary, the specimens preserve sufficient anatomy to allow for a more complete morphological definition. However, a thorough, anatomical comparison of all material to determine the validity of this grouping remains lacking in the embolomere literature.

Calligenethlon is most well known for being the smallest embolomere (Godfrey et al., 1991). Embolomere skull lengths (from the tip of the premaxilla to the posterior margin of the postparietal, after Panchen, 1972) range from about $15.5 \mathrm{~cm}$ (Proterogyrinus [Holmes, 1984] and Eoherpeton [Smithson, 1985]) to $42 \mathrm{~cm}$ (Anthracosaurus [Panchen, 1977]). The anterior portion of the skull is not known for Calligenethlon but an estimate by Holmes and Carroll (2010) suggests a total skull length of about $5.8 \mathrm{~cm}$. The unusually small size has led to speculation that Calligenethlon represents a juvenile of one of the larger animals, such as "Baphetes" minor (Godfrey et al., 1991). However, Carroll (1967) published a review of all the known tetrapods from Joggins in which he stated that the level of ossification seen in all the Calligenethlon specimens suggested the preserved animals were mature, if not full adult size. The larger specimens described by Godfrey et al. (1991) are more Proterogyrinus-like in size and 
again question the validity of 'small adult size' as a diagnostic characteristic of Calligenethlon. However, the growth stages for these animals remain unknown, and therefore limit the conclusions that may be drawn from the current data. Either way, the findings by Godfrey et al. (1991) indicate that larger embolomerous taxa are indeed preserved at Joggins, though rare, and challenge the identity of any specimens that have been assigned to this genus primarily based on location and body size.

\section{Institutional Abbreviations}

$\mathrm{BM}(\mathrm{NH})$ : British Museum (Natural History), London, United Kingdom.

DMSW: D. M. S. Watson Collection, Cambridge University, Cambridge, United Kingdom.

NMC: National Museum of Canada, Ottawa, Ontario, Canada.

NSM: Nova Scotia Museum of Natural History, Halifax, Nova Scotia, Canada.

RM: Redpath Museum, McGill University, Montreal, Quebec, Canada.

\section{Anatomical Abbreviations}

ano, anocleithrum; art, articular; atar, atlas arch; at ic, atlas intercentrum; at pc, atlas pleurocentrum; axar, axis arch; ax ic, axis intercentrum; ax pc, axis pleurocentrum; bo, basioccipital; c3, $3^{\text {rd }}$ cervical vertebra; cap, capitulum; cen $4,4^{\text {th }}$ centrale of tarsus; cl, clavicle; cle, cleithrum; d th, dentary teeth; dp, deltopectoral crest; ect, ectepicondylar process; eo, exoccipital; ep, epipterygoid; f, frontal; fem, femur; fib, fibula; fr, fibulare; 
h, humerus; hs, haemal spines; i, intermedium; ic, intercentrum; icl, interclavicle; il, ilium; it, intertemporal; j, jugal; mt5, $5^{\text {th }}$ metatarsal; mx, maxilla; na, neural arch; ole pr, olecranon process; op, opisthotic; p, parietal; part, prearticular; pc, pleurocentrum; pel, pelvic elements; po, postorbital; pof, postfrontal; pp, postparietal; prf, prefrontal; proat, proatlas; ps, parasphenoid; pt, pterygoid; $\mathbf{q}$, quadrate; qj, quadratojugal; r, radius; sa, surangular; scc, scapulocoracoid; sch, scapulohumeral depression; sgf, supraglenoid foramen; sq, squamosal; st, supratemporal; $\mathbf{t}$, tabular; $\mathbf{t 4}, 4^{\text {th }}$ distal tarsal; $\mathbf{t 5}, 5^{\text {th }}$ distal tarsal; troch not, trochlear notch; tub, tuberculum; u, ulna.

\subsection{MATERIALS AND METHODS}

Specimen NSM 994GF1.1 was found as beach float on the tidal flats near the town of Joggins, Nova Scotia, Canada. The specimen was found with the ventral surface exposed, revealing an extensive pelage of scales and portions of the skull and forelimbs (Figure 2.14). Due to significant erosion of the ventral side, the specimen was embedded in plaster and the dorsal side was prepared as described in Holmes and Carroll (2010). An anatomical description of the specimen was performed by Holmes and Carroll (2010).

Photographs of the specimen were taken using a Sony Alpha ILCE 5000 camera and formatted in Photoshop CS6 (Adobe, San Jose, CA). Interpretive drawings of NSM 994GF1.1 and all other figures were created and formatted using Photoshop CS6 (Adobe, San Jose, CA).

NSM 994GF1.1 was CT scanned at the University of Texas High-Resolution Xray Computed Tomography Facility (UTCT) in Austin, Texas. This produced 2996 slices 
which were saved as TIFF images and segmented in batches of 500 images each using Amira 5.4.3 software. Bone elements within each batch were segmented and labelled individually. Following this, the surface files from each batch were combined to create the 3D model of the whole specimen. This model was then used to describe the external and internal anatomy of NSM 994GF1.1. The new and revised morphological data was compared to the descriptive literature of the holotype to confirm the validity of its identity as Calligenethlon. Once satisfied on that account, the anatomy of NSM 994GF1.1 plus the holotype was then compared to all known Calligenethlon specimens to provide confident justification for their referral to this genus. To explore the deeper context of Calligenethlon within the greater embolomere group, comparisons were also made with other embolomeres and early tetrapods from other localities, including Archeria, Proterogyrinus, Pholiderpeton, Leptophractus, Pteroplax, Neopteroplax, Anthracosaurus, Eoherpeton, and others.

\subsection{RESULTS}

NSM 994GF1.1 is a $23 \mathrm{~cm}$ long anterior portion of a Calligenethlon specimen in articulation, preserving the posterior half of the frontals to the 19th dorsal vertebra (Figure 2.15). The anteriormost portion of the snout is lost and the entire skeleton has been dorsoventrally compressed. The CT data shows that the fossilized bone is similar in density to the surrounding matrix, and this has obscured some of the fine details, such as ornamentation, on the elements not exposed to the surface. 
A

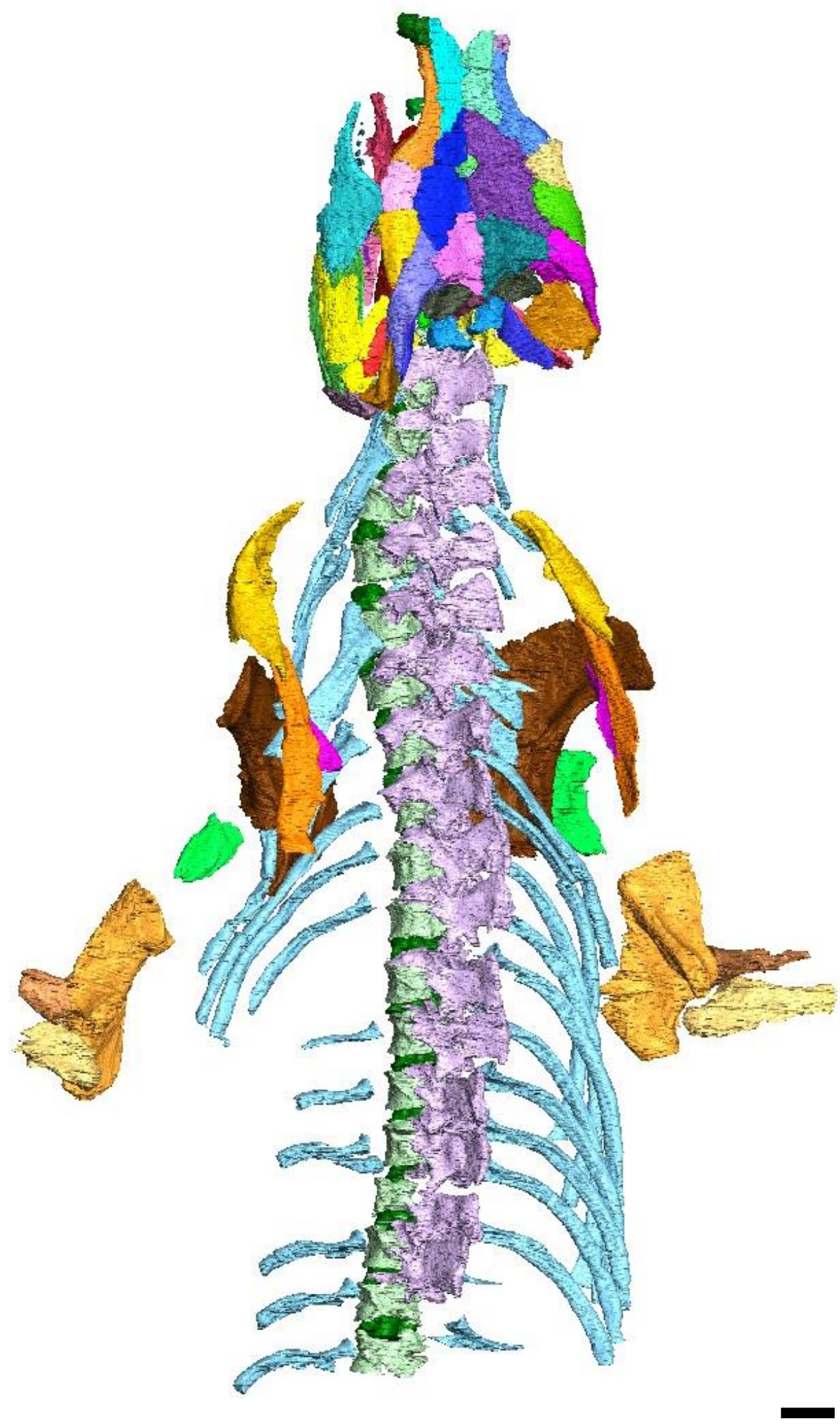


B

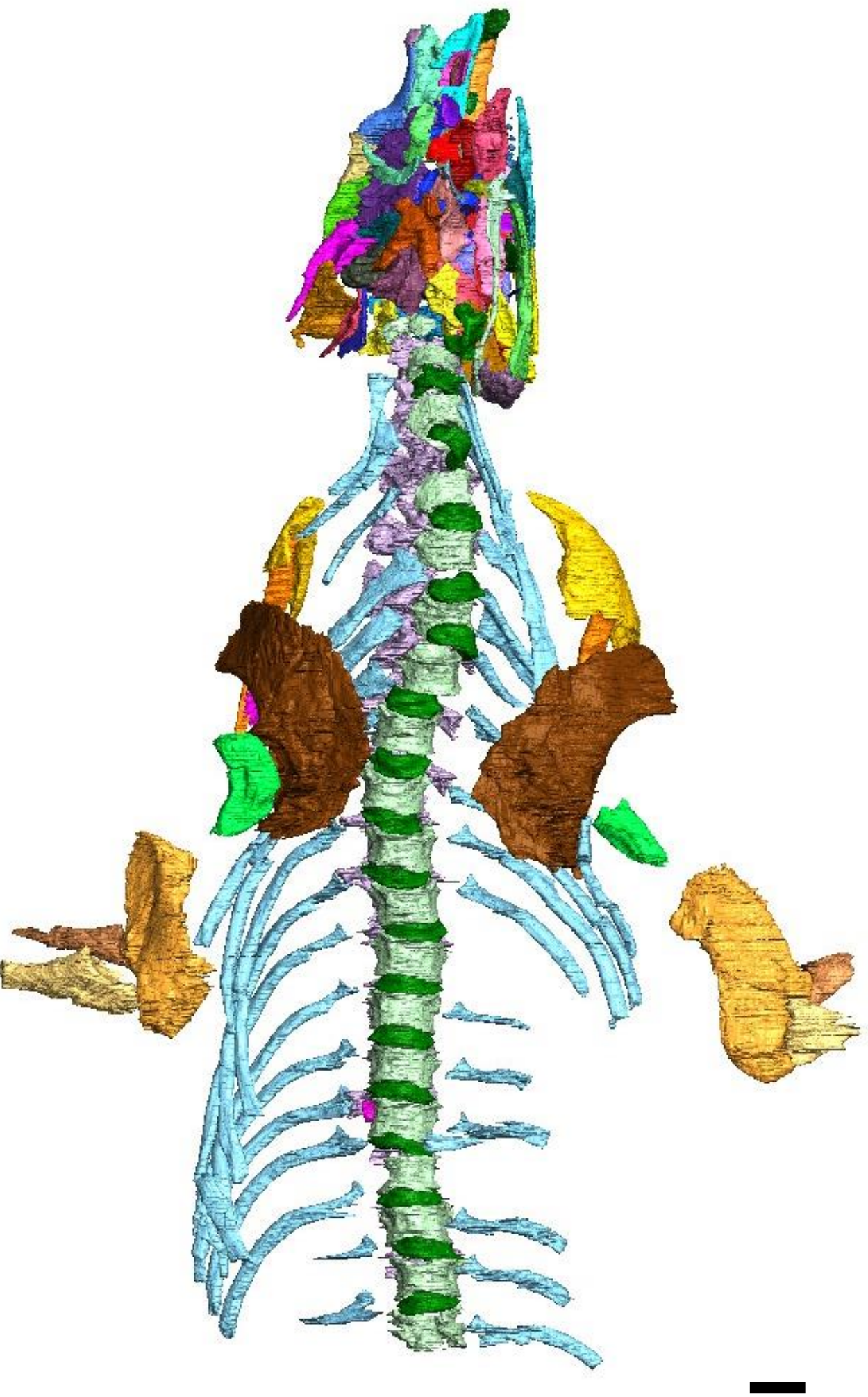


C

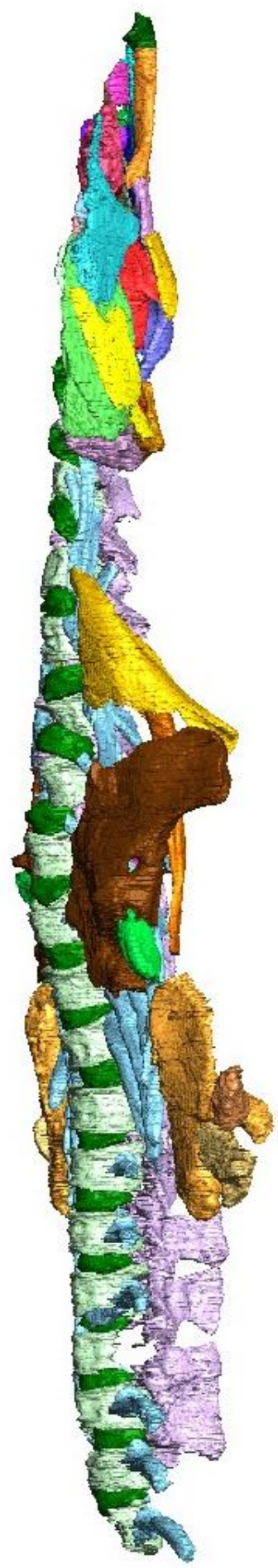

Figure 2.15: The full skeleton of NSM 994GF1.1 as revealed by segmentation of the CT data. A, dorsal; B, ventral; and C, left lateral view. Anterior to the left in A and B and to the top in C. Scale bar is $1 \mathrm{~cm}$. 


\section{The Skull}

\section{The Skull Table}

Taphonomic pressures have destroyed most of the internal skull elements on the right side and broken many of the internal elements on the left side. The external elements of the skull table are intact except for a slender crack along the left frontalprefrontal suture, and a small deformation of the left parietal, which pushes the anterior half of the element into the gap left by the pineal foramen (Figure 2.16).

The anteriormost portion of the skull is not preserved but the posterior portion is very well preserved and articulated; however, it has been flattened and somewhat depressed along its midline. The skull table preserves a maximum width of about $3.4 \mathrm{~cm}$ and a length of $2.2 \mathrm{~cm}$ between the midpoint of the parietal foramen and the posteriormost margin of the postparietal. None of the skull material associated with the genus Calligenethlon includes elements anterior to the prefrontals, and therefore the total length of the skull in this genus is unknown and difficult to estimate.

The frontals are elongate and narrow with large, pitted ornamentation. They are incomplete anteriorly, but posteriorly they contact the parietals at an angle. There is not enough preserved to determine whether the frontals narrow significantly between the orbits as is common for embolomeres (Holmes, 1984). The frontal is excluded from the orbit margin by a contact between the prefrontal and postfrontal.

NSM 994GF1.1 includes the first instance of a prefrontal preserved for Calligenethlon. Only the posteriormost edge of each prefrontal is preserved and both show the same 

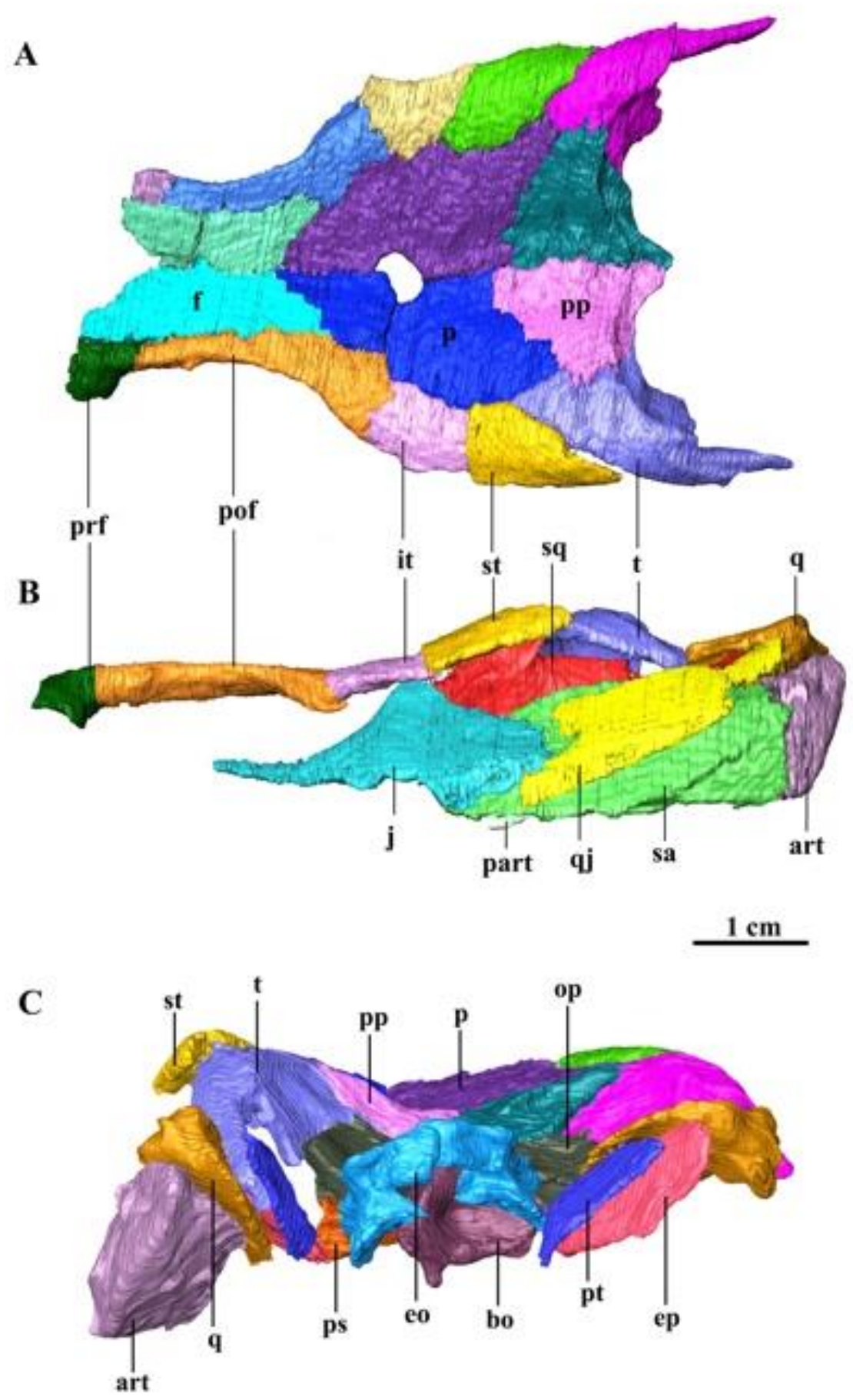

Figure 2.16: The skull table of NSM 994GF1.1 as revealed by segmentation of the CT data. A, dorsal; B, lateral; and C, posterior view. Anterior to the left in A and B. See anatomical abbreviation list above. 
pitting as seen on the frontal. The prefrontal contributes only to the anteriormost dorsal corner of the orbit and shares the anterior margin of the orbit equally with the lacrimal. In this way, NSM 994GF1.1 is distinct from Archeria (Holmes, 1989), in which the prefrontal extends posteriorly along the dorsal margin of the orbit. In NSM 994GF1.1, the suture between the posterior edge of the prefrontal and anterior edge of the postfrontal is a smooth line, perpendicular to the midline of the skull, similar to that seen in Proterogyrinus (Holmes, 1984).

The postfrontal is a narrow, elongate, falciform element that widens posteriorly. Like Proterogyrinus (Holmes, 1984), this element forms the dorsal margin of the orbit and contributes only briefly to its posterior margin. The postfrontal contacts the prefrontal anteriorly and the parietal posteromedially, and it shares an interdigitating suture with the intertemporal posteriorly.

The intertemporal is a rather short, rectangular element. Its lateral margin does not follow the laterally directed curve of the postfrontal by expanding laterally but instead retains a flat, parallel edge that is continued by the supratemporal and tabular. This feature is distinct from the conditions seen in other embolomeres and may be diagnostic for Calligenethlon.

The supratemporal is a roughly triangular element. Its lateral margin follows the straight lateral margin of the intertemporal until its point of contact with the tabular and is therefore consistent with the skull tables attributed to Calligenethlon by Steen (1934) and Carroll (1967). 
The tabular is a large element bearing a blade-like, posteriorly directed horn that extends far beyond the posteriormost margin of the skull table. The element is similar to that seen in Archeria (Holmes, 1989), although it is more slender, elongate, and gracile. Like Archeria (Holmes, 1989) or Neopteroplax (Romer, 1963), the horns are oriented parallel to one another, rather than pointing outwards like in Pholiderpeton (Clack, 1987) or inwards like in Anthracosaurus (Panchen, 1977). The tabular contacts the parietal at its anteriomedial margin, as is diagnostic for embolomeres (Holmes, 1984).

The parietal is a large, roughly triangular element, bearing pitted ornamentation radiating outward from the pineal foramen. The left parietal is cracked, causing damage to the foramen, which would likely have been circular in life. Compared to other embolomeres, the pineal foramen is quite large relative to the size of the parietal and sits at the midpoint of the bone, rather than anterior to the midpoint. There is a subtle ridge around the pineal foramen and a slight depression lateral to the median suture line posterior to the foramen.

The postparietal is generally trapezoidal in shape. Whether the depression posterior to the pineal foramen continues onto the postparietal, like in Proterogyrinus (Holmes, 1984), is unknown because the skull table has been compressed here. Beyond the posterior margin of the skull table, the postparietal is deflected ventrally, making up the dorsal portion of the occiput, as is common in embolomeres. At its most posterior extent, the postparietal comes to a triangular point, as is seen in Proterogyrinus (Holmes, 1984), Archeria (Holmes, 1989), and other embolomeres. 


\section{The Cheek Margin}

The cheek elements (Figure 2.17) are only preserved on the left side, except for the quadrates, of which both are preserved. All elements anterior to the orbit have been lost during preservation and those surviving elements have been slightly broken and displaced.

A left postorbital is present but has been displaced posteriorly and rotated in a counter-clockwise direction. In lateral view, the element is T-shaped and very slightly concave. In its displaced orientation, the ventral margin bears a subtle ridge which outlines the margin. The morphology of this ridge is similar to the ridge that rims the lateral edge of the orbital. The abrupt curve in this element defines the morphology of the

posterior half of the orbit of NSM 994GF1.1 as being more pinched posteriodorsally, like in Neopteroplax (Romer, 1963), Archeria (Holmes, 1989), and Pholiderpeton (Clack, 1987), than smoothly rounded, like in Proterogyrinus (Holmes, 1984). The postorbital also extends farther along the posterior edge of the orbit than is described for Proterogyrinus (Holmes, 1984). In general, the postorbital is similar to the morphology seen in Neopteroplax (Romer, 1963). Although all embolomeres except Anthracosaurus bear a lateral line sulcus on the postorbital (Holmes, 1984), there is no obvious lateral line present in NSM 994GF1.1. However, it is possible that this detail is too fine to be captured by the CT scan of NSM 994GF1.1 rather than the trait being truly lost in Calligenethlon.

The left jugal has been displaced vertically so that its dorsalmost surface touches the intertemporal and covers the postorbital and squamosal. Otherwise, the jugal is fairly 


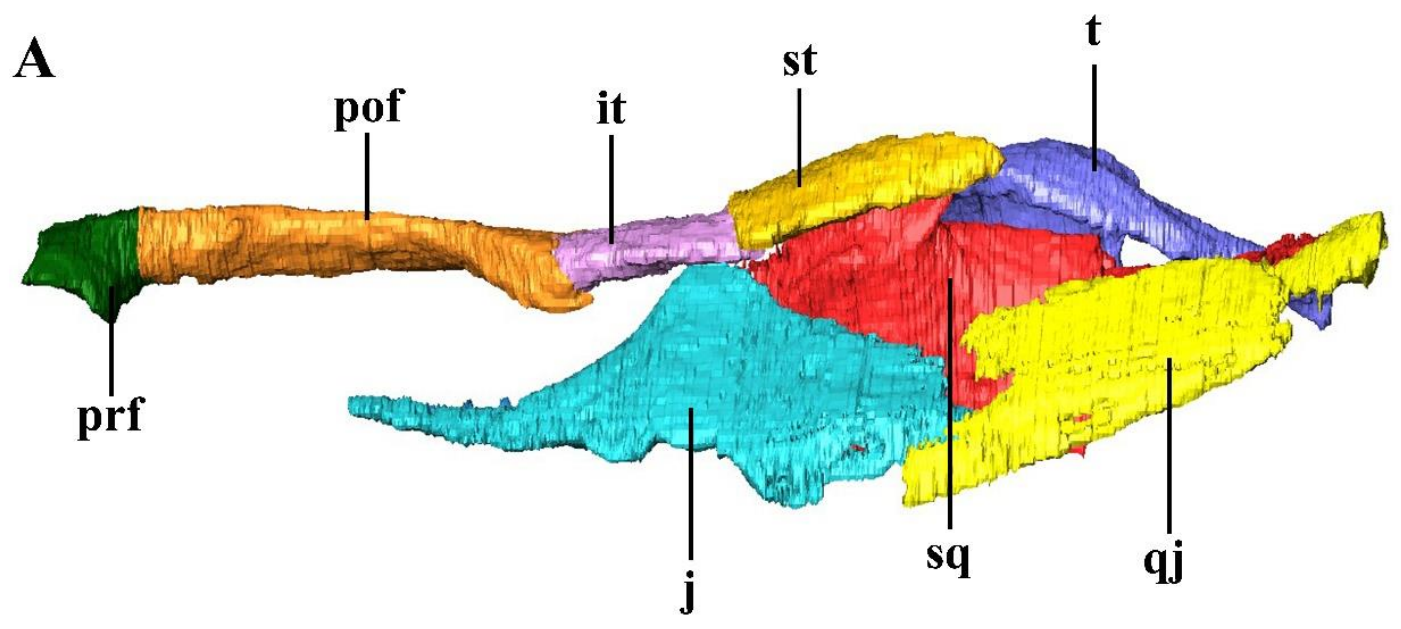

B

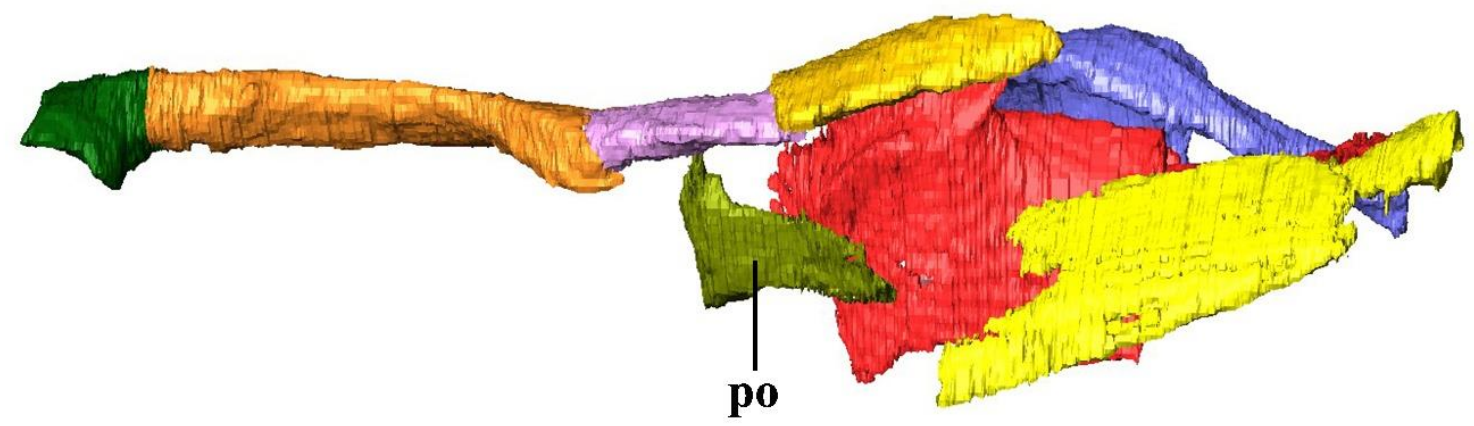

$1 \mathrm{~cm}$

Figure 2.17: The left cheek margin of NSM 994GF1.1 as revealed by segmentation of the CT data. A, lateral view as preserved; and B, in lateral view with the jugal removed to show the postorbital. Anterior to the left. See anatomical abbreviation list above. 
well preserved and shows pitted ornamentation over its entire surface and a lateral-line sulcus on its suborbital ramus. This feature is common in embolomeres (Holmes, 1984).

The overall morphology of the jugal is more similar to Proterogyrinus (Holmes, 1984) than to Archeria (Holmes, 1989) in that the element extends farther dorsally, sharing about $50 \%$ of the posterior margin of the orbit with the postorbital, rather than having almost no contribution to it. This morphology is unlike that of Proterogyrinus (Holmes, 1984), where only a $1 \mathrm{~cm}$ section of the jugal extends dorsally to form the margin of the orbit but the rest does not extend much above the base of the orbit. The dorsalmost margin of the jugal slopes downward posteriorly, creating a vaguely concave dorsal margin to the sheet-like lateral face. The ventral margin of the jugal is unpreserved.

The left squamosal is a large, relatively flat element. It has been broken such that only its posteriormost blade-like flange is still in articulation with the quadratojugal ventrally. The large anterior portion of the element has collapsed inward under the skull table and the anteriormost and ventral margins are incomplete. The medial surface of the bone is concave and the element thickens moving dorsally. As pictured in Clack (1983) for Pholiderpeton (Clack, 1987), at the anteriodorsal margin there is a robust dorsolaterally-directed extension with a slightly concave dorsal surface, where the element would contact the supratemporal and support the skull table in NSM 994GF1.1. Overall, the morphology of the squamosal is consistent with that of Neopteroplax (Romer, 1963), Proterogyrinus (Holmes, 1984), Archeria (Holmes, 1989), and most embolomeres. 
The quadratojugal has also been broken and displaced. The dorsal piece of the quadratojugal is still in articulation with a part of the squamosal, but it has been separated from the rest of the element and moved in a dorsomedial direction. The rest of the element is extremely thin and is incomplete anteriorly. It preserves a rounded rectangular shape, similar to that seen in Proterogyrinus (Holmes, 1984), or as is reconstructed for Pholiderpeton (Clack, 1987).

The quadrate in NSM 994GF1.1 is similar in morphology to that described in Proterogyrinus (Holmes, 1984), Archeria (Holmes, 1989) and other embolomeres. During preservation, the right quadrate was rotated counterclockwise approximately $90^{\circ}$ about its anteroposterior axis, and the left was rotated clockwise approximately $135^{\circ}$ about its anteroposterior axis. Based on its placement, the quadrate likely would have sat well behind the occipital condyle in life, as is typical for embolomeres (Holmes, 1984). The quadrate is wider in its ventral region and tapers moving dorsally, making the element appear triangular in posterior view. The dorsal margin is parabola shaped and the medial and lateral surfaces are smooth.

\section{The Braincase}

The elements making up the braincase and the occiput (Figure 2.18) are less well preserved than the external skull elements in that they are more incomplete and several are slightly displaced. The anterior half of the parabasisphenoid complex has been lost, but the basisphenoid portion of the complex is articulated and fairly complete. The paired 


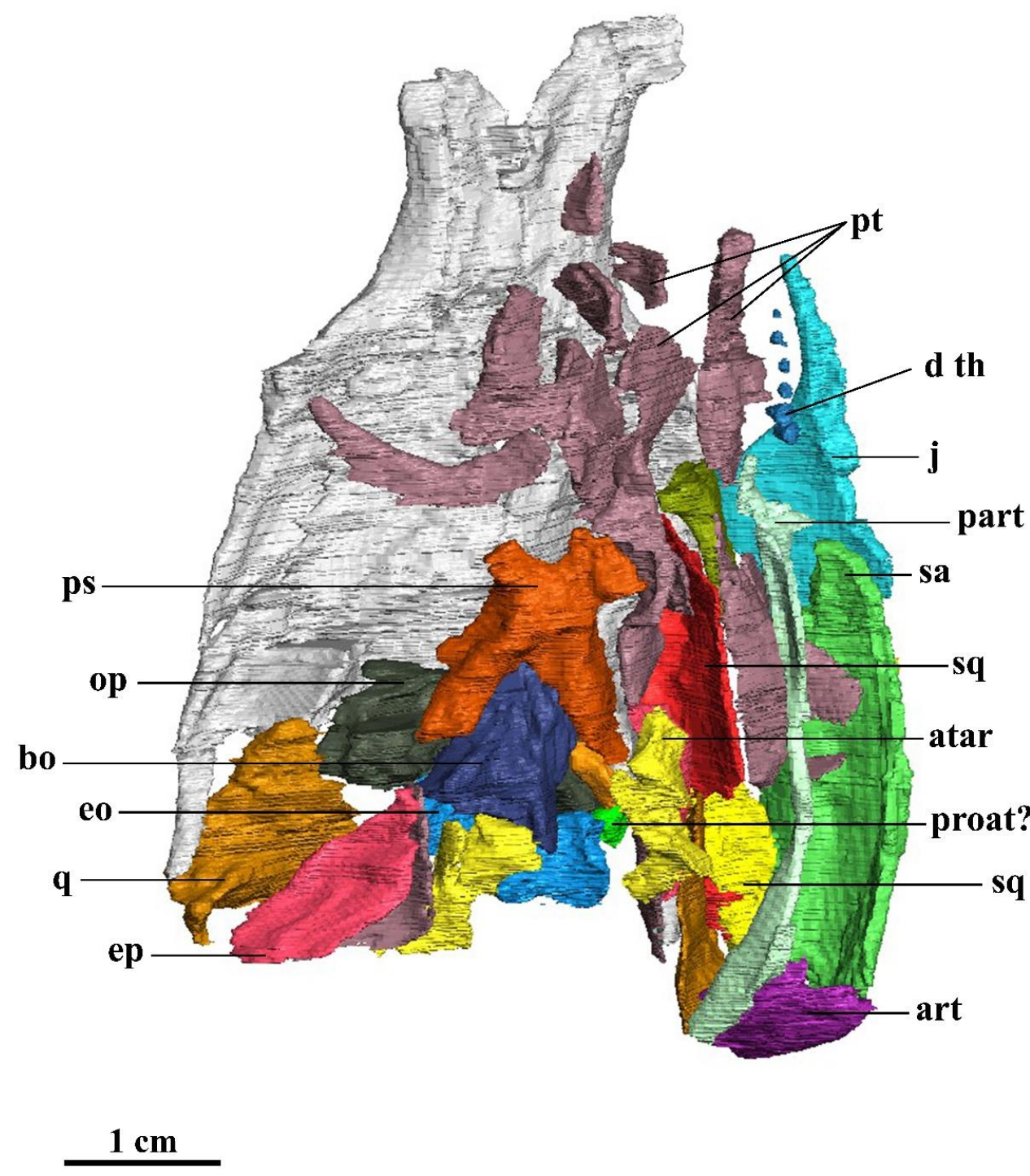

Figure 2.18: The skull of NSM 994GF1.1 in ventral view as revealed by segmentation of the CT data. Skull table elements in grey, elements visible in ventral view in colour. See anatomical abbreviation list above. 
opisthotics and exoccipitals are present and well preserved, as is the basioccipital, but are all slightly disarticulated. The prootics could not be discerned.

The opisthotic is preserved in articulation contacting the postparietal dorsomedially and the tabular dorsolaterally. The opisthotic is vaguely ovoid in dorsal outline and preserves a concave dorsal surface. This morphology of the opisthotic is quite similar to that of Pholiderpeton (Clack, 1987) and Proterogyrinus (Holmes, 1984), and unlike the hook-shaped opisthotic figured in Archeria (Holmes, 1989).

The dorsal surface of the parasphenoid is tightly attached to the ventral surface of the basisphenoid just anterior to the basal tubera, forming a parabasisphenoid complex, similar to the condition seen in Proterogyrinus and other embolomeres. The cultriform process of the parasphenoid portion of the complex has been completely lost, likely due to damage during preservation. The basipterygoid processes are incompletely preserved; however, they are still more prominent than those described for Archeria (Clack and Holmes, 1988) and Proterogyrinus (Holmes, 1984), and more similar to those of Pholiderpeton (Clack, 1987). Posterior to the basipterygoid processes, the parabasisphenoid complex of NSM 994GF1.1 is well preserved. This portion of the complex is generally similar to that described for other embolomeres, but preserves striking similarities to that of Pholiderpeton (Clack, 1987), firstly in that the posterior margin of the basal plate of the parasphenoid is deeply incised with a pair of basal tubera extending ventral to the basioccipital. Also, the degree of development of the basal tubera is more extreme than that found in Proterogyrinus (Holmes, 1984) and Archeria (Clack and Holmes, 1988), but is quite similar to that seen in Pholiderpeton (Clack, 1987), except that the tubera diverge laterally throughout their entire length, rather than initially 
extending laterally before turning inwards to become parallel to one another. Although the dorsal side of the parasphenoid is incomplete, the raised ventrolateral margins of each basal tuber indicates the presence of the supratuberal pocket, like those described for Archeria (Clack and Holmes, 1988), Proterogyrinus (Holmes, 1984), and Pholiderpeton (Clack, 1987). As in Archeria (Clack and Holmes, 1988), the ventrolateral margins of the basioccipital would have contributed to the dorsal walls of the pocket, but the opisthotics did not.

The morphology of the basioccipital is similar to that seen in other embolomeres and early tetrapods. The basioccipital of NSM 994GF1.1 forms most of the occipital condyle, as is the case in other embolomeres (Holmes, 1984; Clack and Holmes, 1988). In occipital view, the element is ovoid with a depression in the center. Like in Archeria (Clack and Holmes, 1988), there are wing-like processes on either side of the posterior face of the basioccipital in ventral view. Moving anteriorly from the condylar surface, the element narrows and then abruptly expands, continuing anteriorly with parallel lateral margins. The anteriormost tip of the basioccipital suddenly narrows into a blunt point. The anterior half of the element rests atop the parasphenoid.

The exoccipital in NSM 994GF1.1 is most similar to that of Pholiderpeton (Clack, 1987) in that its medially-projecting flange extends further medially than that of Archeria (Holmes, 1989) and is dorsoventrally taller than that of Proterogyrinus (Holmes, 1984). The medial flange is sub rectangular with a concave posterior surface. The element would articulate with the proatlantal arch at the proatlantal facet, which is preserved as a flat surface on the medial part of the medial flange. The medial flange is supported ventrally by a narrow neck region, which expands ventrally to form the 
condylar region of the exoccipital. The ventral surface of the condylar region is subrectangular and concave and would have articulated with the basioccipital.

\section{The Lower Jaw}

Only the posteriormost elements of the left lower jaw are preserved in NSM 994GF1.1 (Figure 2.19), with the exception of 6 dentary teeth described separately below. The surangular is present but incomplete anteriorly. Posteriorly, it contacts a fairly complete articular. Of the mesial surface of the lower jaw, only the prearticular is preserved. It is slightly displaced to the right, but in general it is well preserved. No other elements of the mandible are preserved.

The surangular of NSM 994GF1.1 is well preserved and fairly complete. It has been displaced vertically such that it sits between the fragments of the quadratojugal. The lateral surface of the surangular shows a rounded rectangular main body, with an anterior extension. The anterior and ventral margins are incomplete, but the element bears a horizontal dorsal crest, a characteristic thought to be unique to Archeria (Holmes, 1989). There is no direct evidence of the posterior coracoid contributing at all to the anterior portion of the surangular crest, but this condition is also present in Archeria (Holmes, 1989), Pholiderpeton (Clack, 1987), and Neopteroplax (Romer, 1963), and is assumed to be the primitive condition for tetrapods (Clack, 1987), as it is also seen in Eryops (Sawin, 1941) and Seymouria (White, 1939). However, like in these animals, the anterior margin of the surangular crest of NSM 994GF1.1 ends abruptly with a vertical margin, rather than tapering gradually as seen in Proterogyrinus (Holmes, 1984), Pholiderpeton (Clack, 
A

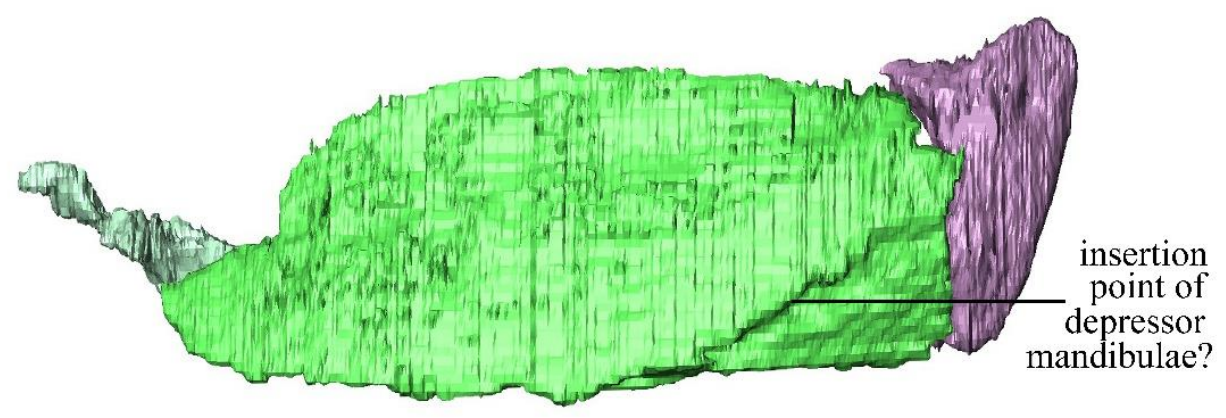

B

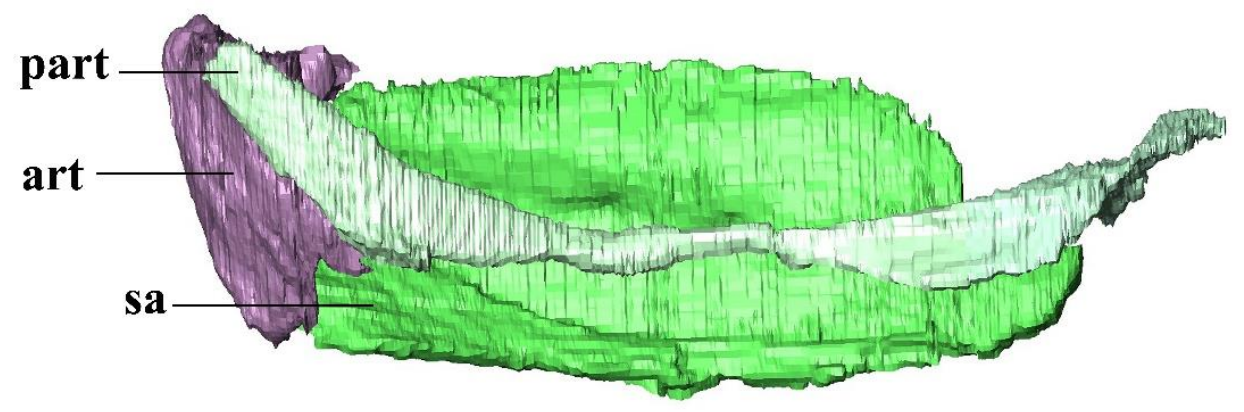

C
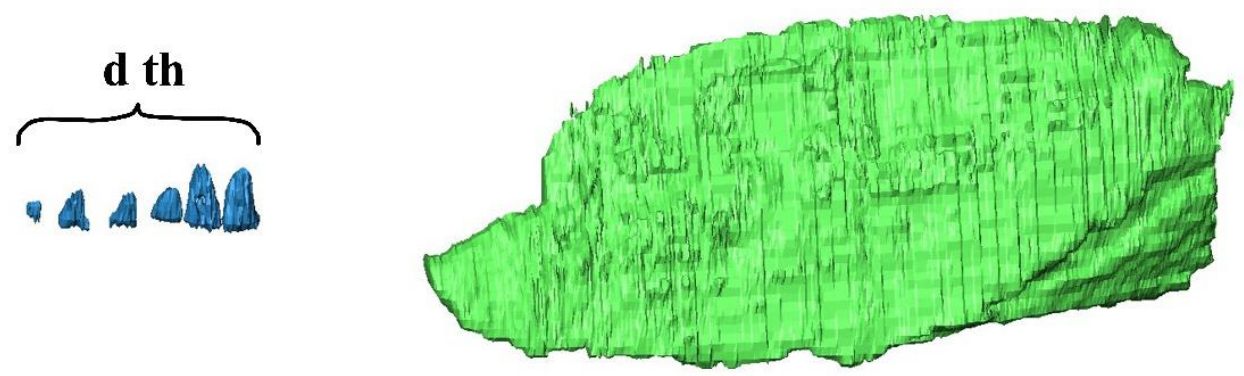

$1 \mathrm{~cm}$

Figure 2.19: Lower jaw of NSM 994GF1.1 as revealed by segmentation of the CT data, showing the isolated prearticular, surangular, and articular. A, left lateral and B, medial view. C, isolated surangular and dentary teeth in left lateral view (prearticular removed). See anatomical abbreviation list above. 
1987) and other embolomeres. The surface of the posterior portion of the surangular bears a deep groove that runs anteroventrally from the posterior to ventral margin of the element. This feature is not figured or mentioned in the descriptions of Archeria (Holmes, 1989) or Proterogyrinus (Holmes, 1984), but is present in Pholiderpeton (Clack, 1987), where it is described as an insertion point for the depressor mandibulae (Clack, 1987).

The prearticular is preserved lying medially to the surangular. It is a long, slender element, similar to that seen in Archeria (Holmes, 1989) and other embolomeres. Similarly to Proterogyrinus (Holmes, 1984), the prearticular expands posterodorsally, such that its posteriormost margin almost reaches the height of the articular. The dorsal margin of the prearticular is smooth and creates a concave bowl shape, but the bone alternatively widens and shortens dorsoventrally such that the ventral surface has a wavy appearance. In life, the bone sits above the Meckelian fenestra and is shortest where the Meckelian fenestra is largest. The shape of the dorsal outline of the fenestra suggests that its size and placement is similar to that in Archeria (Holmes, 1989), Neopteroplax (Romer, 1963), and Pholiderpeton (1987), and larger than that of Proterogyrinus (Holmes, 1984).

The articular is preserved in relatively good articulation with the surangular and prearticular. It is a robust element and similar to that seen in other embolomeres. In general, the articular forms a keel shape, with a high posterior tip and convex lateral and medial sides that sweep anteroventrally to form a V-shape. Between the lateral and medial walls of the element is hollow. The highest point of the keel is formed by the posterior tip of the saddle-shaped glenoid. Like Archeria (Holmes, 1989), Proterogyrinus 
(Holmes, 1984), and other embolomeres, the anterior ridge of the glenoid does not protrude dorsally as high as its posterior ridge. In life the surangular would have covered the entire lateral wall of the articular except for the glenoid.

\section{The Dentition}

There 6 dentary teeth preserved in a row, probably as they were in life (shown in Figure 2.19). Holmes and Carroll (2010) identify these as maxillary teeth, but due to their dorsally directed apexes and otherwise undisturbed position revealed by the CT data, they are more likely dentary teeth. Morphologically, these are distinct from the undifferentiated, elongated, peg-like dentition of Archeria (Holmes, 1989) and Proterogyrinus (Holmes, 1984), and are more similar to the conical shape seen in the dentition of Anthracosaurus (Huxley 1863) or Eoherpeton (Panchen, 1975). Unlike Neopteroplax (Romer, 1963) and Eoherpeton (Panchen 1975), however, the teeth are not leaning posteriorly or recurved, but the apex of each tooth is directly above the midpoint of its base. The teeth are short with blunt apices and have ovoid bases. Teeth 5 and 6 are significantly larger than the previous four and may represent a canine peak or a sudden increase in tooth size moving posteriorly along the tooth row. The latter is not seen in any known embolomere, making the canine peak more likely despite their relatively posterior location, in close proximity to the surangular.

\section{The Axial Skeleton}

The Atlas-Axis Complex 
NSM 994GF1.1 is the first specimen of Calligenethlon to preserve an almost complete atlas-axis complex (Figure 2.20). Like the ventral surface of the skull, the atlas- axis complex has been slightly disturbed and is in relative disarticulation compared to the rest of the vertebral column.

There is a possible left proatlantal arch preserved (Figure 2.20F). This identification is equivocal because the element is preserved posteriorly to the left opisthotic instead of posterior to the exoccipital; however, the presence of prezygapophyses on the atlantal arches suggest the presence of a proatlas, and the concave oval to rectangular shape of the element is similar to the proatlas of the diadectomorph Tseajaia (Vaughn, 1964). Proatlantal arches are rarely preserved in any early tetrapod finds (Clack, 2012), and although they are unknown from other embolomeres, all embolomeres show developed prezygapophyses for articulation with the proatlas.

The atlas of NSM 994GF1.1 consists of a paired neural arch, and a singular pleurocentrum and intercentrum, distinguishing it from the atlas of Proterogyrinus (Holmes, 1984), which has a paired pleurocentrum. The left neural arch of the atlas is broken and has been displaced in the dorsolateral direction. Otherwise, both arches are well-preserved and resemble those elements in Archeria (Holmes, 1989). The arches are gracile at their dorsalmost extensions and become more robust moving ventrally (Figure 2.20D-E). Overall, the elements are more robust than those seen in Archeria (Holmes, 1984) but are still more gracile than those seen in Pholiderpeton (Clack, 1987) and Proterogyrinus (Holmes, 1984). Each arch is longest along the anteroposterior axis and unlike that of Proterogyrinus, the element is not concave laterally but instead remains 
A

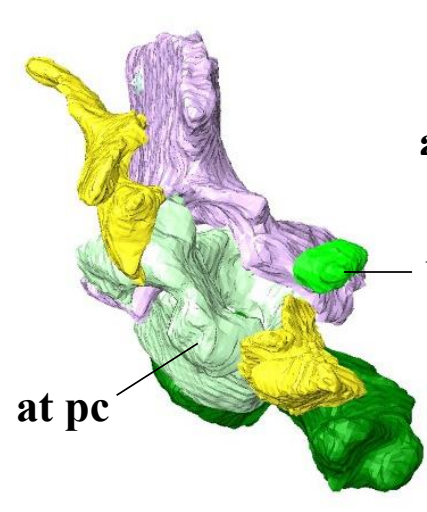

B

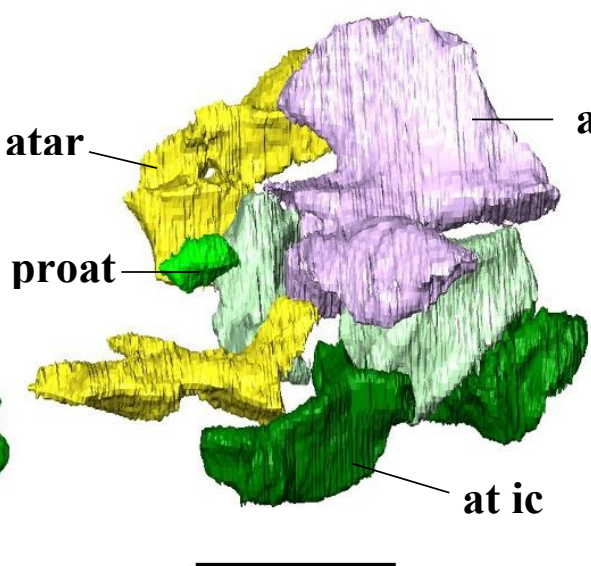

D

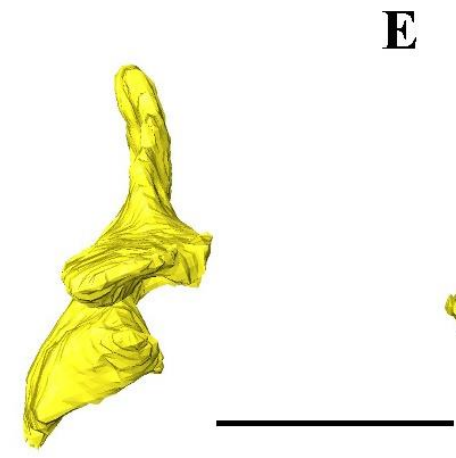

E

G

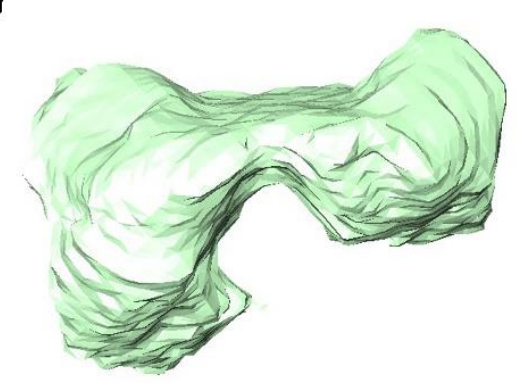

C

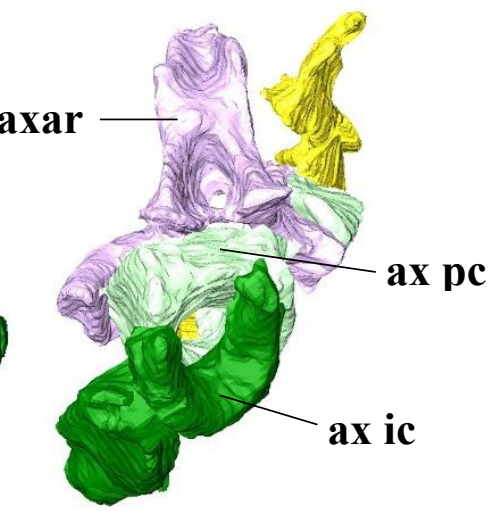

$\mathbf{F}$

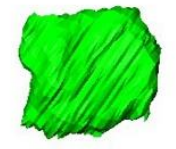

H

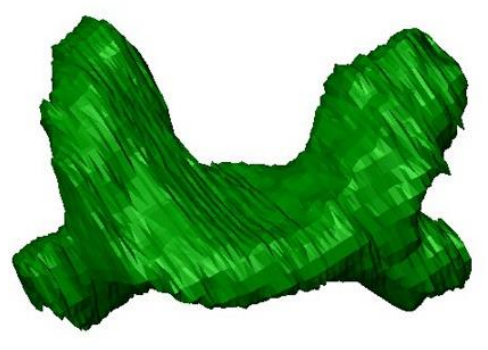

Figure 2.20: Elements of the atlas-axis complex of NSM 994GF1.1 as revealed by segmentation of the CT data. A-C, articulated complex in anterior, left lateral, and posterior view. D-E, right atlas arch in anterior and medial view. F, left proatlas in dorsal view. $\mathrm{G}$, atlas pleurocentrum in anterior view. $\mathrm{H}$, atlas intercentrum in anterior view. Scale bars equal $1 \mathrm{~cm}$. See anatomical abbreviations above. 
relatively straight like that in Archeria (Holmes, 1984). Each arch supports a broad, blade-like dorsal spine and then widens as it slopes away ventrolaterally. Like in Archeria (Holmes, 1989) and Proterogyrinus (Holmes, 1984), a short, horizontal medially-directed projection is present on the medial surface of each atlantal arch, which may indicate the presence of a cartilaginous bridge between the two arches, as suggested by Holmes (1984).

Like the atlas neural arches, the atlas pleurocentrum has been slightly displaced in the vertical direction (Figure 2.20A). However, based on its position relative to the other atlantal elements, it is most likely identified correctly. The element is extremely gracile compared to more posterior pleurocentra, with an anteroposterior length of about half of the other centra. The preserved portion of this element is crescent shaped and would have been the portion that rested above the notochord (Figure 2.20G). The element bears parapophyses on either side. This morphology is quite unlike the atlantal pleurocentrum seen in Proterogyrinus (Holmes, 1984), which sits above the notochord like NSM 994GF1.1 but is a paired element and Archeria (Holmes, 1989), which preserves a robust ring-shaped atlantal pleurocentrum. An unpaired, crescent-shaped, and ossified element otherwise only appears in large, mature specimens of Seymouria baylorensis (Sumida et al., 1992).

The atlas intercentrum has been displaced in the ventrolateral direction (Figure $2.20 \mathrm{H})$. It is similar in shape and size to the more posterior intercentra, except it bears two very prominent ventrolaterally directed parapophyses. It forms a robust U-shape, with rounded margins and concave anterior and posterior faces. The lateral surfaces are smooth. This morphology is most like the atlantal intercentrum described for 
Proterogyrinus (Holmes, 1984), differing only in that the element's anteroposterior length tapers moving dorsally.

The morphology of the axis arch is similar to the morphology of the other neural arches, although the former is slightly more robust. The neural spine of the arch tilts anteriorly. The spine of the axial arch is anteroposteriorly longer than most of the more posterior neural arches and is curved along its dorsalmost margin rather than terminating with a horizontal margin. Viewed dorsally, the neural spine bifurcates to create a V-shape that opens posteriorly. The zygapophyses are similar to those of the more posterior arches and show articulation sites for the tuberculum of the rib. In life, the prezygopophyses would have contacted the atlantal arches. The postzygapophysis is still in articulation with the neural spine posterior to it.

The axis intercentrum preserves ventrally directed parapophyses but is otherwise not significantly different from those in the rest of the vertebral column. The axis pleurocentrum is morphologically identical to the more posterior pleurocentra.

\section{The Vertebral Column}

A series of 19 presacral vertebrae are present in NSM 994GF1.1. Embolomeres such as Proterogyrinus (Holmes, 1984) have 32 presacral vertebrae, and Pholiderpeton (Clack, 1987) may have as many as 47 , suggesting that some presacral vertebrae are missing in NSM 994GF1.1. The vertebral column consists of alternating intercentra and pleurocentra. Each neural arch is supported by a single intercentrum and pleurocentrum 
(Figure 2.21A, F). The pleurocentra are about twice as anteroposteriorly long as the intercentra, similar to those of embolomeres such as Eogyrinus (Panchen 1966), Proterogyrinus (Holmes 1984) and Anthracosaurus (Panchen, 1977), and distinct from those of Archeria (Holmes 1989) and Pholiderpeton (Clack 1987). Unlike Proterogyrinus (Holmes, 1984), however, the pleurocentra always form complete rings with no trace of a dorsal suture (Figure 2.21B-C). Both the anterior and posterior faces of the pleurocentra are deeply concave, as well as the smooth outer surface of the ring. The notochordal perforation is small relative to the size of the element, although it is larger compared to the condition seen in Archeria (Holmes, 1989), Anthracosaurus (Panchen, 1977), and Eogyrinus (Panchen, 1966), and smaller than the condition described for Proterogyrinus (Holmes, 1984). In this character, NSM 994GF1.1 is most similar to Calligenethlon (Steen, 1934), Carbonoherpeton (Klembara, 1985), and Pholiderpeton (Clack, 1987). Unlike Proterogyrinus (Holmes, 1984), Archeria (Holmes, 1989), and other embolomeres, there are no dorsolateral projections where the neural spines articulate with the centra.

The intercentra are preserved as ventral crescents, similar to the morphology of those seen in Proterogyrinus (Holmes, 1984), Eoherpeton (Smithson, 1985), and other early tetrapods such as Gephyrostegus (Carroll, 1970) and Greererpeton (Godfrey, 1989). The intercentra appear as robust wedges in lateral view and have concave anterior and posterior faces (Figure 2.21D-E). Several specimens attributed to Calligenethlon possess both complete rings and crescentic presacral intercentra, where the ends of the anteriorly placed, crescent-shaped centra do not meet, but there is progressive closure of this gap posteriorly, such that the more posterior elements form a fully fused, ring morphology. 
$\mathbf{A}$
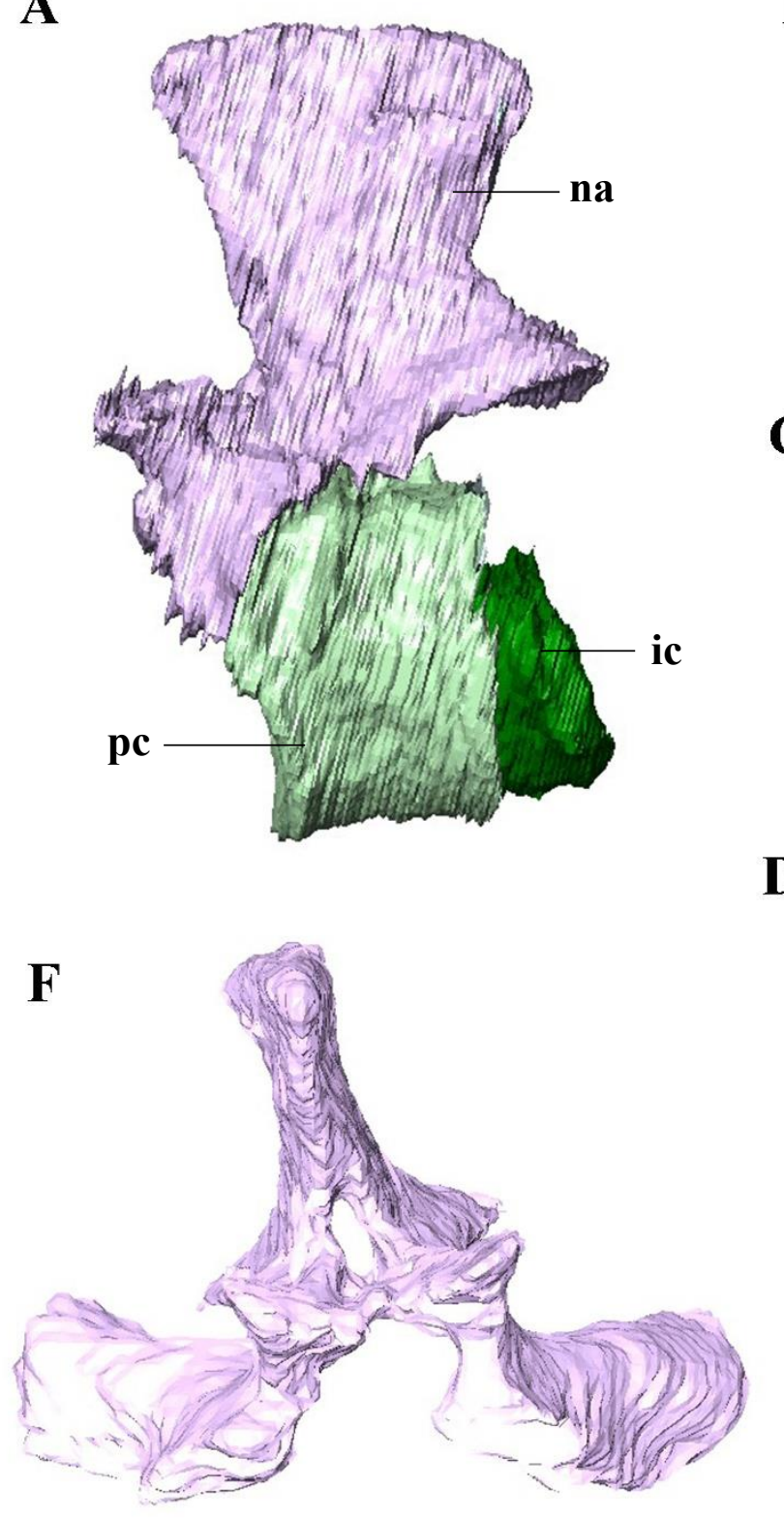

B

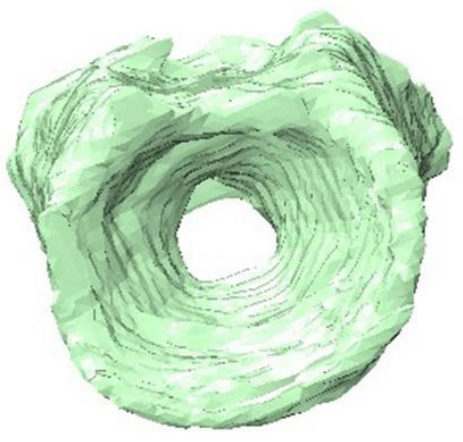

C

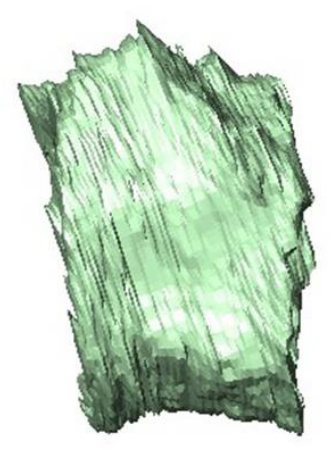

D

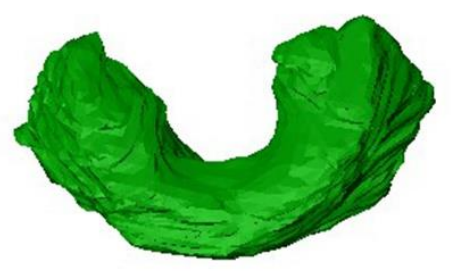

$\mathbf{E}$

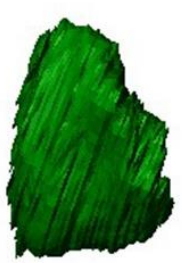

$1 \mathrm{~cm}$

Figure 2.21: Vertebral elements of NSM 994GF1.1 as revealed by segmentation of the CT data. A, articulated neural arch, pleurocentrum, and intercentrum. B-C, pleurocentrum in anterior and left lateral view. D-E, intercentrum in anterior and left lateral view. F, neural arch in anterior view. Anatomical abbreviation listed above. 
Only the crescentic morphology is preserved in NSM 994GF1.1; however, this may be due to the fact that only the anterior portion of the presacral series is preserved in NSM 994GF1.1. The perforation in the center which allows for the notochord is always bigger in the intercentrum than in the pleurocentrum. Other than those included in the atlas-axis complex, the intercentra do not preserve ventrally directed parapophyses.

\section{Neural Arches}

The neural arches of NSM 994GF1.1 are similar to those seen in other embolomeres (Figure 2.21). The main body of the neural arch rests atop the pleurocentrum. Like other embolomeres, the dorsal spine extends vertically from its base. Unlike the strictly rectangular arches in Archeria (Holmes, 1989) and Proterogyrinus (Holmes, 1984), each arch flares dorsally to make a slight fan shape in lateral view. This morphology is also depicted in Pholiderpeton (Clack, 1987). As is common in embolomeres, the spines are all about the same height and thickness along the column, although the spines of the anteriormost arches thicken slightly posteriorly, such that they appear slightly triangular in dorsal view. Each neural arch has two horizontally protruding prezygapophyses, which articulate with the postzygapophyses of the arch anterior to it. Ventral to the prezygapophyses are the transverse processes which contact the ribs. 
There are two rib morphologies present (Figure 2.22). The first are short, straight ribs, like those described by Steen (1934) and Carroll (1967) for other specimens of Calligenethlon and pertain to the cervical region which consists of seven ribs. As Carroll (1967) noted, these ribs are double-headed and lie near the shoulder blades. The more anterior ribs in articulation with the cervical vertebrae also follow this morphology, although the degree of separation between the tuberculum and the capitulum of the rib varies. The most obviously double-headed ribs are those between vertebrae 5-7. These ribs are also the most robust, with broad, flat shafts which expand slightly at their proximal and distal tips. The second rib morphology present in NSM 944GF1.1 is seen adjacent to vertebrae 9-19 in the trunk region, when preserved. These ribs are singleheaded and curve sharply distally. They are circular in cross section and retain the same thickness throughout their whole length.

\section{The Appendicular Skeleton}

\section{The Pectoral Girdle}

The pectoral girdle in NSM 994GF1.1 is fairly complete and well preserved (shown in Figure 2.23). The elements are mostly preserved as they were in life, although the anocleithrum, scapulocoracoid, and cleithrum have all been displaced slightly anteriorly. 


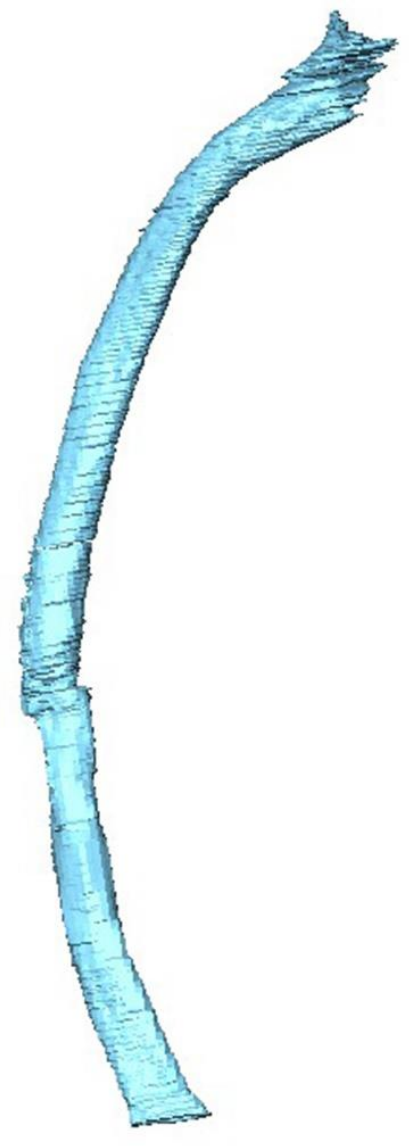

$1 \mathrm{~cm}$

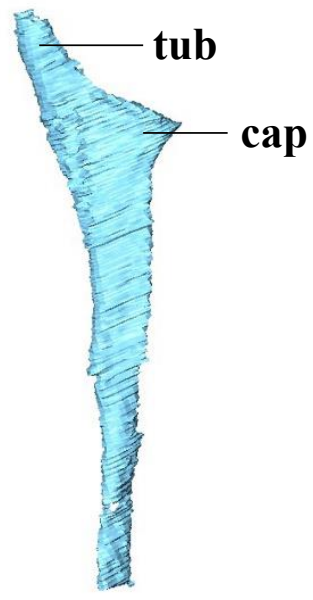

Figure 2.22: Ribs in NSM 994GF1.1 as revealed in CT data. A, $8^{\text {th }}$ left presacral rib from the trunk region; $\mathrm{B}, 3^{\text {rd }}$ left presacral rib from the cervical region. Note the elongated and curved morphology of the trunk ribs compared to the short straight morphology of the cervical ribs. Anatomical abbreviation listed above. 
A

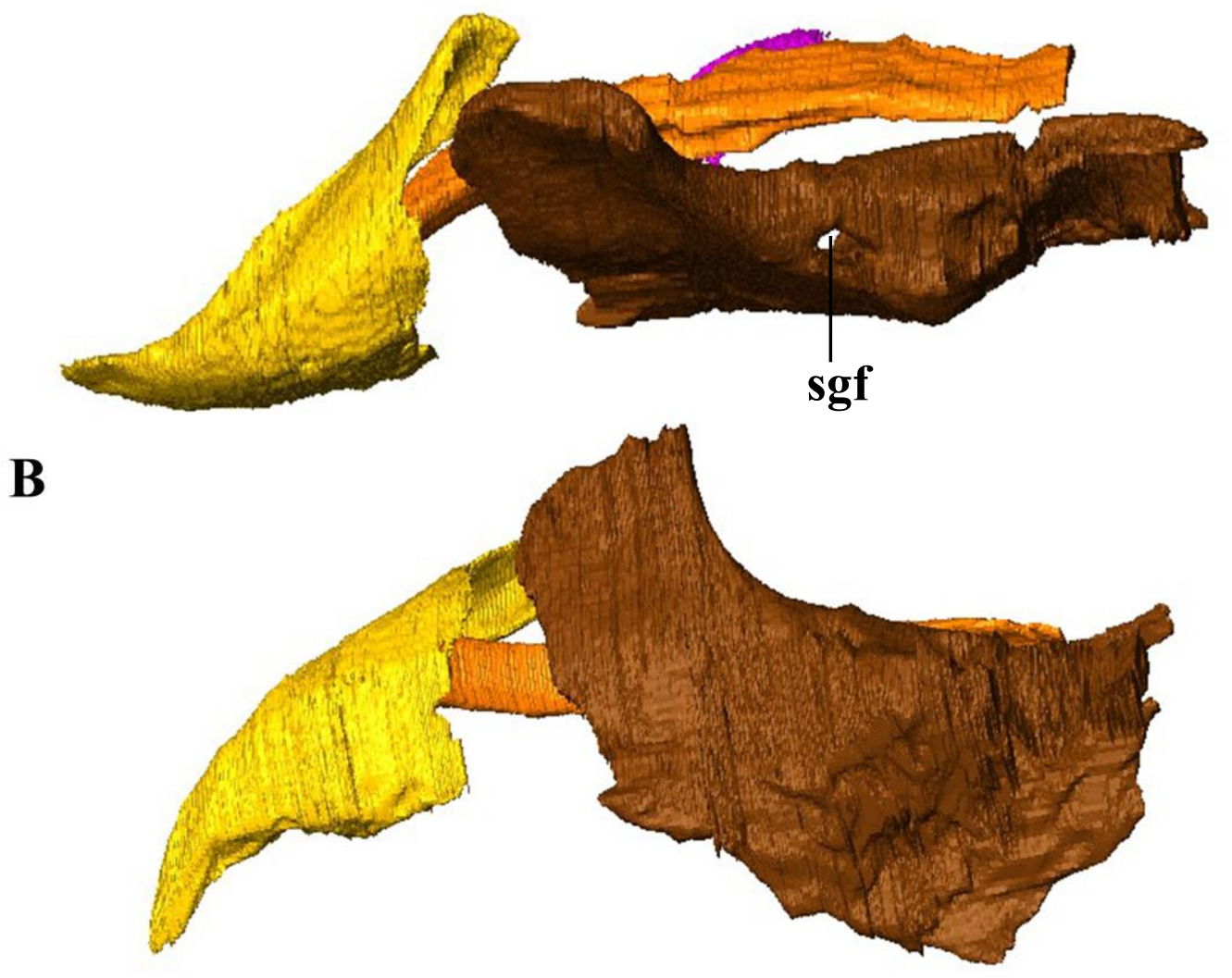

C

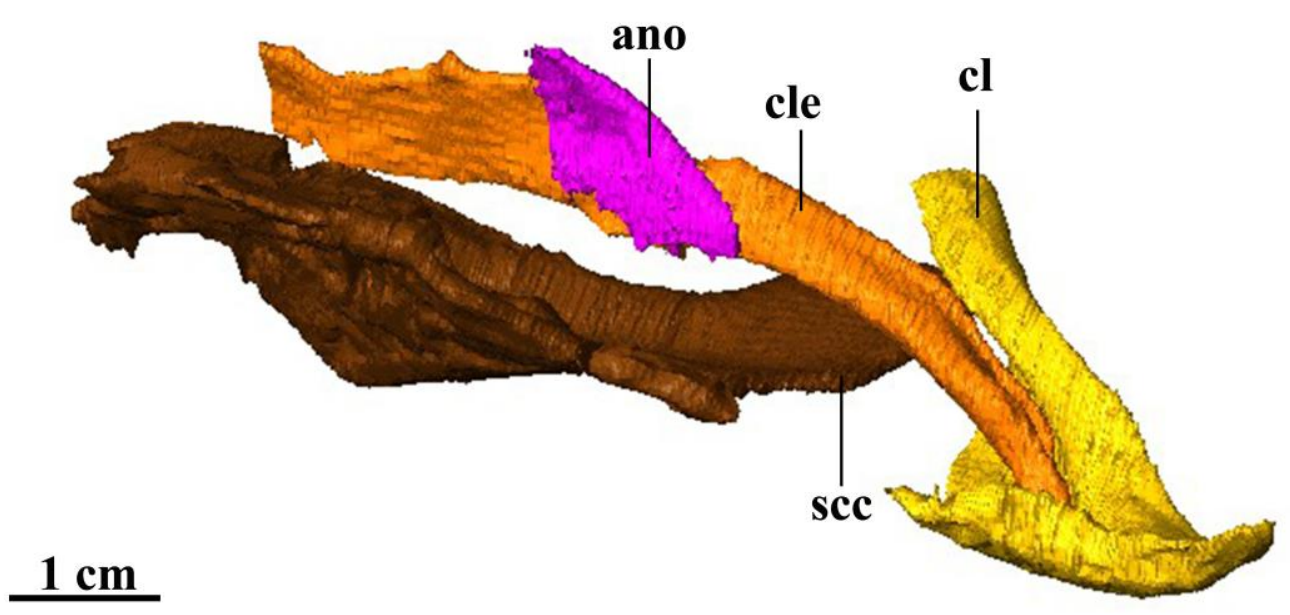

Figure 2.23: Left pectoral girdle of NSM 994GF1.1 as revealed by the CT data in A, left lateral; B, ventral; and C, medial view. Anatomical abbreviation listed above. 
The clavicle is well preserved. In lateral view it is a triangular element, with a plate that extends ventrally in the anterior and posterior direction from the main stem of the element. The overall morphology of the element is similar to most embolomeres, although it is thinner anteroposteriorly with a gracile, narrow stem like that in Archeria (Romer, 1957) and Pholiderpeton (Clack, 1987), unlike the robust clavicle in Proterogyrinus (Holmes, 1980). The anteriormost tip of the ventral plate points inward toward the midpoint of the animal and would have articulated with the interclavicle in life. Posteriorly, the lateral face of the plate extends dorsoposteriorly and curls in on itself to form the medial surface of the stem. This extension would have articulated with the ventral stem of the cleithrum. The anterior surface of the stem bears a ridge along its entire length, although it becomes much less prominent posteriorly. This morphology is also present in Proterogyrinus (Holmes, 1984) and postulated to be an attachment site for the ventral throat musculature (Holmes, 1980). More derived embolomeres such as Pholiderpeton (Clack, 1987) describe crenellations here rather than a ridge.

The interclavicle of NSM 994GF1.1 seems to have been mostly destroyed since the discovery of the specimen and all that is left is a fragment of the right flange. The fragment does not show any true edges of the element but has been identified based on its location medially to the right clavicle, its thin, flat morphology, and acknowledgement of its previous existence (Holmes and Carroll, 2010: fig. 3).

The cleithra are long, slender elements with a paddle-like expansion at their posterior tips. In life, the cleithrum would have been articulated with the scapulocoracoid posteriorly and overlapped with the clavicle ventrally. The element extends posteriorly with a slight downward curve. The shaft is generally triangular in section, but the 
extended posterior surface is thin and blade-like. This morphology is similar to that seen in Archeria (Romer, 1957) and other early tetrapods.

The scapulocoracoid is a massive element. It is more extensive than is seen in other embolomeres, although this is likely due to the poor preservation of most embolomere finds rather than a true autapomorphy. Like Archeria (Romer, 1957) and other embolomeres, the scapulocoracoid preserves a large supraglenoid foramen close to its lateral edge.

Interestingly, NSM 994GF1.1 preserves an anocleithrum, originally suggested to be the expanded end of a posterior right cervical rib (see Holmes and Carroll, 2010: fig. 1). However, the CT data reveals no further length of rib and the same bone is present medial to the left cleithrum as well. Anocleithra are rare elements in early tetrapods (Klembara and Bartík, 1999), but have been reported in Acanthostega (Coates and Clack, 1991; Coates, 1996), Devonian tetrapod Tulerpeton (Lebedev and Coates, 1995) and were thought to be lost after the Devonian tetrapods until one was identified in Pennsylvanian-aged Pholiderpeton ('unidentified bone', Clack, 1987; see Lebedev and Coates, 1995) and Permian seymouriamorph Discosauriscus (Klembara and Bartík, 1999). This shows that the presence of an anocleithrum may be retained until the Early Permian reptiliomorphs and therefore must not be thought of as a necessarily basal character. In NSM 994GF1.1, the element is extremely thin and sub rectangular, as is described for Pholiderpeton (Clack, 1987) and Discosauriscus (Klembara and Bartík, 1999) and distinct from the kidney shaped element described for Tulerpeton (Lebedev and Coates, 1995). As in other tetrapods, the element preserves a slightly convex lateral surface and sits immediately medial to the cleithrum. Both elements have been moved 
anteriorly from their natural position of articulation with the posterior tip of the cleithrum.

\section{The Forelimb}

The forelimb of NSM 994GF1.1 is well preserved and fairly well articulated (Figure 2.24). The humerus preserved in NSM 994GF1.1 (Figure 2.24, 2.25A-D) is a large, robust element with the L-shape typical of early tetrapods (Romer, 1947). It is most similar to Archeria in its possession of three features originally thought to be unique to that genus: a well-developed entepicondylar region, a prominent ectepicondyle, and a small amount of twisting of the ends (Romer, 1957). In general, the humerus is quite thin dorsoventrally, like Archeria (Romer, 1957). The ectepicondylar process in NSM 994GF1.1 is extremely developed, beyond the condition seen in Archeria, such that it creates a wave-like silhouette in anterior view. Its dorsal extension suggests against much dorsoventral flattening of the rest of the element. The scapulohumeral depression is a smooth surface on the proximal head of the humerus, where the scapulocoracoid would articulate. The deltopectoral crest is small but present on the ventral surface of the proximal condyle, similar to that described for Archeria (Romer, 1957). Moving distally from the proximal condyle, the shaft of the humerus constricts slightly until its anterior margin extends outward to create the concave surface of the subcoracoscapularis process. The entepicondylar region is well developed, as in Archeria (Romer, 1957) or Proterogyrinus (Holmes, 1984), but is more like Proterogyrinus in that it extends posteriorly at an obtuse angle to the main shaft of the humerus, rather than 
A

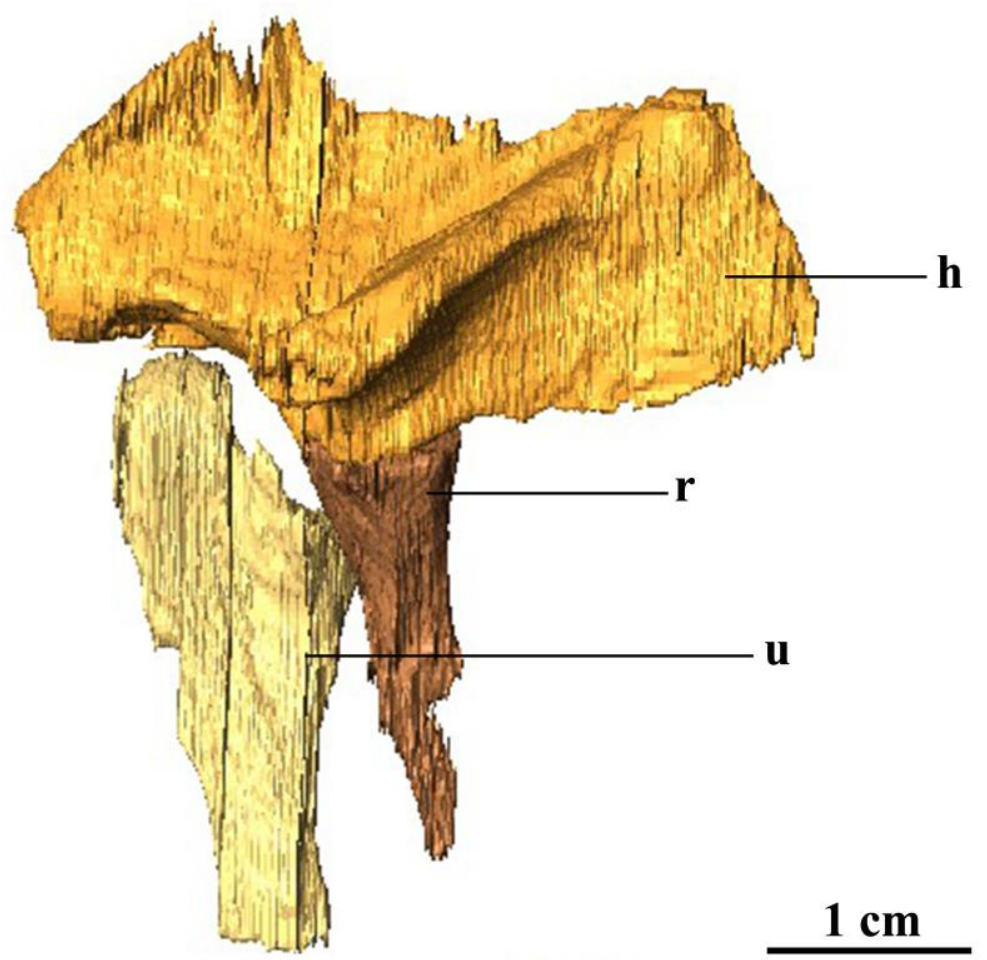

B

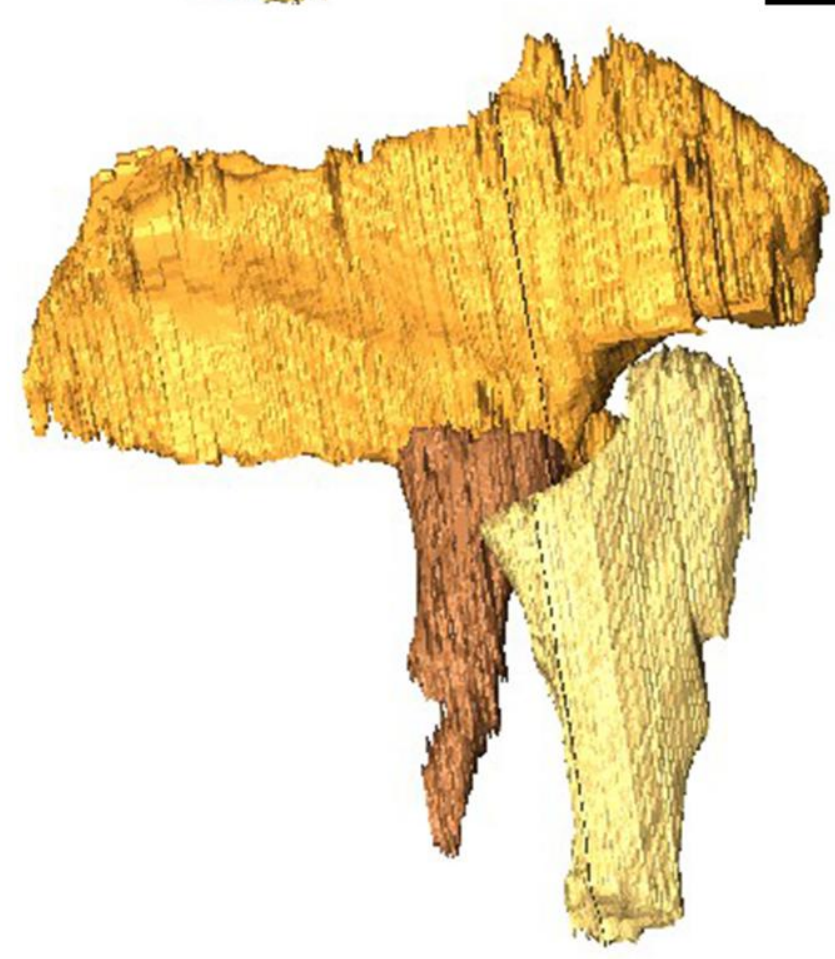

Figure 2.24: Articulated right forelimb of NSM 994GF1.1 as revealed by the CT data in A, dorsal and B, ventral view. Anatomical abbreviation listed above. 
A

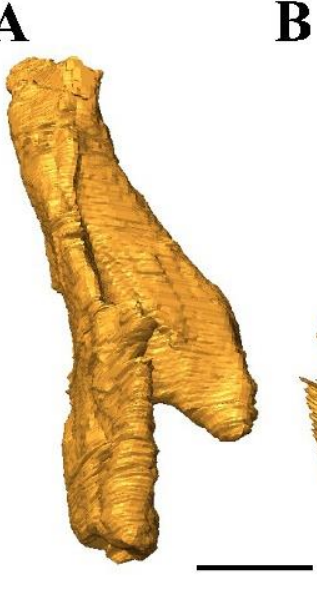

B

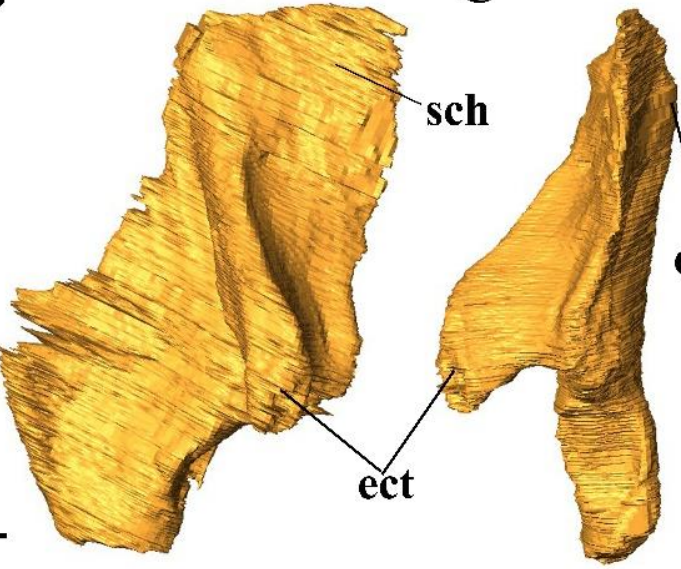

$\mathbf{E}$

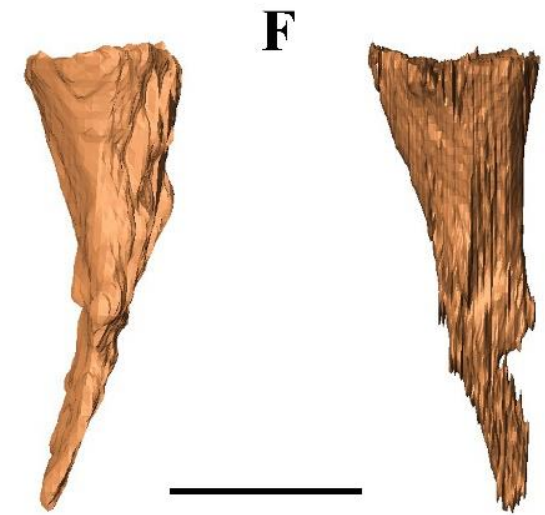

I

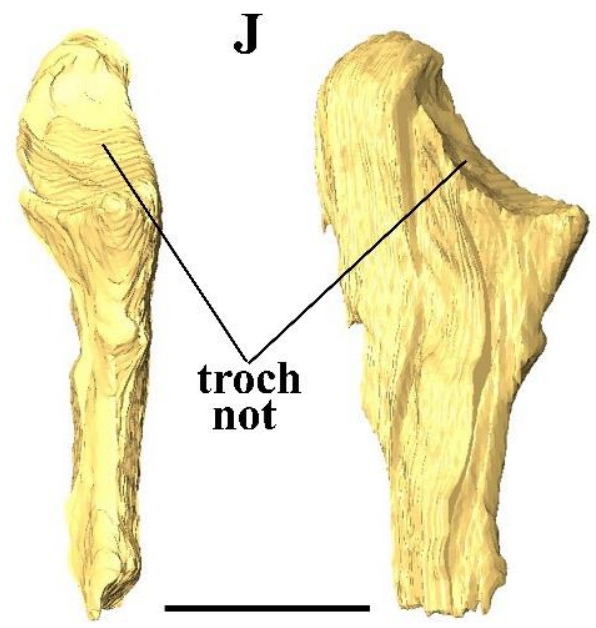

G

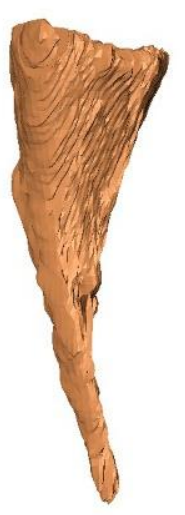

D

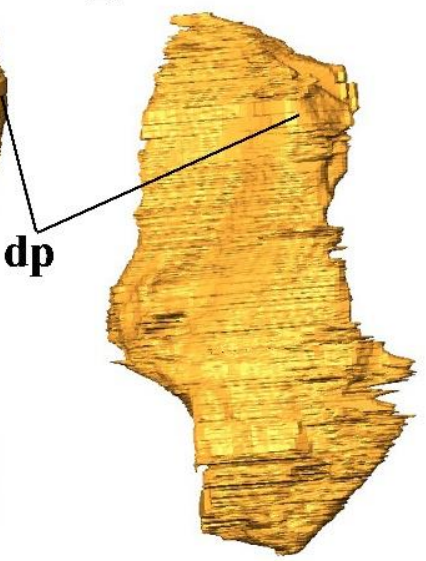

H

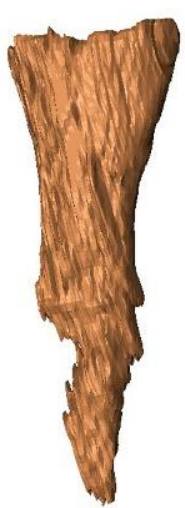

$\mathbf{K}$

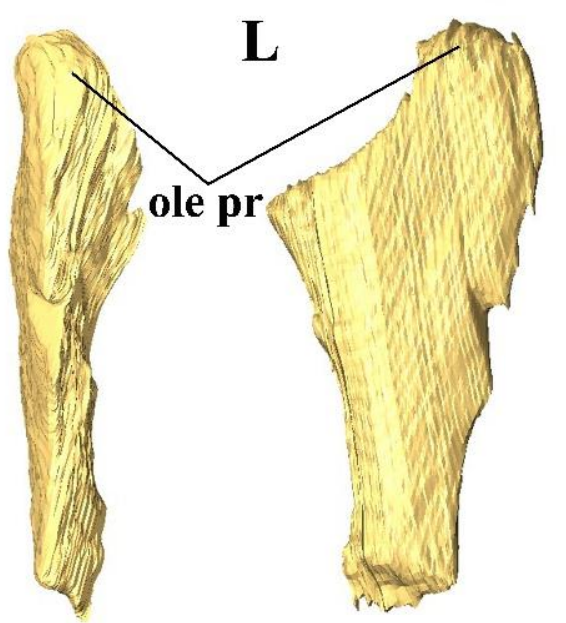

Figure 2.25: Isolated forelimb elements of NSM 994GF1.1 as revealed by the CT data. A-D right humerus in anterior, dorsal, posterior, ventral view. Note the extremely well developed ectepicondylar process. E-H right radius in anterior, dorsal, posterior, ventral view. I-L, right ulna in anterior, dorsal, posterior, ventral view. Note the well-developed olecranon process. Anatomical abbreviation listed above. Scale bars equal $1 \mathrm{~cm}$. 
perpendicularly as in Archeria. As is typical for embolomeres, the posteriormost surface of the entepicondylar plate is depressed, creating a concave surface between the proximal and distal corners of the plate, where the radius and ulna would have articulated. Like Proterogyrinus, the proximal corner, where the radius would have articulated, is further anterior than the distal corner of the entepicondyle, rather than both corners lying in the same plane, as in Archeria. However, this morphology is much more exaggerated in NSM 994GF1.1 than in Proterogyrinus. The entepicondyle is distinct from Proterogyrinus (Holmes, 1984), Archeria (Romer, 1957), and all other embolomeres where the humerus is known, in that it lacks an entepicondylar foramen.

Unlike Archeria (Holmes, 1989), Pholiderpeton (Clack, 1987), or any embolomere where the humerus is known, there is no entepicondylar foramen present, although this apparent loss may be due to the relatively poor quality of the CT scan around this region.

Only the proximal heads of the radii are preserved in NSM 994GF1.1 (Figure $2.25,2.25 \mathrm{E}-\mathrm{H})$. The right radius is more complete and therefore will be described here. The radius is preserved close to its natural position. The proximal head is cylindrical with a smooth, slightly concave articular surface, where it contacts the humerus. The element thins distally to form a relatively gracile shaft, similar to Archeria (Romer, 1957), but more robust than that of Seymouria (Berman et al., 2000).

Both ulnae in NSM 994GF1.1 are present and in both the distalmost portion of the shaft has been lost (Figure 2.24, 2.25I-L). The right ulna is more complete and therefore is the element described here. The overall morphology of the ulna is most similar to that 
seen in Archeria (Romer, 1957). Like Archeria (Romer, 1957), Pholiderpeton (Clack, 1987), or Seymouria (Berman et al., 2000), the ulna possesses an extremely welldeveloped olecranon process of the ulna, which suggests that this is a mature specimen (Berman et al., 2000). Just anterior to the olecranon is the concave semilunar notch where the ulna would contact the humerus. The articular surface is surrounded by a prominent ridge, like in Archeria (Romer 1957). The expanded proximal heads converge to meet a gracile, parallel sided shaft, much like that of Archeria (Romer, 1957), which further distinguishes it from Seymouria (Berman et al., 2000) and Pholiderpeton (Clack, 1987).

\subsection{DISCUSSION}

The specimen of the embolomere Calligenethlon investigated here provides an important opportunity to revisit both the problematic anatomical diagnosis of the genus, as well as the validity of historically referred specimens to the genus. Analysis of the computed-tomography data of NSM 994GF1.1 reveals several new insights into its anatomy and the anatomy known for Calligenethlon watsoni.

\section{Referral of NSM 994GF1.1 to Calligenethlon watsoni}

Although the original description of NSM 994GF1.1 by Holmes and Carroll (2010) was remarkably thorough, they were hesitant to confidently assign this specimen to Calligenethlon because so much of the exposed anatomy was nondiagnostic and generally similar to any other known embolomere (Holmes and Carroll, 2010). The anatomy described here, based on the new micro-computed tomography data, reveals several autapomorphies which may be attributed to Calligenethlon if NSM 994GF1.1 can 
be shown to be consistent with the type specimen, RM 2.1122. I believe this to be the case for the following reasons.

First, as established by Holmes and Carroll (2010), NSM 994GF1.1 is undoubtedly an embolomere. Although the anteriormost region is not preserved, the contours of the bones indicate long frontals and therefore an elongated snout shape. As is always the case for embolomeres, the quadrates in NSM 994GF1.1 lie posterior to the occiput (Holmes, 1984). The parietals extend posterolaterally to contact the tabulars and the tabulars bear horns, both of which are considered diagnostic traits for embolomeres (Holmes, 1984).

Second, the skull of NSM 994GF1.1 is consistent with that of the type specimen of Calligenethlon described by Steen (1934) and resembles Calligenethlon more closely than any other embolomere. Like the type specimen, RM 2.1122, the skull table of NSM 994GF1.1 is rather narrow and, unlike any other embolomere, parallel-sided. This is due to the lack of a lateral expansion of the intertemporal - a condition present in both NSM 994GF1.1 and the type specimen. As is described for RM 2.1122, the tabular of NSM 994GF1.1 and its horn are larger and more elongate than those in other embolomeres.

Third, although lateral lines are typical in embolomere skull tables, they are neither present in NSM 994GF1.1 nor in RM 2.1122, further uniting the specimens. Additionally, of the preserved postcrania of RM 2.1122, the scapulocoracoid is quite incomplete but preserves impressions indicating it was a similarly massive element to that seen in NSM 994GF1.1. The two rib morphologies in NSM 994GF1.1 are both present in the type specimen and there is evidence of a similar cleithrum morphology in both specimens. Because the postcrania in RM 2.1122 is extremely fragmentary, the 
similarities between it and NSM 994GF1.1 are necessarily more general; however, the morphology of the skull is consistent enough to confidently refer NSM 994GF1.1 to Calligenethlon watsoni.

\section{Reassessment of specimens referred to Calligenethlon}

The official referral of NSM 994GF1.1 provides a new opportunity to review the specimens that were previously attributed to Calligenethlon based primarily on circumstantial evidence. The exceptional preservation of NSM 994GF1.1 allows for broader and more complete anatomical knowledge than may be provided by the holotype specimen. The validity of these referrals are re-evaluated in the light of this updated anatomical data. Each specimen is discussed below and officially referred to or excluded from Calligenethlon based on morphological similarity to NSM 994GF1.1 or RM 2.1122.

RM 2.1193a. The type specimen of "Atopotera moneres", referred to Calligenethlon watsoni by Carroll (1967) is extremely fragmentary; however, it preserves some features that justify its placement in Calligenethlon (Figure 2.2). The first and strongest argument concerns the morphology of the intertemporal and the prefrontal. Although the posterolateral margin of the intertemporal is incomplete, its preserved lateral margin follows the exact line of the prefrontal, without expanding laterally. This appears to be the beginning of the parallel sided skull table, which is a diagnostic characteristic of Calligenethlon. RM 2.1193a preserves the impression of a parietal, and only a small fragment of the tabular is preserved, the element must have been fairly large based on the placement of its articulation with the parietal and the position of the articulated postparietal (Figure 2.2B). Lastly, although maxillary teeth are unknown in NSM 994GF1.1 and the type, the teeth in RM 2.1193a are similar in morphology to the 
dentary teeth in NSM 994GF1.1 in that they are conical with non-recurved apices, unlike those seen in Proterogyrinus (Holmes, 1984) and Archeria (Holmes, 1989). Like the dentary teeth in NSM 994GF1.1, the maxillary teeth of RM 2.1193a are more similar to the dentition of Anthracosaurus, but are a much smaller size. Therefore, RM 2.1193a can confidently be referred to Calligenethlon.

RM 12115. The strong fimbriation or comb-like structures on the anterior surface of the interclavicle is more distinct than that seen in other embolomeres and is quite similar to that seen in the type of Calligenethlon. As the associated pterygoid, radius, and scapulocoracoid are also not inconsistent with the morphologies shown in NSM 994GF1.1, I suggest that RM 12115 maintain its referral to Calligenethlon.

NMC 10050. This specimen preserves a femur in three dimensions and a tibia (Figure 2.3). The femur is difficult to compare with that present in the type specimen RM 2.1122 because it unfortunately preserves only the parts of the femur which are lost in RM 2.1122. The shaft appears similarly gracile compared to the width of the proximal condyle, but this is also true for Proterogyrinus and other embolomeres. Although it is distally incomplete, enough is preserved in NMC 10050 to show that the condyles expand distally, probably forming robust tibial and fibular condyles like those in RM 2.1122, but this is speculation. The tibia is not known from any other Calligenethlon specimen. However, the greatest difference between NSM 10050 and the Calligenethlon specimens is the vertebral morphology. While Carroll (1967) originally identified the dorsally incomplete elements as pleurocentra, Godfrey et al. (1991) point out that in embolomeres it is typically the pleurocentra that close first and therefore these are likely intercentra. Godfrey et al. (1991) also point out that morphologically the centra of NMC 10050 are 
structurally different from those seen in the type specimen, and although it is never explicitly stated what these differences are, they are likely referring to the extremely strong ridge surrounding the concave anterior face of the element and the type of dorsal incompletion. A ridge is present in the pleurocentra of NSM 994GF1.1 but not nearly as prominent, and never on the intercentra. The type of dorsal incompletion of the intercentrum of NMC 10050 is unusual in that there is no gap between opposing sides of the intercentrum; rather, the element is fully ossified above the central opening for the notochord, there is simply a piece of the ridge missing dorsally such that the element does not make a circular outline. This vertebral morphology is not seen in any embolomere and may challenge the classification of NMC 10050 as such. I deem these features sufficient to exclude NMC 10050 from Calligenethlon and label it provisionally as an embolomere incertae sedis.

NMC 10096. This basioccipital is strikingly similar in morphology to that of NSM 994GF1.1 in its overall bullet shape and distinctive wing-like posterolateral processes. Interestingly, Carroll (1967) labelled it as having a possible association with NMC 10050, but given that the taphonomy of the Joggins stump fauna can lead to several individuals being preserved together, even a strong association does not preclude NMC 10096 from belonging to a different individual and thus a different species. Therefore, I retain the referral of NMC 10096 to the genus Calligenethlon.

NMC 10119. This isolated interclavicle shows similar fimbriation along the anterior surface of the element to those seen in the type specimen. The morphology is perhaps not as distinct as RM 12115, but is still stronger than that seen in Archeria and 
other embolomeres. This suggests that NMC 10119 can be included in the genus Calligenethlon.

DMSW B.224. The humerus in this specimen may not be embolomerous. This is not explicitly stated in the literature but where known, embolomerous humeri possess a concave dip on the distalmost surface of the entepicondylar plate, where the radius and ulna would articulate. This is most prominent in Archeria, but even more strongly developed in NSM 994GF1.1. The humerus of DMSW B.224 does not possess this feature at all and is instead perfectly flat along this surface like the condition in Acanthostega, although much more lightly built (Molnar et al., 2018). This specimen is different enough from NSM 994GF1.1 to exclude it from Calligenethlon, and I recommend this specimen be treated provisionally as a tetrapod incertae sedis.

BM(NH) R.442. The morphology of the ulna and radius in this specimen are very similar to those preserved in NSM 994GF1.1. The ulna shows the same extremely well developed olecranon process and deeply concave trochlear notch that is seen in NSM 994GF1.1. This morphology is also similar to that of Archeria. The radius may be distinguished from Proterogyrinus in that it exhibits a shaft that is almost the same width as the proximal condyle, such that there is very little expansion to form the condyles. This feature is similar to that seen in NSM 994GF1.1 (see Figure 2.8H) and Archeria. This specimen may be considered Calligenethlon.

BM(NH) R.4553. This specimen was originally named "Dendryazousa dikella” by Steen (1934) but was referred to Calligenethlon by Carroll (1967). Two maxillae are preserved, both of which appear to have the same conical and non-recurved dentition present in some of the previously referred material and in the dentary teeth of NSM 
994GF1.1. An articulated fragment of the posterior corner of a skull table reveals a broken but still large tabular compared to the preserved size of the parietal. There are both dorsally complete and incomplete centra present. This specimen is currently considered to represent a juvenile form of Calligenethlon watsoni (Holmes and Carroll, 2010) based on the wider notochordal opening in the vertebrae and Carroll's (1967) observation of poor ossification. However, even in an immature form, BM(NH) R.4552 displays an extensive olecranon process. I consider this specimen to be correctly referred to as a juvenile form of Calligenethlon.

NSM 988GF70.1. This specimen preserves the first evidence of an embolomere possessing both dorsally complete and dorsally incomplete intercentra within a single vertebral series. Although there are no dorsally complete intercentra preserved in NSM 994GF1.1, the vertebral morphology of the incomplete intercentra of NSM 988GF70.1 is exactly the same as those present in NSM 994GF1.1. There is no evidence of any dorsally fused intercentra in the vertebral column in NSM 994GF1.1, but as the fusion in NSM 998GF70.1 occurs within the posterior trunk region, it is likely that NSM 994GF1.1 is not preserved far enough posteriorly to show any changes in intercentrum morphology and therefore this character is not unusual in its absence. The robust morphology of the pleurocentra of NSM 988GF70.1 is also consistent with that of NSM 994GF1.1; they are about twice the anteroposterior length of the intercentra and dorsally fused with no trace of a suture. The ribs are also quite similar to those preserved in NSM 994GF1.1 in that they are bicipital, elongated and curved. Based on the vertebral morphology, NSM 998GF70.1 can be confidently referred to Calligenethlon, bringing with it the autapomorphy of possessing both complete and incomplete intercentra. This character 
also explains the conflicting reports of complete and incomplete intercentra in other Calligenethlon specimens (Carroll, 1967). However, NSM 998GF70.1 is almost twice the size of any previously known specimen of Calligenethlon, and this must be taken into consideration and is discussed below.

RM 20.4984. The articulated vertebral column in RM 20.4984 is consistent with the vertebral morphology outlined in NSM 994GF1.1 and other Calligenethlon specimens. There is no way to tell for sure whether the intercentra are dorsally fused or not because they are only preserved in lateral view, but they are almost of equal height to the pleurocentra, making it not unreasonable to suggest they are. This specimen also preserves an ilium with the diagnostically gracile posterior process, suggesting its immediate referral to Calligenethlon. The specimen is, however, 220\% larger than the type of Calligenethlon. Godfrey et al. (1991) argued that such an extremely high ratio of iliac length to dorsoventral width is such an unusual and apparently derived feature that its appearance in both specimens greatly suggests they are congeneric. RM 20.4984 must then be considered part of Calligenethlon or at least very closely related and the implications of this are discussed further below.

\section{The diagnosis of the genus Calligenethlon}

The genus Calligenethlon is now represented by ten specimens, and a formal diagnosis can be created based on re-evaluation of the anatomy shared by all referred specimens. Any autapomorphies shown in individual specimens can now be treated as part of the anatomical diagnosis as well. 
Diagnosis. Embolomere with skull pattern and body proportions generally similar to Archeria and other small embolomeres. The skull table is narrow, with parallel lateral margins. There is no evidence of lateral lines. The tabular is large, with an elongated horn that extends posteriorly well beyond the occiput. The tabular horns follow the line of the lateral surface of the skull table, such that they are parallel to each other. Surrangular exhibits a horizontal crest. The dentition is conical, non-recurved, and not densely packed. The interclavicle has strong fimbriation anteriorly. The atlas pleurocentrum is completely ossified dorsally but incomplete ventrally. The more posterior pleurocentra are robust, well ossified, and always larger than the intercentra. The intercentra are wedge-shaped in lateral view and are incomplete dorsally, but moving posteriorly along the vertebral column, they progressively ossify dorsally in larger forms. The pectoral girdle and limbs are generally similar to embolomeres, especially Archeria and Pholiderpeton, but the processes are generally more developed. There is an anocleithrum present. The humerus lacks an entepicondylar foramen. The ectepicondylar process of the humerus is extremely well-developed, as is the olecranon process of the ulna. The ilium bears an extremely long and gracile posterior process.

\section{Further questions regarding Calligenethlon morphology}

It is interesting to note that in all specimens where the skull is preserved, the anteriormost portion is missing, preventing a confident reconstruction of the skull of Calligenethlon. General assumptions based on such a small sample size must be provisional, but a lack of preservation of the anterior portion of the skull for this genus may be evidence of an elongate and gracile snout, similar to that seen in Archeria. In 
contrast, Holmes and Carroll (2010) proposed a reconstruction that estimated a skull length of about $8.7 \mathrm{~cm}$, assuming skull proportions similar to other small embolomeres such as Proterogyrinus, but based on the greater overall similarity of Calligenethlon to Archeria (Carroll, 1967), a more elongated skull shape and length estimation could also be reasonably proposed. Until further evidence is found, neither possibility can be confirmed.

The confirmation of consistency in the anatomy observed among specimens of Calligenethlon leads to the question of the great disparity in sizes from the smallest specimen, $\mathrm{BM}(\mathrm{NH}) \mathrm{R} .4553$, to the largest, RM 20.4984. The former pertains to “Dendryozousa”, now known as a junior synonym of Calligenethlon (Holmes and Carroll, 2010), and shows more poorly ossified centra and a large perforation for the notochord, both of which are considered juvenile characteristics (Holmes, 1984). The other Calligenethlon specimens vary slightly in size, most pertaining to an individual about half the size of Proterogyrinus, but two revealing a larger, more Proterogyrinussized individual or morph (Godfrey et al., 1991). Such a dramatic difference in size makes a simple explanation of individual variation unlikely, although Godfrey et al. (1991) point out that the differing body sizes may be growth stages of Calligenethlon watsoni. However, most specimens attributed to Calligenethlon show evidence of some maturity, such as tight suturing of the cranial bones, well-developed processes of limb elements, and overall good ossification (Carroll, 1967; Godfrey et al., 1991; Holmes and Carroll, 2010). It is especially telling that the braincase of NSM 994GF1.1 is also so wellossified. These features all indicate that Calligenethlon must have attained some level of 
maturity while still at a small size (Godfrey et al., 1991; Holmes and Carroll, 2010), and maybe also grew to much larger sizes.

Alternatively, I propose that RM 20.4984 and NSM 988GF70.1 represent a larger species or subspecies belonging to the genus Calligenethlon. This hypothesis can account for the apparent maturity of the small specimens while allowing for remarkably similar anatomy in the large specimens. The larger species would be only known from vertebral and pelvic elements, and more information is required to determine how morphologically distinct it is from the smaller C. watsoni.

\section{Implications for embolomere diversity at Joggins}

The potential presence of a large species or morph of Calligenethlon calls for the re-examination of several other large-bodied tetrapod remains from Joggins. The first, “Baphetes” minor, known only by an incomplete lower jaw, was originally named by Dawson (1870) and figured by Romer (1963). The classification of this specimen as a baphetid has been challenged and there has been some speculation as to whether this animal should instead be considered an embolomere (Romer, 1963; Holmes and Carroll, 2010). The jaw, about $15 \mathrm{~cm}$ in length, was too large to belong to any known Calligenethlon specimens at the time, and a lack of any other embolomeres at Joggins to compare it to discouraged further investigation. However, with the possible presence of a large, Proterogyrinus-sized Calligenethlon species or morph, a $15 \mathrm{~cm}$ jaw is no longer out of place. The strongly convex curvature of the jaw margin is reminiscent of Archeria, but the dentition is more similar to that seen in NSM 994GF1.1. Since the surangular known from NSM 994GF1.1 bears many similarities to Archeria, it seems possible that 
"Baphetes" minor is related to the large Calligenethlon species or morph. However, more material is required for a definitive conclusion.

Besides "Baphetes" minor, other large bodied tetrapod material has come out of Joggins, much of which has not been reported on yet. Specimen FGM 000GF15 is a block preserving scattered cranial and postcranial elements, including possible skull material, ribs, neural spines, and vertebrae, as well as some silicified wood. Another specimen, so far unnumbered, preserves postcranial remains including hindlimb elements and the impression of a possible ischium. Both specimens have remained unprepped, but preliminary examination suggests embolomere affinities. Some lone vertebrae and neural arches have also been found and reported by Romer (1963), as well as by more recent field teams lead by Maddin, all of which are known to have embolomere affinities but have not been classified further. The relationship of these specimens to Calligenethlon is unknown and further investigation is required to determine whether they pertain to the larger Calligenethlon species or morph, a distinct taxon encompassing the "Baphetes" minor material, or represent a new large embolomere at Joggins. The presentation of the new Calligenethlon anatomical data here provides a richer, more complete knowledge of embolomere morphology and will aid both the revision of existing embolomere material and the identification of new embolomere material from Joggins. 


\section{Chapter 3: A phylogenetic analysis of embolomeres including the new anatomical data from NSM 994GF1.1}

\subsection{INTRODUCTION}

The taxonomy of the embolomere clade has always been associated with the order Anthracosauria, usually as an infraorder (e.g. Holmes et al., 1995) or suborder (e.g. Schneck and Fritz, 1985); however, a clear definition of either of these taxa has remained elusive. Most relevant literature considers Anthracosauria as an order within the amphibian subclass Labyrinthodontia. Anthracosaurs have been known since 1863, when T. H. Huxley described and named the first remains, Anthracosaurus russelli, from the Carboniferous of Great Britain. At the time, Huxley placed A. russelli within what was then known as Amphibia (i.e., non-amniote tetrapods), and although he did not formally erect a clade, subsequent discoveries of similar animals came to be referred to as 'anthracosaurs' informally. Cope (1875) described the first North American anthracosaurs from the Carboniferous of Texas and Illinois, and five years later defined the order Embolomeri on the basis of their distinctive disc-shaped vertebral morphology. In this scheme, all the animals that had been previously referred to as anthracosaurs were then separated into two groups: Embolomeri, which included Diplovertebron and Cricotus, and Gastrolepidoti, which included Anthracosaurus (Zittel, 1888). However, Watson (1929) later revised these groups and instead redefined Embolomeri as a grade of tetrapod taxa that included the superfamilies Anthracosauroideae and Loxommoideae. This publication also put forward the hypothesis that anthracosaurs (i.e. animals he considered part of Anthracosauroideae) should be considered closely related to reptiles. 
Accepting this, Säve-Söderbergh $(1934,1935)$ placed anthracosaurs within Reptiliomorpha, defined as animals more closely related to amniotes than to extant amphibians. This study classified loxommatids (i.e. animals placed within Loxommoideae), ichthyostegids, and other amphibians as the more basally branching Batrachomorpha. This idea of anthracosaurs as close to relatives of amniotes sparked further studies (e.g. Brough and Brough, 1967), which argued for a new taxonomic group Eoreptilia comprising anthracosaurs, seymouriamorphs, gephyrostegids, and Lepospondyli, as defined by Romer (1947). This does not seem to have been widely adopted among embolomere researchers but was never formally rejected either, as some more recent studies still refer to embolomeres as reptiliomorphs (e.g. Buchwitz et al., 2012).

When Romer (1947) reviewed all of Labyrinthodontia, he brought together anthracosaurs (which he termed Embolomeri) and seymouriamorphs to make up Anthracosauria. This classification, rather than the one put forward by Watson (1929), has been much more widely accepted and used ever since (Panchen, 1970). In a more recent taxonomic overview of Embolomeri, Holmes (1984) included British and North American eogyrinids, the Carboniferous-aged Anthracosaurus, archeriids, and proterogyrinids within the Embolomeri. He also expanded the infraorder Anthracosauria to include Gephyrostegoidea as well as Seymouriamorpha and Embolomeri, all of which he considered to be part of Batrachia. Today, Batrachia is no longer considered to include these groups, and the group is restricted to the last common ancestor and descendants of frogs and salamanders only (see Pardo et al. 2017b or Anderson et al., 2008). 
The historically inconsistent distinction between anthracosaurs and embolomeres has never fully been resolved and, in recent years, taxa referred to as embolomeres in some publications (e.g., Pardo et al., 2017a) are called anthracosaurs (e.g. Witzmann, 2016) or 'anthracosauroids' (e.g. Clack et al. 2016) elsewhere. Some publications use the term anthracosaur to also include Silvanerpeton or the family Eoherpetontidae (e.g. Ruta and Clack, 2006; Matsumoto and Evans, 2016), some authors include gephyrostegids (e.g. Carroll et al. 1972; Holmes, 1984; Ruta et al., 2003), and still others tentatively include Seymouriamorpha (Romer, 1947; Holmes, 1984), although this is not universally accepted (Holmes, 1984; Clack, 1987). This work will use the terms 'Anthracosauria' and 'anthracosaur' after the definition of Panchen (1970), which includes Gephyrostegus, Silvanerpeton, and the Embolomeri. In Panchen (1970), as well as most studies, Embolomeri consistently includes the families Anthracosauridae, Archeriidae, Eogyrinidae, and Proterogyrinidae and therefore, the terms 'Embolomeri' and 'embolomere' will be used to refer to these taxa here.

Order Anthracosauria

Gephyrostegus bohemicus

Silvanerpeton miripedes

Embolomeri

Family Anthracosauridae Anthracosaurus russelli

Family Archeriidae Archeria crassidisca

Family Eogyrinidae Eogyrinus attheyi

Pholiderpeton scutigerum Calligenethlon watsoni

Family Proterogyrinidae Proterogyrinus scheelei 
The placement of Calligenethlon within embolomeres has been debated as well. It was originally placed within the archeriid family (Holmes, 1989) but further morphological investigation showed that the dentition lacked the distinctive parallelsided tooth morphology with a chisel-shaped apex seen in all archeriids (Panchen, 1970). The genus was provisionally included in Eogyrinidae based purely on dentition by Panchen (1970) and no further investigation has taken place.

While embolomere interrelationships are rather ambiguous, almost certainly contributing in part to their long history of convoluted taxonomy, their relatedness to other tetrapods are also poorly understood. As mentioned above, embolomeres have traditionally been considered to be stem amniotes (e.g. Panchen, 1970; Paton et al., 1999; Clack, 2001; Ruta et al., 2003; Klembara and Ruta, 2004; Clack et al, 2016); however, a recent analysis of tetrapod relationships challenged this hypothesis (e.g. Pardo et al., 2017a), recovering embolomeres instead as stem tetrapods (Figure 3.1). This result adds to a growing list of studies challenging the traditional placement of embolomeres on the amniote stem in favour of a stem tetrapod position (see Anderson, 2001; Vallin and Laurin, 2004; Clack and Finney, 2005). The Pardo et al. (2017a) analysis was novel in that it included over 50 new characters pertaining to aspects of braincase morphology. Several recent studies have demonstrated that because the tetrapod braincase develops very early, is formed from a cartilaginous precursor, and is shaped by the central nervous system, braincase morphology is less influenced by functional or environmental pressures and therefore can be more phylogenetically informative than other parts of the skull (Lieberman et al., 2000; Cardini and Elton, 2008; Goswami and Polly, 2010; Maddin et 

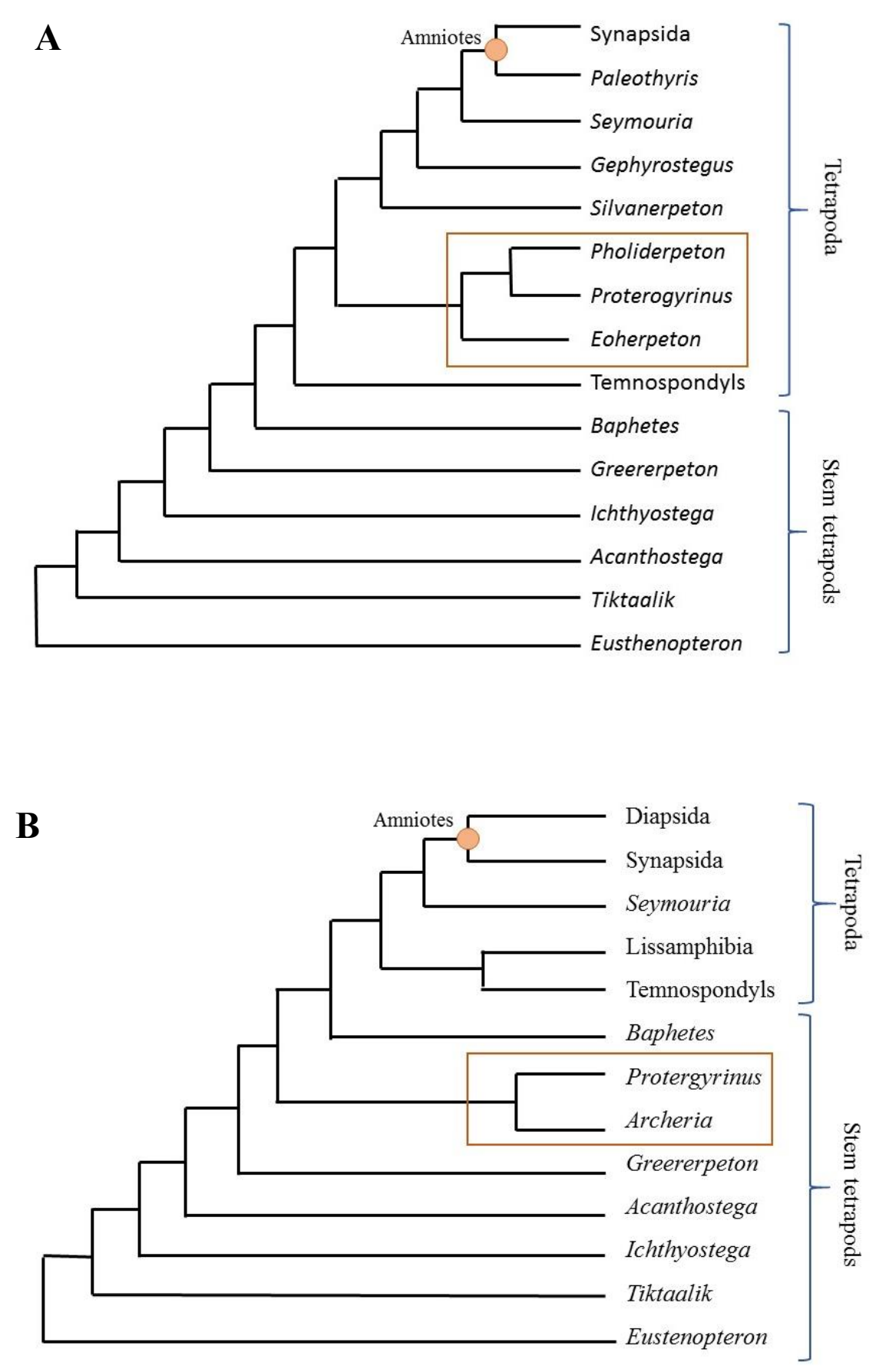

Figure 3.1: The two prevailing theories of embolomere placement within the tetrapod tree. A, embolomeres (boxed in red) considered as reptiliomorphs on the amniote stem (Figure modified from Clack et al. (2016); and B, embolomeres (boxed in red) considered stem tetrapods (Figure modified from Pardo et al. (2017a). 
al., 2012), especially in early tetrapods (e.g. Maddin et al., 2011; Pardo and Anderson, 2016; Pardo et al., 2015; Clack and Holmes, 1988).

The goal of this Chapter is to determine if new, more complete anatomical data from the embolomere Calligenethlon can aid in resolving controversy in the phylogenetic position of the group. Through the acquisition of internal anatomy from micro-computed tomography, I aim to further test the hypothesis that braincase characteristics result in a stem tetrapod position for embolomeres by adding newfound anatomical data from Chapter 2 for Calligenethlon to the matrix of Pardo et al. (2017a). I additionally include several stem tetrapod taxa missing from the Pardo et al. (2017a) matrix but that are present in other analyses, as well as several taxa belonging to the traditional definition of anthracosaurs with the aim of shedding some light on the currently ambiguous relationship between embolomeres and anthracosaurs.

\subsection{MATERIALS AND METHODS}

The analyses of Clack et al. (2016) and Pardo et al. (2017a) are the most recent and broadly-sampled studies of tetrapod interrelationships. The matrix of Pardo et al. (2017a) was used as the base for the analyses conducted here, to test the implication that the braincase characteristics were involved in placing embolomeres on the stem of the tetrapod tree. In addition to their new braincase characters, characters included in the matrix of Clack et al. (2016) that were not in that of Pardo et al. (2017a) were added here (See Appendix 1; characters 371-374) and character 55 of the Pardo et al. (2017a) matrix was replaced by character 67 of the Clack et al. (2016) matrix because it allowed for 
more morphological detail (See Appendix 1; character 371). No changes were made to their original scores.

There were 24 taxa in the Clack et al. (2016) matrix that were not included in Pardo et al. (2017a) and of these, only 12 do not belong to a group that was already represented by other members in the Pardo et al. (2017a) matrix. These twelve taxa Ossirarus, Perittodus, Diploradus, Aytonerpeton, Koilops, Ossinodus, Caerorhachis, Doragnathus, Sigournea, Tulerpeton, Gephyrostegus, and Silvanerpeton - were added for this study to ensure that a taxon sampling bias was not influencing the placement of the Embolomeri.

Of the Embolomeri, the Pardo et al. (2017a) matrix included only Archeria crassidisca and Proterogyrinus scheelei as representatives of the clade, whereas Clack et al. (2016) included only Proterogyrinus and Pholiderpeton. All three embolomere taxa were included in this analysis. As well, Anthracosaurus, Eoherpeton, and Calligenethlon, which consists of NSM 994GF1.1 described in Chapter 2 and all known Calligenethlon material were added for more complete embolomere sampling. Although many of these embolomere taxa were too incompletely known to be coded for many of the fine detail braincase characters, they were included regardless to lend support and confidence to the placement of the Embolomeri on the basis of the most complete taxonomic sample available. The final matrix included 74 taxa and 374 characters, including the outgroup Eusthenopteron foordi. Where impossible to observe a specimen firsthand, taxa were coded based on the descriptive literature. Analyses were completed in PAUP 4.0a167 (Swofford 2002) for MacIntosh. 
The new data was added to the matrix in a step-wise fashion in an attempt to determine the role each new piece (i.e. the braincase characters, the addition of further embolomere species, the addition of further characters, and the addition of stem tetrapod taxa) played in influencing the final outcome. First, the original matrix of Pardo et al. (2017a) was re-run to ensure replication of the results. The heuristic search option was used, with an ACCTRAN optimization method. All characters were equally weighted and unordered, and 10000 random addition sequence replicates specified. The second analysis added the embolomeres Anthracosaurus, Eoherpeton, Pholiderpeton, and Calligenethlon. The third analysis added four characters found in the matrix of Clack et al. (2016), which were not in the Pardo et al. (2017a) analysis. The search criteria were the same as those used in the analysis that replicated the result from the study by Pardo et al. (2017). The fourth analysis included 12 stem tetrapod taxa from the Clack et al. (2016) matrix that were not included in the Pardo et al. (2017a) matrix. As in the first three analyses, the fourth analysis used a heuristic search run with 10000 random addition sequence replicates. The search in the fourth analysis had to be constrained to 10000 rearrangements per addition sequence replicate in order to finish within a reasonable timeframe.

\subsection{RESULTS}

Using the same data and search parameters from their study, the first analysis successfully recreated the topology found by Pardo et al. (2017). The addition of Anthracosaurus, Eoherpeton, Pholiderpeton, and Calligenethlon in the second analysis did not change the position of embolomeres obtained in the original analysis. This 
analysis returned 100 most parsimonious trees (MPTs) and both the strict consensus tree (Figure 3.2) and the majority rule tree (Figure 3.3) showed that the Embolomeri were well supported in a basal position, one node stemward of a clade formed by Baphetes and Eucritta and one node crownward of Greererpeton, which is located two nodes stemward of the node uniting crown tetrapods. Both trees grouped Anthracosaurus and Eoherpeton together in a sister taxon relationship, and the majority rule tree further recovered Pholiderpeton as the next most closely related taxon, followed by Proterogyrinus, Calligenethlon and Archeria in sequentially more basal branching positions.

Adding characters that were unique to the Clack et al. (2016) matrix in the third analysis resulted in some unresolved relationships among the Devonian tetrapods but otherwise did not significantly change the topology obtained in the analysis that replicated the result from the Pardo et al. (2017) paper or the analysis that added more embolomere taxa. The strict consensus of the 120 MPTs (Figure 3.4) supported the position of embolomeres between Baphetes and Greererpeton. Similarly to the analysis that added more embolomere taxa, the strict consensus (Figure 3.4) did not resolve any relationships within the Embolomeri except that Anthracosaurus and Eoherpeton were again united as sister taxa and the relationships between the rest of the Embolomeri were uncertain. The pattern of relationships among the embolomeres in the majority rule consensus tree is also the same as in analysis which added more embolomere taxa (Figure 3.5). The fourth analysis added twelve stem tetrapod taxa from the analysis of Clack et al. (2016). This analysis returned 59 MPTs. The strict consensus tree (Figure 3.6) showed some poorly resolved relationships among the stem tetrapod taxa, but the embolomere clade was well resolved. Both it and the majority rule tree (Figure 3.7) recovered the 


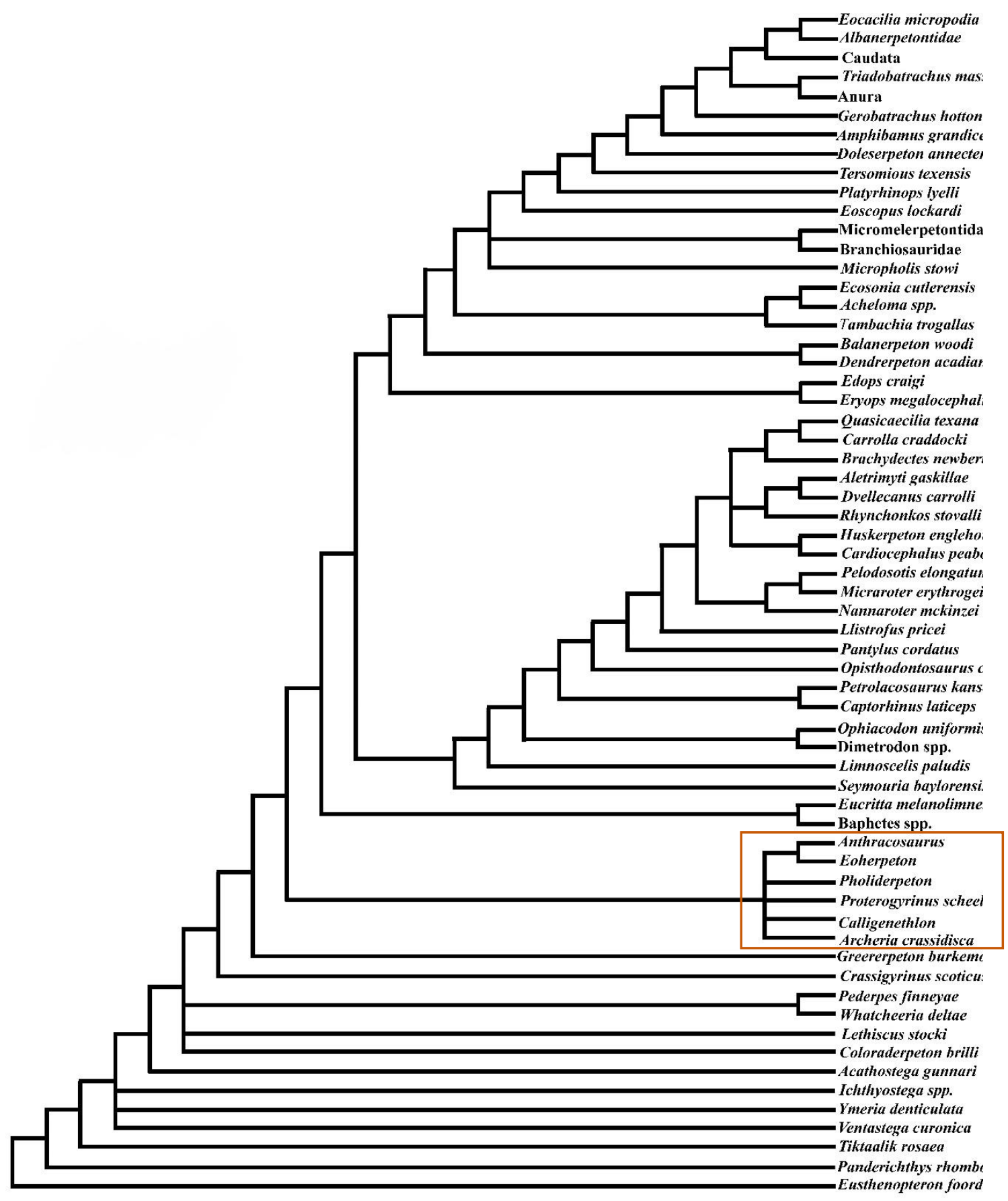

Figure 3.2: The strict consensus tree of the analysis that included a more extensive sampling of embolomeres taxa. Note embolomeres (boxed in red) in a stem tetrapod position. 


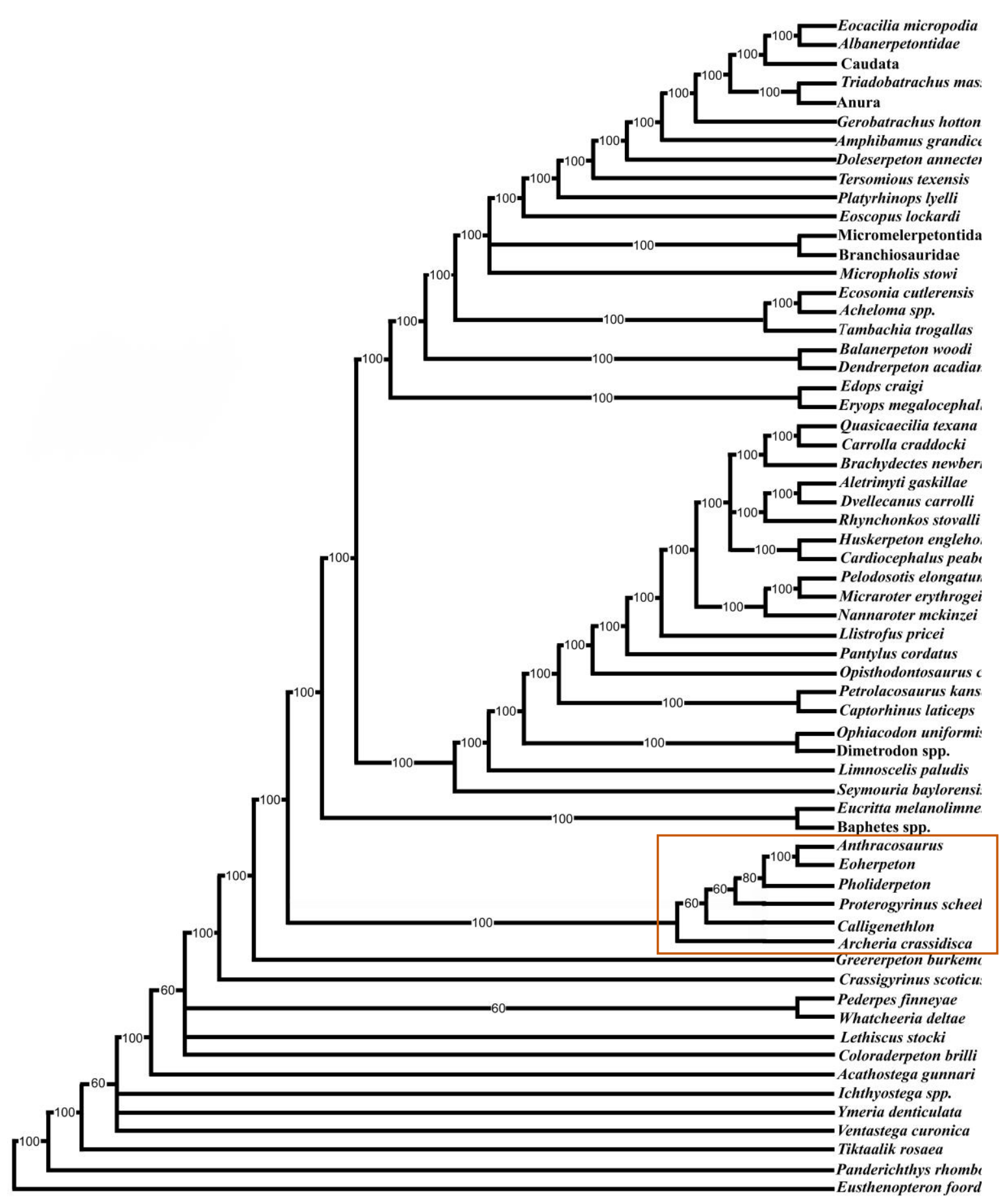

Figure 3.3: The majority rule consensus tree of the analysis that included a more extensive sampling of embolomere taxa. Note embolomeres (boxed in red) in a stem tetrapod position. Branch labels indicate the percentage of parsimonious trees that recovered this node. 


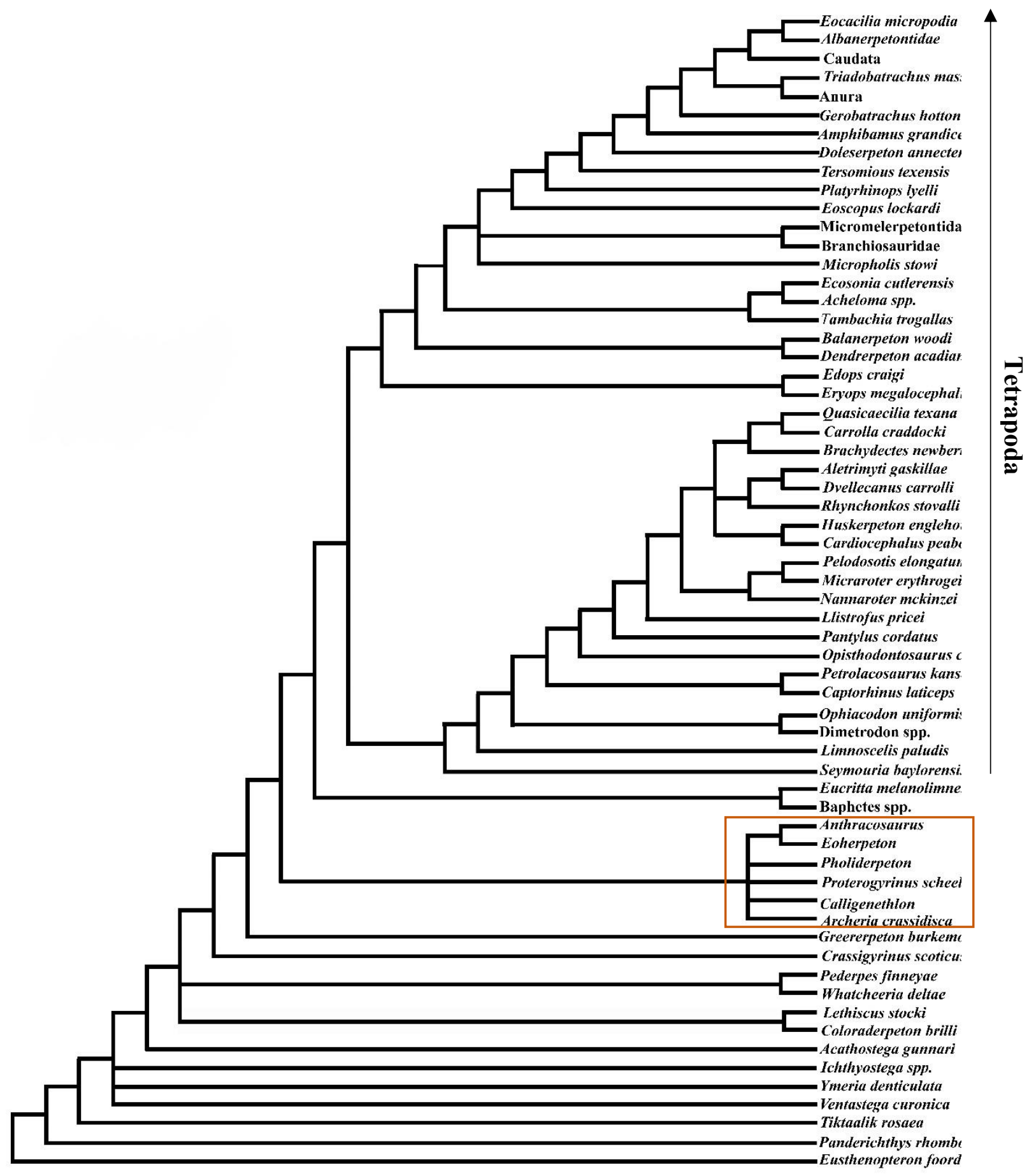

Figure 3.4: The strict consensus tree of the analysis that included non-overlapping characters from the study by Clack et al. (2017). Note embolomeres (boxed in red) in a stem tetrapod position. 


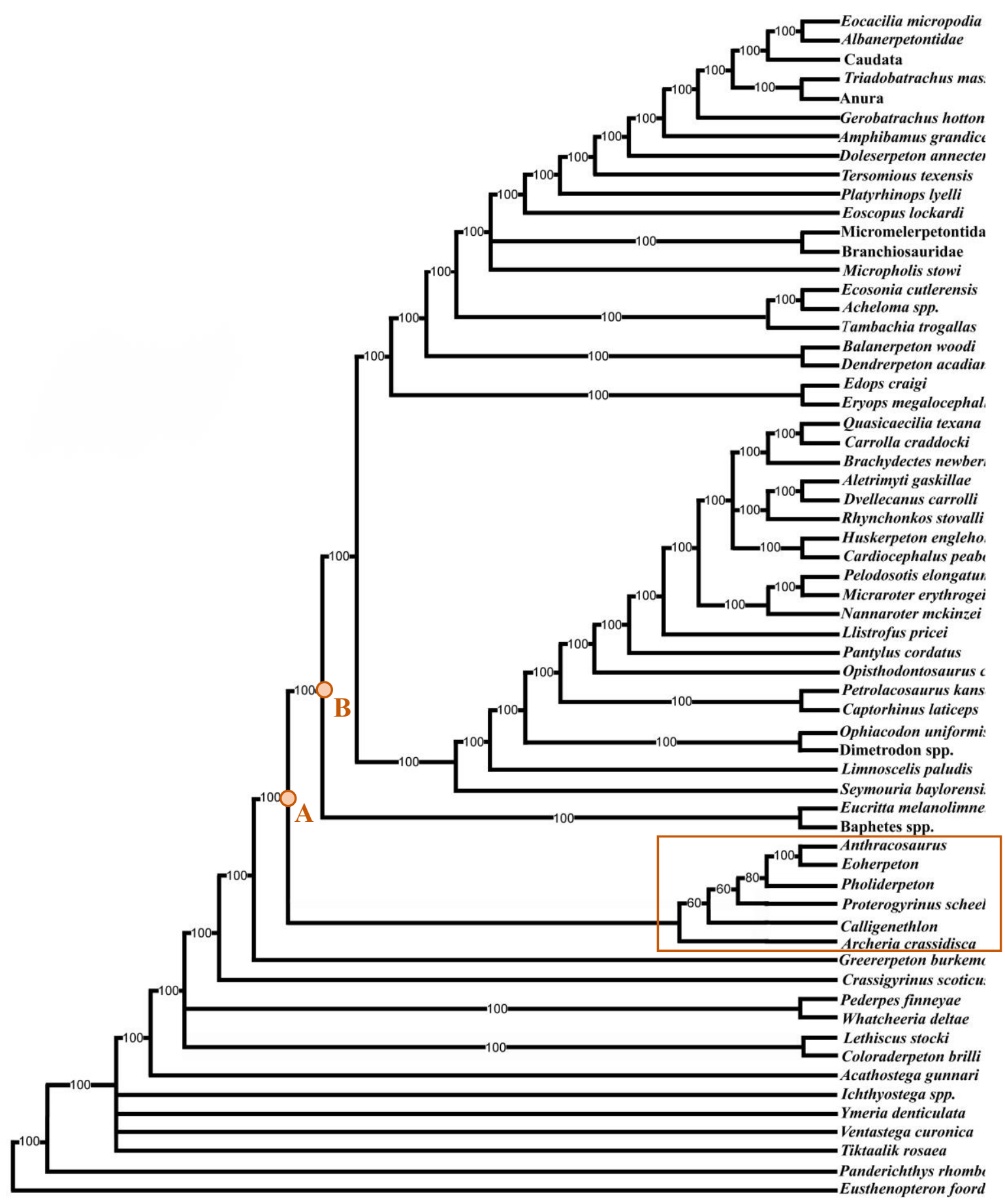

Figure 3.5: The majority rule consensus tree of analysis that included non-overlapping characters from the study by Clack et al. (2017). Note embolomeres (boxed in red) in a stem tetrapod position. Nodes of interest are labelled: A, the characters that place embolomeres in a stem tetrapod position (characters listed in Appendix C1); B, characters that exclude embolomeres from a more derived position (characters listed in Appendix C2). Branch labels indicate the percentage of parsimonious trees that recovered this node. 


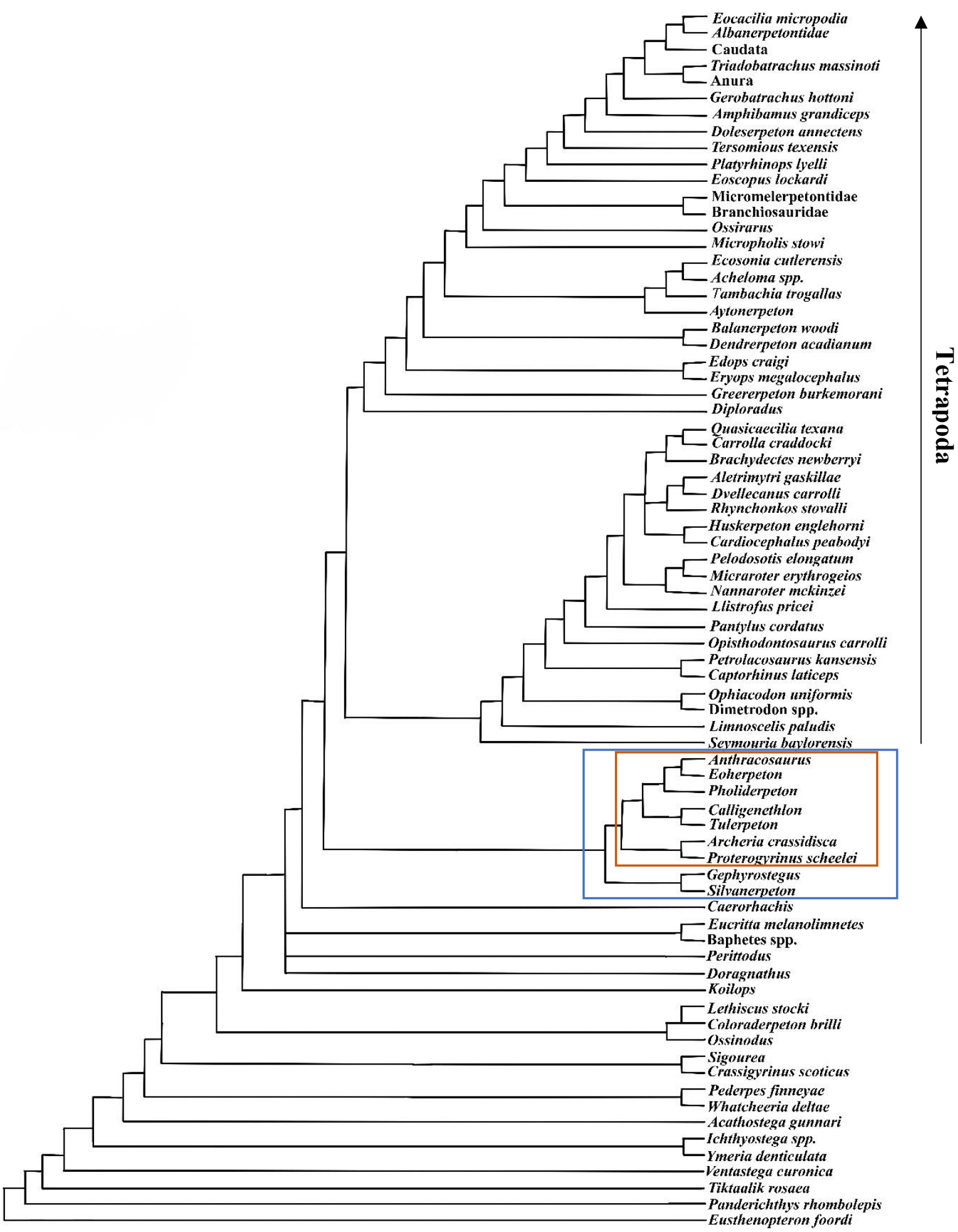

Figure 3.6: The strict consensus tree of the analysis that included stem tetrapod taxa from the study by Clack et al. (2017) that were not used in the study by Pardo et al. (2017a). Note embolomeres (boxed in red), grouping with other anthracosaurian taxa (boxed in blue) in a more crownward position within the stem tetrapods. 


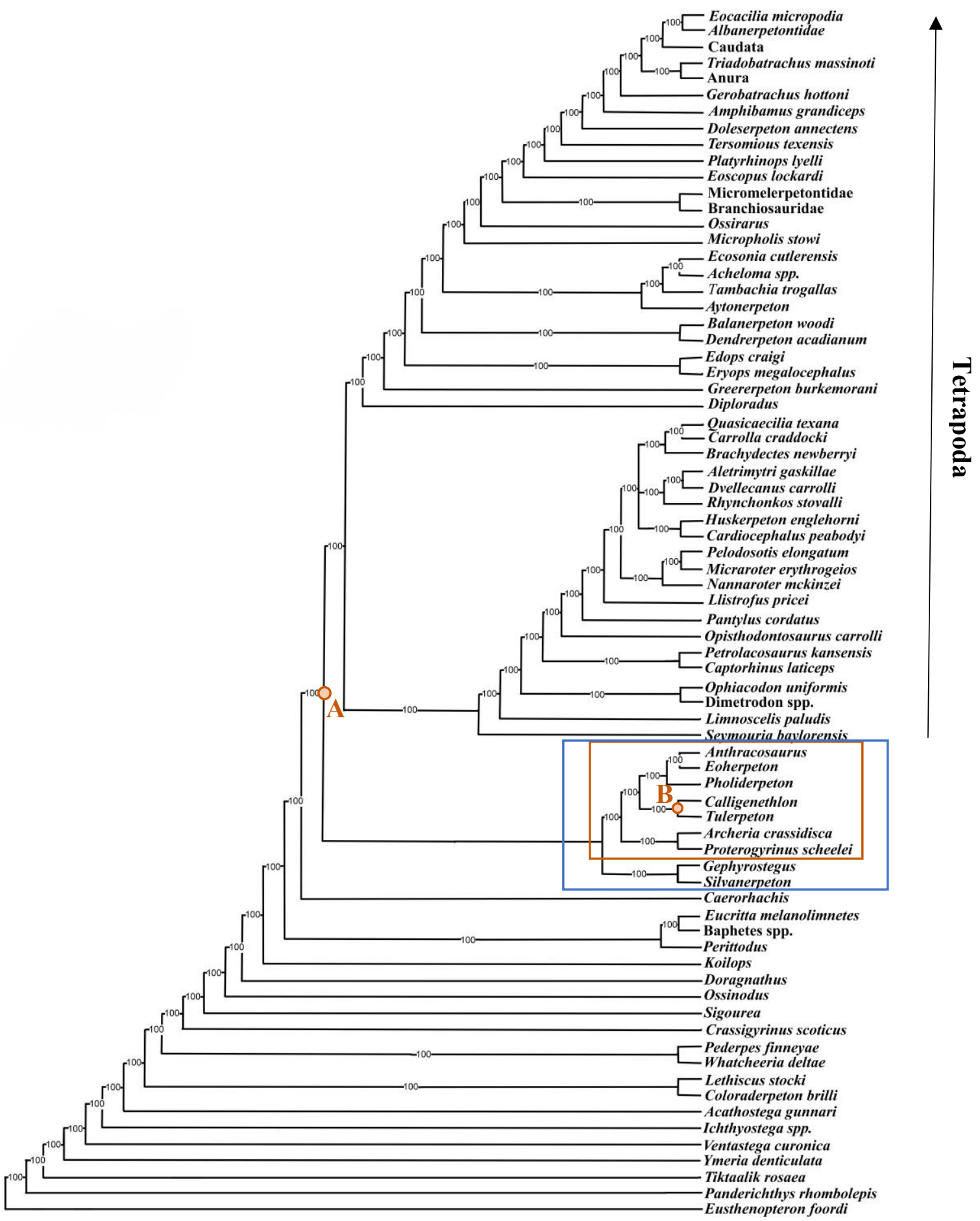

Figure 3.7: The majority rule consensus tree of the analysis that included stem tetrapod taxa from the study by Clack et al. (2017) that were not used in the study by Pardo et al. (2017a). Note embolomeres (boxed in red), grouping with other anthracosaurian taxa (boxed in blue) in a more crownward position within the stem tetrapods. Nodes of interest are labelled: A, the characters that unite embolomeres in a more crownward position (characters listed in Appendix C3); B, the characters that unite Calligenethlon and Tulerpeton (characters listed in Appendix C4). Branch labels indicate the percentage of parsimonious trees that recovered this node. 
Embolomeri in a more crownward position than in the previous analyses, such that they are placed only one node stemward of the node uniting crown tetrapods and are now retrieved two nodes crownward of the clade including Baphetes. As in the analysis that added more embolomeres taxa and the analysis that added characters from the study by Clack et al. (2016), Anthracosaurus was grouped most closely with Eoherpeton, with Pholiderpeton as the sister taxon to that clade. Calligenethlon formed the sister taxon to Tulerpeton, and Archeria and Proterogyrinus formed a sister group relationship as the basalmost embolomere branch. Gephyrostegus and Silvanerpeton, which are classically thought of as anthracosaurs, were recovered as the sister clade to the Embolomeri, resulting in the creation of both a monophyletic Embolomeri and Anthracosauria clade.

\subsection{DISCUSSION}

The repositioning of embolomeres to a stem tetrapod position in the study by Pardo et al. (2017a) provided support for the emerging hypothesis regarding the relationships of these animals within the tetrapod tree. Because embolomeres have a longstanding history as being considered fairly derived reptiliomorphs, and the primary focus of their study was not on embolomeres, the results of Pardo et al. (2017a) necessitates further exploration. The hypothesis driving the analysis of Pardo et al. (2017a) was that braincase characters have a greater ability than other parts of the skull to reveal phylogenetic relationships due to their early development and insusceptibility to environmental and other extrinsic influences (Lieberman et al., 2000; Cardini and Elton, 2008; Goswami and Polly, 2010; Maddin et al., 2012). Therefore, it was presumed that 
these characters greatly influenced their controversial placement of embolomeres on the tetrapod stem.

\section{The role of braincase characters in determining the phylogenetic position of embolomeres}

Careful study of the synapomorphies optimized at relevant nodes shows that the braincase characters do not seem to play a significant role in the placement of embolomeres in any of the four analyses run here. Instead, they appear to be much more influential in grouping together and forming the subsequent relationships within the amniote and temnospondyl groups, regardless of whether or not embolomeres fall as the direct outgroup to these clades, as in analysis adding more stem taxa, or are placed further down the tetrapod stem, as in the analysis replicating the result from the study by Pardo et al. (2017), or the analyses adding the more embolomere taxa or more characters (see Appendix $\mathrm{C}$ for character lists uniting the embolomere clade and surrounding nodes). In the analyses that added more embolomere taxa and the analysis that added more characters, embolomeres are excluded from a more derived position by 13 synapomorphies (Figure 3.5B; character list in Appendix C2). Interestingly, of these 13 synapomorphies, only three of them pertain to the braincase and the others pertain to skull, axial skeleton, and limb characteristics. Similarly, of the characters tying embolomeres to a stem position (Figure 3.5A), only three pertain to the braincase (character list in Appendix C1) and the rest are a mix of skull, vertebral, and limb characters. The fact that so few braincase characters are involved suggests that other variables are influencing embolomere placement more drastically than character type. 
Because the position of embolomeres shifted crownward in the fourth Analysis, which only differed in that stem tetrapods were added to the matrix, it may be that the addition of more basal taxa overpowers the influence, if any, of the braincase characters on embolomere phylogeny. However, it should be noted that out of 66 braincase characters in the matrix, Pholiderpeton, Eoherpeton, and Anthracosaurus were only able to be coded for 4-7, and Calligenethlon was only able to be coded for 15. Comparatively, Pardo et al. (2017a) were able to code Archeria for 61 and Proterogyrinus for 52 of the braincase characters. This allows for the possibility that had enough braincase characters been coded for all taxa, embolomeres may have been recovered in the same basal position Pardo et al. (2017a) obtained. However, as mentioned above, that position was supported by three out of 66 of the new braincase characters in the analyses that replicated the results found by Pardo et al. (2017), added more embolomere taxa, and included more characters. Together, the results of these analyses suggest that the braincase data was actually not extremely influential in grouping embolomeres in their stem tetrapod position and that this result was brought about by other factors.

\section{The role of taxon sampling in determining the phylogenetic position of embolomeres}

As braincase characters do not seem to be playing a huge role in tying embolomeres to the stem of the tree other reasons for this dramatic shift from their traditional placement must be explored. It is known that taxon sampling plays an important role in the accuracy of phylogenetic inference (Nabhan and Sarkar, 2011), and it may be that taxon sampling is the cause of the differences in the results of the analyses performed here. 
In the body of work debating the placement of embolomeres, the matrices that recover embolomeres in a stem tetrapod position tend to include more derived taxa than primitive taxa, and those that recover embolomeres in a stem amniote position tend to focus on primitive taxa (see Anderson, 2001; Vallin and Laurin, 2004; Clack and Finney, 2005 compared to Paton et al., 1999; Clack, 2001; Ruta et al., 2003; Klembara and Ruta, 2004). This is also true in the two studies this work is based on: the matrix of Clack et al. (2016) focuses on early tetrapods with some members of the more derived groups such as lepospondyls, seymouriamorphs, and other traditionally stem amniote groups, whereas the Pardo et al. (2017a) matrix excludes many of the primitive taxa Clack et al. (2016) use and samples heavily from more derived taxa, especially the lepospondyls. The results of the analysis that added further stem tetrapod taxa support the hypothesis that taxon sampling may have played a role in the recovery of embolomeres in a derived position, since the embolomere clade moved slightly crownward with the addition of more primitive taxa.

Since this result does not seem to be linked to a focus in the data on braincase characters as mentioned above, perhaps sampling plays a larger role in embolomere placement than previously thought. There are 24 taxa included in the matrix of Clack et al. (2016) that were not used by Pardo et al. (2017), but of these only 12 were added here. The further addition of the other 12 stem tetrapods may help to determine the influence these inclusion of stem taxa have on the results shown here.

\section{Insights into embolomere interrelationships}


In general, embolomere interrelationships are poorly understood (e.g. Holmes, 1994, 1989; Clack, 1987; Ruta et al., 2003), and the addition of taxa traditionally classified as anthracosaurs allows for some insight into the relationship between Calligenethlon and the other embolomeres, as well as their relationship within the larger group, Anthracosauria. The second and third analyses provided uncertain relationships within the Embolomeri, but the fourth analysis returned much improved resolution of embolomere interrelationships within a monophyletic Anthracosauria that includes Gephyrostegus and Silvanerpeton (Figures 3.6 and 3.7). A close sister taxon relationship between Anthracosaurus and Eoherpeton is supported in all the analyses, and most support Pholiderpeton as the sister taxon to that group. Relationships within the rest of the clade are well supported in the analysis that added further stem tetrapod taxa but uncertain in all other analyses performed for this Chapter. The former analysis returns the Anthracosauridae family as nested within the Eogyrinids, but suggests that although Calligenethlon is closely related, it may be separate from this family, unless Tulerpeton can also be considered an eogyrinid. Archeria and Proterogyrinus are placed as the most basal-branching group in this analysis, which is an unusual grouping, although Proterogyrinus is generally considered to be a primitive embolomere (Holmes, 1984). As in several other studies (e.g. Ruta et al., 2003), Gephyrostegus and Silvanerpeton are obtained as sister taxa here, which together make up the sister group to the embolomeres. Caerorhachis forms the outgroup to the clade Anthracosauria plus crown-group tetrapods.

Seymouriamorpha is sometimes included in the anthracosaur clade (e.g. Holmes, 1984; Ruta et al., 2003), but here it is separated from the rest of the anthracosaurian taxa, 
as it was retained in its position on the amniote stem, as the outgroup taxon to Limnoscelis plus the amniotes, whereas the embolomeres plus Gephyrostegus and Silvanerpeton were recovered outside of the crown-tetrapod group.

\section{The surprising relationship between Calligenethlon and Tulerpeton}

Interestingly, Calligenethlon groups most closely with Tulerpeton, a Devonianaged tetrapod, rather than any other embolomere, sharing 17 autapomorphies including conical dentition, atlas and cervical rib morphology, and pectoral girdle characters (Figure 3; see a list of the characters uniting them in Appendix C4). A close relationship with this animal was an initially unexpected result; however, investigation into the history of Tulerpeton provided some interesting insights. Tulerpeton was originally considered to be a proterogyrinid by Lebedev (1984), although a subsequent publication provided a more cautious classification of the animal as a reptiliomorph with anthracosaur affinities (Lebedev and Coates, 1995). Although Tulerpeton is only known from postcranial remains, its anatomy reveals several similarities with Calligenethlon, including an extremely well developed ectepicondylar process of the humerus, the lack of an entepicondylar foramen, and the highly unusual presence of an anocleithrum (Lebedev and Coates, 1995). Notably, Lebedev and Coates (1995) consider Tulerpeton the earliest member of Tetrapoda according to their definition that the only taxa included are those that exhibit the basal synapomorphies that can be found in all living lineages, except where secondarily lost (Lebedev and Coates, 1995). A close relationship to a Devonianaged tetrapod may explain the retention of several basal characteristics seen in embolomeres, such as tabular horns (present in all embolomeres; Holmes, 1984), 
anocleithra (present in Calligenethlon and Pholiderpeton; Clack, 1987), a paired atlas pleurocentrum (present in Proterogyrinus; Holmes, 1984), a shagreen teeth on the pterygoid (present in Proterogyrinus and Pholiderpeton; Holmes, 1984; Clack, 1987), and a synovial joint contact between the braincase and the basipterygoid (present in Archeria; Clack and Holmes, 1988).

The current classification of Tulerpeton as having anthracosaur affinities brings back to the forefront the question of what an embolomere is with respect to a nonembolomerous anthracosaur. Most researchers agree that embolomeres arose from the non-embolomerous anthracosaurs, but a clear morphological distinction between them has remained elusive, which has only added to the confusion surrounding the classification of the Embolomeri (Panchen, 1970). However, the results obtained here merit a renewed effort. Clarity on this point may help to resolve whether Tulerpeton should be considered an embolomere, as is suggested by these results. As much of the morphological definition of Embolomeri is based on skull characteristics and the skull of Tulerpeton is unknown, further fieldwork is necessary to obtain new material to help resolve uncertainty on this issue.

The grouping of Calligenethlon with Tulerpeton rather than any known embolomere also challenges its own placement within Embolomeri. There is no question that Calligenethlon fits within the anthracosaur clade; it exhibits a large and welldeveloped intertemporal, a supratemporal-squamosal joint, a tabular-parietal suture, and a tabular horn, all of which are distinctive features of anthracosaurs (Panchen, 1970). However, as there is little in the descriptive literature that definitively separates embolomerous anthracosaurs from non-embolomerous anthracosaurs, the grouping of 
Calligenethlon with Tulerpeton muddies any distinction even further. Calligenethlon has been regarded as an embolomere in all its relevant literature (e.g. Carroll, 1967; Godfrey et al., 1991; Holmes and Carroll, 2010), but the parallel sided skull table and lack of lateral lines in Calligenethlon are reminiscent of Gephyrostegus, a tetrapod often considered an anthracosaur but never an embolomere (Klembara et al., 2014). Lateral lines are typically conspicuous in embolomeres, especially on the jugal and squamosal (Holmes, 1984), but are not seen anywhere in the cranial material for NSM 994GF1.1, and notably, are missing in all known skulls of Gephyrostegus (Klembara et al., 2014), except for one possible and very weak occurrence noted by Brough and Brough (1967). Lateral lines are absent completely in the non-embolomerous anthracosaur Silvanerpeton (Ruta and Clack, 2006). It is possible that this feature is too delicate to have been preserved in the CT scans of NSM 994GF1.1, but no hint of any lateral lines is found on any other Calligenethlon skull material (Carroll, 1967).

It is not explicitly stated in the literature, but generally, non-embolomerous anthracosaurs seem to be much more terrestrially adapted, as evidenced through strongly ossified and robust limb elements and a lack of lateral lines (Ruta and Clack, 2006; Klembara et al., 2014), whereas embolomeres are aquatic to semiaquatic (Holmes, 1984). As several of these characteristics have previously been shown to be present in the anatomy of Calligenethlon, it may be that it is more closely related to the nonembolomerous anthracosaurs than to the embolomeres, or represent a transition between groups. Although the results of the phylogenetic analyses performed here do not support this idea, the relationships with the group were poorly resolved and distinction between these groups remains extremely unclear (e.g. Witzmann, 2016; Clack et al., 2016; Ruta et 
al. 2003). Further research is required to clarify the definitions of these clades, which will aid in a more complete definition of the evolutionary and phylogenetic relationships of Calligenethlon in the future. 


\section{Chapter 4: Conclusions and further research}

This thesis set out to address some of the many mysteries surrounding the enigmatic embolomere Calligenethlon watsoni from Joggins, Nova Scotia, Canada. Foremost of these was the lack of a clear morphological diagnosis of the genus, which resulted in questionable referrals of subsequent embolomere discoveries. The aim of this work was to use micro-computed tomography to describe a tentatively referred but exquisitely preserved specimen (NSM 994GF1.1) and create the first ever robust anatomical diagnosis of the genus Calligenethlon. The new morphological data obtained here for Calligenethlon was then used to explore the controversial placement of embolomeres within the tetrapod tree through the combination of the most updated character list and the most wide-ranging taxon samplings relevant to embolomere phylogeny to date.

\subsection{THE 3D DESCRIPTION OF NSM994GF1.1}

The internal and external anatomy of specimen NSM 994GF1.1 was described here in 3D for the first time. This provided previously unknown insights into the morphology of the braincase, dentition, atlas-axis complex, vertebral structure, pectoral girdle, and forelimb. NSM 994GF1.1 was then compared to other embolomeres and early tetrapods and was shown to preserve many similarities to the holotype of Calligenethlon, RM 2.1122, including a narrow skull table with parallel sides, large tabulars with extremely prominent tabular horns, and a lack of lateral lines. 


\subsection{THE REVISION OF THE GENUS CALLIGENETHLON}

Confirmation of the anatomical consistency between NSM 994GF1.1 and the holotype of Calligenethlon permitted the reevaluation of all specimens previously referred to the genus. Each specimen was evaluated for consistency with the newly established anatomical framework created by the holotype plus NSM 994GF1.1. This process revealed that of the original ten specimens referred to the genus Calligenethlon, only eight were anatomically consistent with the holotype and NSM 994GF1.1. The two specimens that were excluded from Calligenethlon were rendered incertae sedis. This process resulted in a fairly complete knowledge of the anatomy for Calligenethlon, which was synthesized into the first ever robust morphological diagnosis for the genus.

I then discussed some of the outstanding questions surrounding the morphology of Calligenethlon, including the huge disparity in body size observed among the referred specimens. As was suggested by Godfrey et al. (1991), the different body sizes could represent different growth stages of Calligenethlon watsoni. However, if correct, we would expect to see a progressive maturation in the specimens - perhaps in features such as quality of ossification, suturing of cranial bones, and development of processes on the limb bones - with the smallest being the least mature and the largest being the most mature. This was not found to be the case. Most of the small specimens, including NSM 994GF1.1, show several signs of maturation, which led to the conclusion that in Calligenethlon at least, small size is not indicative of immaturity. As an alternative hypothesis, I proposed that the larger specimens represent a large morph or perhaps a separate species within the genus Calligenethlon. This merits a closer look at "Baphetes" 
minor, the only other named embolomerous tetrapod at Joggins. It is only known by an incomplete lower jaw, but may be referable to the large Calligenethlon morph.

\subsection{EMBOLOMERE TAXONOMY}

The focus of this section was twofold. First, it aimed to shed some light on the confusion surrounding the placement of Calligenethlon and the embolomeres within the tetrapod tree. Second, it attempted to further investigate and comment on the role braincase characters play regarding embolomere phylogeny. To do this, a novel matrix was developed using characters and taxa from two recent and widely sampled early tetrapod studies - Pardo et al. (2017a) and Clack et al. (2016). A series of analyses were performed in which more embolomere taxa, more characters, and finally more stem tetrapod taxa were sequentially added to the data matrix in an attempt to determine which factors most influenced the results. These analyses returned three phylogenies, all of which placed embolomeres in a stem tetrapod position, similar to the result of Pardo et al. (2017a). The analyses adding more embolomere taxa and more characters were unable to resolve confident relationships within the Embolomeri, but all the branches were well resolved in the analysis that added more stem tetrapod taxa.

According to this study, braincase characteristics do not play a significant role in the placement of embolomeres within the tetrapod tree. A slight crownward shift occurred in the placement of embolomeres in the analysis that added more stem tetrapod taxa, in which more stem tetrapod taxa were added to the matrix, suggesting that taxon sampling could be strongly influencing the results. This working hypothesis is supported by the observation that the matrices that return embolomeres in a stem tetrapod position 
tend to be overpopulated with more derived taxa, such as microsaurs and lepospondyls, while the matrices that place embolomeres in more derived positions tend to focus on earlier stem tetrapod taxa.

\subsection{THE PLACEMENT OF CALLIGENETHLON}

The grouping of Calligenethlon with Devonian tetrapod Tulerpeton is a surprising result and requires further investigation. That Tulerpeton was originally defined as an embolomere (see Lebedev, 1984) lends some credibility to this result; however, later publications classify it more generally as a reptiliomorph with anthracosaur affinities (Lebedev and Coates, 1995). Its close relationship with Calligenethlon here questions whether Tulerpeton should be considered an embolomere or instead Calligenethlon should be considered a non-embolomerous anthracosaur. Calligenethlon displays several adaptations for terrestriality, including robust limb elements with well-developed processes and a lack of lateral lines. This is in contrast to the known preferentially aquatic habits of other embolomeres and may be uniting Calligenethlon to the more terrestrially adapted anthracosaurs. The anthracosaur clade is extremely understudied, with even its membership debated (e.g. Klembara et al., 2014 versus Ruta et al., 2003). Further research is necessary to understand the implications of a close relationship between Calligenethlon and Tulerpeton on the embolomere-anthracosaur clade and their surrounding relationships.

\subsection{DIRECTIONS FOR FURTHER RESEARCH}


The creation of a morphological definition of Calligenethlon is a good start, but there remains much uncertainty surrounding this genus and its evolutionary relationships. The question as to whether the large Calligenethlon specimens are part of an ontogenetic series or should be thought of as a separate species within the genus has not been satisfactorily answered. Further study is required to confirm that larger specimens are not simply older and more mature than the smaller specimens. Answers to these questions may be achievable through histological investigation and further fieldwork to produce a larger dataset for analysis.

There are also several specimens of small bodied embolomeres from Joggins that remain unclassified and whose relationship to Calligenethlon is as yet unknown. The first, NSM 008GF031.093 and its latex peel, RM 206859, preserves an impression of the tip of an embolomere tail within a siderite concretion. The specimen is described briefly in Holmes and Carroll (2010). There they mention that based on the anteroposterior length of the centra, RM 206859 pertained to an animal about the same size as NSM 994GF1.1. As the tips of embolomere tails rarely preserve and are definitely unknown in Calligenethlon, a careful morphological study of the centra, neural and haemal arches and spines will be the only way to determine whether this specimen can be referred to Calligenethlon or if it represents another small bodied embolomere. More fieldwork may again be required to refer the specimens definitively to a genus.

There is much work still to be done to resolve the placement of embolomeres. As a slight crownward shift occurred in embolomere placement with the inclusion of more stem taxa, the next step will be to determine whether further inclusion of stem taxa produces a further crownward shift. This will help to determine why, if they are really 
stem tetrapods, embolomeres have been placed on the amniote stem in so many analyses. The inclusion of further primitive taxa will allow an investigation into whether a focus in the data on either extreme within the tetrapod tree, that is, either an oversampling of derived tetrapods or a focus on primitive taxa is influencing the placement of embolomeres. Preliminary action has been taken in the revelation that braincase characters do not seem to be affecting the placement of this taxon, but continued study must determine what characters are. Clarification of this issue will further the understanding of embolomeres as a group as well as broader tetrapod evolution and relationships. I think the inclusion of more taxa that fall between the derived tetrapod and the primitive tetrapod groups will help to resolve the middle of the tree and may shed some light on embolomere placement as well.

The surprising close relationship between Calligenethlon with Tulerpeton merits a closer look at Tulerpeton to determine whether it may be considered an embolomere as per its original publication (Lebedev, 1984), or it is more likely a non-embolomerous anthracosaur, or close relative of the anthracosaurs, as suggested by (Lebedev and Coates, 1995). Further study of Tulerpeton will provide a greater understanding of this animal and its relationships, which may then provide further insight into embolomeres and its relationship to them.

\subsection{FINAL REMARKS}

In summary, Calligenethlon retains its status as one of the most enigmatic embolomeres known. The research presented here provides the first ever comprehensive diagnosis of its anatomy, but this only begins to answer the questions surrounding this 
important genus. Further study will help to clarify its relationships to embolomeres, anthracosaurs, and the broader tetrapod tree. 


\section{Appendices}

APPENDIX A: An overview of all specimens previously attributed to Calligenethlon watsoni.

\begin{tabular}{|c|c|c|}
\hline $\begin{array}{l}\text { Specimen } \\
\text { Number }\end{array}$ & $\begin{array}{l}\text { Original } \\
\text { Description }\end{array}$ & Anatomy Preserved \\
\hline $\begin{array}{l}\text { RM 2.1122, type } \\
\text { specimen }\end{array}$ & Steen, 1934 & $\begin{array}{l}\text { Preserves a skull table, disarticulated limb elements, } \\
\text { and ribs. }\end{array}$ \\
\hline RM 2.1193a & Steen, 1934 & $\begin{array}{l}\text { Preserves interior impressions of two disarticulated } \\
\text { skull tables. }\end{array}$ \\
\hline $\begin{array}{l}\mathrm{BM}(\mathrm{NH}) \mathrm{R} .439 \text {, } \\
\mathrm{BM}(\mathrm{NH}) \mathrm{R} .4553 \\
\text { (part and } \\
\text { counterpart) }\end{array}$ & Steen, 1934 & $\begin{array}{l}\text { Preserves a skull table and various disarticulated } \\
\text { postcranial bones. }\end{array}$ \\
\hline RM 12115 & Carroll, 1967 & $\begin{array}{l}\text { Preserves an incomplete pterygoid, disarticulated } \\
\text { pectoral girdle elements, and a radius. }\end{array}$ \\
\hline NCM 10050 & Carroll, 1967 & $\begin{array}{l}\text { Preserves disarticulated vertebral elements, as well } \\
\text { as a femur and tibia. }\end{array}$ \\
\hline NMC 10096 & Carroll, 1967 & Preserves a basioccipital. \\
\hline NMC 10119 & Carroll, 1967 & Preserves a clavicle and interclavicle. \\
\hline DMSW B.224 & Carroll, 1967 & Preserves a right humerus. \\
\hline $\mathrm{BM}(\mathrm{NH}) \mathrm{R} .442$ & Carroll, 1967 & $\begin{array}{l}\text { Preserves various disarticulated elements from the } \\
\text { pectoral and pelvic girdle. }\end{array}$ \\
\hline
\end{tabular}




\begin{tabular}{|l|l|l|}
\hline NSM 988GF70.1 & $\begin{array}{l}\text { Godfrey Holmes } \\
\text { and Laurin, 1991 }\end{array}$ & $\begin{array}{l}\text { Preserves an articulated series of trunk vertebrae, } \\
\text { neural spines, and ribs. }\end{array}$ \\
\hline RM 20.4984 & $\begin{array}{l}\text { Godfrey Holmes } \\
\text { and Laurin, 1991 }\end{array}$ & $\begin{array}{l}\text { Preserves an articulated series of presacral vertebrae, } \\
\text { neural spines, and haemal arches. Also includes an } \\
\text { ilium, femur, and some manus elements. }\end{array}$ \\
\hline NSM 994GF1.1 & $\begin{array}{l}\text { Holmes and } \\
\text { Carroll, 2010 }\end{array}$ & Preserves an articulated anterior half skeleton. \\
\hline
\end{tabular}

APPENDIX B: Phylogenetic character list.

Below is the list of 374 cranial, dental, and postcranial characters used in this analysis, modified from Pardo et al. (2017a) and Clack et al. (2016). The list is created using the compilation of significant tetrapod characters put together in the Pardo et al. (2017a) analysis (characters 1-370) and additional characters in the Clack (2016) matrix that were previously not included in Pardo's matrix (characters 371-374).

Original source of character is noted via an acronym:

HPSA: Huttenlocker, Pardo, Small, and Anderson (2013)

MA: Maddin \& Anderson (2012)

CABF: Clack, Ahlberg, Blom, and Finney (2012)

N: Neurocranial character novel to this study

C: Composite character

CL: Clack (2016)

1. Basal Skull Length (HPSA 001): (0) $>70 \mathrm{~mm}$; (1) $50-70 \mathrm{~mm}$; (2) $30-50 \mathrm{~mm}$; (3) $<30 \mathrm{~mm}$. 
2. Skull:trunk ratio (HPSA 002): (0) 0.45; (1) 0.30-0.45; (2) 0.20-0.29; (3) 0.20 .

3. Skull proportions (HPSA 003): (0) longer than wide; (1) wider than long.

4. Intertemporal (C 01): (0) present; (1) Replaced by anterior extension of supratemporal or tabular; (2) replaced by lateral extension of parietal. Note: this character serves as a replacement for HPSA 004, 007, 008, 050, 051, and 052.

5. Supratemporal (HPSA 005): (0) present; (1) absent.

6. ST exposure on occiput (HPSA 006): (0) absent; (1) present.

7. Postfrontal shape (HPSA 009): (0) broadly quadrangular; (1) falciform.

8. Squamosal-Tabular contact (HPSA 010): (0) absent; (1) present; (2) fused.

9. Lacrimal-prefrontal suture (HPSA 012): (0) simple butt joint; (1) interdigitating; (2) prefrontal broadly underplates lacrimal.

10. Lacrimal (HPSA 013): (0) present; (1) absent.

11. Lacrimal extends to naris (HPSA 014): (0) present; (1) absent.

12. Lacrimal extends to orbit (HPSA 015): (0) absent; (1) present.

13. Lacrimal orbital processes (HPSA 016): (0) only ventral present; (1) dorsal and ventral present; (2) neither present

14. Lacrimal-jugal contact (HPSA 017): (0) present; (1) absent.

15. Quadratojugal (HPSA 018): (0) present; (1) absent.

16. Quadratojugal-Jugal contact (HPSA 019); (0) present; (1) absent.

17. Quadratojugal-Maxillary contact (HPSA 020): (0) present; (1) absent.

18. Frontals (HPSA 021): (0) paired; (1) fused.

19. Frontal into orbital margin (HPSA 022): (0) no; (1) yes.

20. Anterior laterally flaring frontals (HPSA 023): (0) absent; (1) present.

21. Nasals (HPSA 024): (0) present; (1) absent.

22. Narial flange (HPSA 025): (0) absent; (1) present.

23. Alary processes of premaxilla (HPSA 026): (0) absent; (1) present.

24. Septomaxilla (HPSA 028): (0) ossified; (1) unossified. 
25. Prefrontal into external narial margin (HPSA 029): (0) distant from; (1) near; (2) present.

26. External naris in dorsal view (HPSA 030): (0) exposed; (1) not exposed.

27. External naris shape (HPSA 031): (0) circular; (1) posteriorly extended, along lacrimal-prefrontal suture; (2) posteriorly extended excavation of lacrimal only.

28. Dorsal exposure of premaxilla (HPSA 032): (0) broad pars dorsalis anteromedial to external naris; (1) pars dorsalis limited, but nasopremaxillary suture exposed dorsally (2) none.

29. Dorsal shape of skull (HPSA 033): (0) triangular; (1) diamond; (2) rounded.

30. Posterior skull margin (HPSA 034): (0) concave; (1) straight; (2) convex; (3) undulating.

31. Snout shape (HPSA 035): (0) blunt; (1) pointed.

32. Snout length (HPSA 036): (0) less than $1 / 4$ total skull length; (1) greater than $1 / 4$ total skull length

33. Quadrate articulates along internal flange of squamosal (HPSA 037): (0) absent; (1) present.

34. Otic/spiracular notch (HPSA 038): (0) present; (1) absent.

35. Large otic notch approaching orbit (HPSA 039): (0) more than $1 / 2$ postorbital length of skull; (1) between $1 / 4$ and $1 / 2$ postorbital length of skull; (2) less than $1 / 4$ postorbital length of skull.

36. Otic notch structure (HPSA 040): (0) open posteriorly; (1) closed posteriorly.

37. Semilunar flange of supratemporal (HPSA 041): (0) absent; (1) present.

38. Supratympanic flange (HPSA 042): (0) absent; (1) present

39. Supratympanic shelf (HPSA 043): (0) absent; (1) present.

40. Raised orbital rim (HPSA 044): (0) absent; (1) present.

41. Postorbital (HPSA 045): (0) present; (1) absent.

42. Jugal-postorbital interfingered processes (HPSA 046): (0) absent; (1) present.

43. Postorbital participates in orbital margin (HPSA 047): (0) present; (1) absent.

44. Shape of postorbital (HPSA 048): (0) irregular trapezoid; (1) triangular, apex caudal. 
45. Palpebral ossifications (HPSA 049): (0) absent; (1) mosaic of bony plates in orbit (new state); (2) Single large plate above orbit (new state).

46. Parietal-tabular contact (HPSA 052): (0) absent; (1) present.

47. Postparietals (HPSA 053): (0) paired; (1) fused; (2) absent.

48. Parietal foramen (HPSA 054): (0) present; (1) absent.

49. Postparietal size (HPSA 055): (0) much smaller than parietals; (1) approximately as large or larger than parietals.

50. Postparietal squamosal contact (HPSA 056): (0) absent; (1) present.

51. Postparietal length (HPSA 057): (0) large, quadrangular; (1) abbreviated anteroposteriorly, elongate lateral rectangle.

52. Squamosal-jugal contact (HPSA 058): (0) present; (1) absent.

53. Tabular (HPSA 059): (0) present; (1) absent.

54. Posterolateral projection from lateral margin of tabular above squamosal embayment (HPSA

060): (0) absent; (1) present.

55. Tabular horns (HPSA 061): (0) absent; (1) present.

56. Tabular horns shape (HPSA 062): (0) parallel or slightly divergent; (1) widely divergent.

57. Squamosal forms base of tabular horn (HPSA 063): (0) absent; (1) present.

58. Lateral line canal grooves (HPSA 064): (0) present; (1) absent.

59. Dermal sculpturing (HPSA 065): (0) circular pits; (1) shallow ridges and grooves; (2) little to none; (3) tuberculate.

60. Premaxilla anterior margin (HPSA 066): (0) vertical; (1) overturned.

61. Maxilla into external naris (HPSA 068): (0) present; (1) absent.

62. Maxilla entire ventral naris (HPSA 069): (0) absent; (1) present.

63. Maxilla (HPSA 070): (0) longer than palatine; (1) shorter than palatine.

64. Marginal teeth orientation (HPSA 071): (0) vertical; (1) turned medially.

65. Marginal teeth largest anterior (HPSA 072): (0) absent; (1) present. 
66. Marginal teeth shape (HPSA 073): (0) pointed pegs; (1) blunt pegs; (2) large cones.

67. Number of premax teeth (HPSA 074): (0) 10-20; (1) 5-9; (2) <5; (3) 20 or more

68. Number of max teeth (HPSA 075): (0) 30-40; (1) 20-29; (2) 15-19; (3) <15; (4) >40.

69. Teeth laterally compressed (HPSA 076): (0) no; (1) yes.

70. Enlarged teeth mid toothrow (maxillary) (HPSA 077): (0) absent; (1) present.

71. Teeth (HPSA 078): (0) simple points; (1) multiple cusps.

72. Multiple cusp orientation (HPSA 079): (0) Labio-lingual; (1) antero-posterior.

73. Enamel fluting (HPSA 080): (0) absent; (1) present.

74. Labyrinthine infolding (HPSA 081): (0) present; (1) absent.

75. Jaw articulation (HPSA 087): (0) posterior to occiput; (1) even with occiput; (2) anterior to occiput; (3) far anterior ( $>20 \%$ basal skull length).

76. Internal nares (HPSA 088): (0) widely separated; (1) narrowly separated.

77. Lateral exposure of the palatine (LEP) (HPSA 091): (0) absent; (1) present.

78. Anterior palatine (HPSA 092): (0) short anteromedial process articulating with vomer at choana;

(1) long anteromedial process more medial than lateral; (2) palatine absent.

79. Teeth on pterygoid (HPSA 098): (0) absent; (1) present.

80. Tooth pedicely (HPSA 099): (0) absent; (1) present.

81. Palatal teeth size (HPSA 103): (0) larger than marginal teeth; (1) equal to marginal;

(2) smaller than marginal.

82. Parasphenoid (HPSA 104): (0) medial of stapes; (1) under footplate of stapes.

83. Interpterygoid vacuities (HPSA 115): (0) narrow or closed; (1) wide; (2) fused at midline.

84. Anterior extent of pterygoids (C 02): (0) Pterygoids contact anteriorly; (1) Pterygoids exclude vomer from interpterygoid vacuity but excluded from median contact by parasphenoid; (2) pterygoids contact vomer but do not exclude vomer from interpterygoid vacuity; (3) pterygoids reach anteriorly only as far as palatine; (4) pterygoids reach ectopterygoid only; (5) pterygoids do not contact lateral palatal bones at all. Note: This character serves as a replacement for HPSA 116, 118, and 119). 
85. Lateral process of pterygoid into posttemporal fossa (HPSA 120): (0) absent; (1) present.

86. Ectopterygoid palatine width (HPSA 122): (0) wider than maxilla; (1) narrower than maxilla.

87. Pharyngeobranchial pouches (HPSA 123): (0) absent; (1) present.

88. Dentary (HPSA 124): (0) tooth row greater than $50 \%$ of total jaw length; (1) tooth row less than $50 \%$ of total jaw length.

89. Dentary forms coronoid process (HPSA 125): (0) absent; (1) present.

90. Surangular (HPSA 126): (0) subequal in size to angular; (1) substantially smaller than angular (2) absent.

91. Angular (HPSA 127): (0) approximately as deep as the dentary mid-tooth-row, or less; (1) deeper than dentary mid-toothrow.

92. Number of splenials (HPSA 128): (0) 2; (1) 1; (2) 0.

93. Splenial exposed laterally (HPSA 129): (0) present; (1) absent.

94. Meckelian fossae (HPSA 130): (0) 2 or more; (1) 1; (2) 0.

95. Ventral border of Meckel's fossa (HPSA 131): (0) splenial; (1) angular.

96. Retroarticular process presence (HPSA 132): (0) absent; (1) present.

97. Retroarticular process shape (HPSA 133): (0) straight; (1) hooked.

98. Vertical position of jaw articulation relative to tooth row (HPSA 134): (0) above; (1) equal; (2) below.

99. Extent of angular in lateral view (HPSA 135): (0) posterior tooth row; (1) middle of tooth row.

100. Number of coronoids (HPSA 136): (0) 3; (1) 2; (2) 1; (3) 0.

101. Splenial participates in symphysis (HPSA 139): (0) yes; (1) no.

102. Jaw sculpture (HPSA 140): (0) present; (1) absent.

103. Ossified hyoids (HPSA 141): (0) present; (1) absent.

104. Gill osteoderms (HPSA 142): (0) absent; (1) present noninterdigitating; (2) toothed interdigitating rakers.

105. Parahyoid (HPSA 143): (0) absent; (1) present. 
106. Number of accessory articulations (HPSA 144): (0) 0; (1) 1; (2) 2 or more.

107. Number of presacrals (HPSA 145): (0) 25-35; (1) 20-24; (2) >35; (3) <20.

108. Vertebral development (HPSA 146): (0) arches then centra; (1) centra and arches simultaneously.

109. Caudal processes between depressions (HPSA 147): (0) absent; (1) present.

110. Trunk intercentra (HPSA 148): (0) present; (1) absent.

111. Trunk neural arch to centrum in adults (HPSA 149): (0) loosely articulated; (1) sutured; (2) fused.

112. Base of neural spine (HPSA 150): (0) equal to or wider than haemal; (1) smaller than haemal spine.

113. Height of neural spines (HPSA 151): (0) even; (1) alternating.

114. Dermal armor associated with neural arches (HPSA 152): (0) Absent; (1) Present. Note: This character was established to recognize the expanded, sculptured structures seen at the top of neural arches in some nectrideans. Upon further examination, this character represents fusion of osteoderms to the neural arch. As this is present in a number of temnospondyls as well as chroniosuchians, we have amended this diagnosis to allow for comparisons outside nectrideans.

115. Neural spine shape in lateral view (HPSA 153): (0) anterior and posterior sides parallel, forming a rectangular surface; (1) non-parallel, triangular

116. Neural spine lateral surface (HPSA 154): (0) smooth; (1) crenulated.

117. Pleurocentra (HPSA 155): (0) paired rhachitomous; (1) closely approaching ventrally; (2) fused dominant weight bearing element; (3) embolomerous (new state).

118. Haemal arch presence (HPSA 156): (0) present; (1) absent.

119. Haemal arch fusion (HPSA 157): (0) loosely articulated to intercentra; (1) fused to mid length of centrum.

120. Haemal arch length (HPSA 158): (0) longer than or equal to neurals; (1) shorter than neurals.

121. Haemal accessory articulations (HPSA 159): (0) none; (1) one; (2) two.

122. Haemal arch shape (HPSA 160): (0) non parallel triangular; (1) parallel rectangular.

123. Tail termination in skeleton (HPSA 161): (0) tapers; (1) deep with sudden end.

124. Tail length (HPSA 162): (0) elongate equal to or exceeding trunk and skull length; 
(1) foreshortened markedly shorter than trunk.

125. Trunk arches (HPSA 163): (0) paired; (1) fused.

126. Spinal nerve foramina (HPSA 164): (0) absent; (1) present.

127. Extended transverse processes (HPSA 165): (0) absent; (1) present.

128. Transverse process (HPSA 166): (0) on arch pedicle; (1) on centrum.

129. Atlas axis intercentra (HPSA 167): (0) present; (1) absent.

130. Atlas Anterior centrum (HPSA 168): (0) same size as posterior; (1) laterally expanded.

131. Atlas centrum (HPSA 169): (0) multipartite; (1) single notochordal; (2) single odontoid.

132. Atlas neural arch centrum fusion (HPSA 170): (0) loosely articulated; (1) sutured to centrum; (2) fused to centrum.

133. Atlas parapophyses (HPSA 171): (0) on centrum; (1) on transverse process; (2) absent.

134. Atlas neural arch midline fusion (HPSA 172): (0) paired; (1) sutured at midline; (2) fused at midline.

135. Atlas accessory articulation (HPSA 173): (0) absent; (1) zygosphene; (2) zygantra.

136. Proatlantes (HPSA 174): (0) present; (1) absent.

137. Second cervical arch (HPSA 175): (0) more expanded to subsequent; (1) equal to subsequent; (2) shorter than subsequent.

138. Atlas ribs (HPSA 176): (0) one pair; (1) two pairs; (2) absent.

139. Cervical rib distal shape (HPSA 177): (0) spatulate; (1) pointed.

140. Ribs anterior to sacrum (HPSA 178): (0) short; (1) long.

141. Ribs (HPSA 179): (0) elongated and sometimes curved; (1) straight; (2) short simple rod.

142. Costal process at rib head (HPSA 180): (0) absent; (1) present.

143. Number of sacrals (HPSA 181): (0) 1; (1) 2; (2) 3.

144. Sacral parapophysis (HPSA 182): (0) on centrum; (1) on transverse process. 
145. Number pairs of caudal ribs (HPSA 183): (0) 5 or more; (1) 4; (2) 3; (3) 2 or fewer.

146. Interclavicle posterior stem length (HPSA 184): (0) no or short; (1) long.

147. Interclavicle posterior stem breadth (HPSA 185): (0) wide; (1) narrow.

148. Interclavicle shape (HPSA 186): (0) diamond shaped; (1) T-shaped.

149. Interclavicle anterior plate (HPSA 187): (0) broad; (1) narrow.

150. Interclavicle shape (if diamond present) (HPSA 188): (0) broad diamond; (1) narrow diamond.

151. Interclavicle anterior fimbriation (HPSA 189): (0) present; (1) absent.

152. Interclavicle sculpture (HPSA 190): (0) present; (1) absent.

153. Cleithrum head dorsal extent (HPSA 191): (0) aligned along anterior rim of scapula; (1) posterodorsally enlarged head wrapping around dorsal scapula.

154. Cleithrum head size and shape (HPSA 192): (0) dorsally greatly expanded much wider than shaft; (1) simple rod without or slight dorsal expansion.

155. Cleithrum ossification (HPSA 193): (0) ossified; (1) unossified.

156. Cleithrum overall shape (HPSA 194): (0) rounded or pointed dorsally; (1) T or Y shaped.

157. Proximal clavicle blades (HPSA 195): (0) widely separate; (1) articulate medially;

(2) interdigitate.

158. Supraglenoid foramen (HPSA 196): (0) present; (1) absent.

159. Number coracoid foramina (HPSA 197): (0) none; (1) 1; (2) 2.

160. Scapulocoracoid ossification (HPSA 198): (0) both; (1) scapula only; (2) absent.

161. Torsion in humerus (HPSA 200): (0) absent; (1) less than 80 degrees; (2) more than 80 degrees.

162. Deltapectoral crest (HPSA 201): (0) weak or absent; (1) intermediate; (2) prominent.

163. Supinator process (HPSA 202): (0) absent; (1) present.

164. Humerus length (HPSA 203): (0) long ( 4 trunk centra); (1) short.

165. Radius-humerus ratio (HPSA 204): (0) $>0.7$; (1) $0.5-0.7 ;(2)<0.5$.

166. Olecranon process (HPSA 205): (0) unossified; (1) ossified. 
167. Carpals (HPSA 206): (0) fully or partially ossified; (1) unossified.

168. Basale commune (HPSA 207): (0) absent; (1) present.

169. Number digits manus (HPSA 208): (0) 5; (1) 4; (2) 3; (3) $>5$.

170. Pelvis (HPSA 209): (0) fused; (1) sutured; (2) poorly ossified.

171. Anteriorly inclined ilium (HPSA 210): (0) absent; (1) present.

172. Iliac blade (HPSA 211): (0) 2 dorsal processes; (1) narrowly bifurcate; (2) single blade.

173. Internal trochanter articulation (HPSA 212): (0) distinct; (1) continuous.

174. Femoral shaft (HPSA 213): (0) robust; (1) slender.

175. Femur (HPSA 214): (0) long; (1) short.

176. Tarsals (HPSA 215): (0) ossified; (1) unossified.

177. Elongate tibiale and fibulare (HPSA 216): (0) absent; (1) present.

178. Number of distal tarsals (HPSA 217): (0) 6; (1) 5 or fewer.

179. Astragalus (HPSA 218): (0) absent; (1) present.

180. Number of digits pes (HPSA 219): (0) 5; (1) 4 or less; (2) $>5$.

181. Dorsal margin of splenial only contacts first coronoid (HPSA 220): (0) absent; (1) present.

182. Postparietal lappet (HPSA 224): (0) mostly exposed posteriorly; (1) equal posteriorly and dorsally; (2) mostly exposed dorsally.

183. Cheek emargination (HPSA 225): (0) absent; (1) present.

184. Parietal anterior waisting (HPSA 226): (0) absent; (1) present.

185. Parietal width relative to frontal (HPSA 227): (0) greater; (1) equal or less.

186. Trabecula cranii (N 01): (0) Without significant median fusion posterior to solum nasi (platytrabic); (1) fused medially posterior to solum nasi to form elongate trabecula communis (tropitrabic).

187. Dorsal trabeculae (N 02): (0) dorsal trabeculae provide dorsolateral bridge between sphenoid region and nasal capsule; (1) dorsal trabeculae absent or incomplete, no dorsolateral bridge between sphenoid region and nasal capsule. 
188. Ossification between optic foramen and pila antotica (N 03): (0) ossification complete between optic foramen and pila antotica; (1) pila metoptica and associated cartilaginous taenia unossified.

189. Ossification within columella ethmoidalis (N 04): (0) absent; (1) present.

190. Path of profundus branch of trigeminal nerve (N 05): (0) enclosed in lateral wall of sphenoid region of braincase and exits separately from maxillomandibular branch via series of small foramina; (1) extramural, exits antotic fissure with other branches of trigeminal.

191. Foramina for optic nerve and trigeminal nerve (N 06): (0) confluent; (1) widely separate.

192. Lateral head vein (N 07): (0) No distinct foramen for lateral head vein; (1) Distinct foramen within the antotic fissure serving the lateral head vein.

193. Anterior extent of cultriform process of parasphenoid (N 08): (0) cultriform process extends to anterior margin of sphenethmoid; (1) cultriform process extends far anterior to sphenethmoid; (2) cultriform process does not reach anterior margin of sphenethmoid.

194. Olfactory bulbs (N 09): (0) narrow; (1) endocasts swollen, leaving considerable impressions in lateral and ventral wall of sphenoid region and in ventral surface of frontal.

195. Flange from skull roof articulating with sphenethmoid (modified from HPSA 223): (0) absent; (1) present on frontal and parietal; (2) present on frontal only.

196. Descending lamina of parietal invades medial orbital wall between 'pleurosphenoid' and 'sphenethmoid' elements (N 10): (0) no; (1) yes.

197. Foramen for oculomotor nerve (N 11): (0) exits braincase far dorsal to foramen for optic nerve; (1) exits braincase at or below optic nerve.

198. Intermaxillary fossa (modified from HPSA 095): (0) present; (1) absent.

199. Intermaxillary fossa (N 12): (0) paired; (1) unpaired.

200. Sphenethmoid forms interorbital septum (N 13): (0) no; (1) yes.

201. Anterior extent of cultriform process along palate (N 14): (0) cultriform process extends anteriorly to level of posterior margin of choana; (1) cultriform process dramatically shortened, barely reaching the level of the posterior margin of the orbit.

202. Sutural contact between cultriform process of parasphenoid and vomer (N 15): (0) no; (1) yes. 
203. Lateral wall of the nasal capsule underplated by lateral processes of the vomer and palatine (N 16): (0) no; (1) yes.

204. Cultriform process vaulted high above palatal surface (N 17): (0) no; (1) yes.

205. Posterior extent of parasphenoid beneath braincase (N 18): (0) floors sphenoid region only; (1) floors sphenoid and otic region; (2) floors sphenoid, otic, and occipital regions.

206. Basal tubera (N 19): (0) present, with significant endochondral contribution; (1) present, with contribution of parasphenoid only; (2) absent

207. Path of common internal carotid artery (N 20): (0) does not run alongside braincase, enters braincase directly in region of sella turcica; (1) follows vidian sulcus along posterior surface of basal plate of parasphenoid, enters parasphenoid via vidian canal in basal plate of parasphenoid, divides into cerebral and palatal branches after entering parasphenoid; (2) follows vidian sulcus along posterior surface of basal plate of parasphenoid or lateral wall of braincase, divides into cerebral and palatal branches prior to entering the skull

208. Buccohypophyseal foramen in parasphenoid (N 21): (0) open; (1) absent.

209. Morphology of pila antotica (N 22): (0) pila antotica is a thin, broad sheet; (1) pila antotica is a robust dorsoventral pillar bracing the skull roof against the palate.

210. Basicranial fissure (N 23): (0) present; (1) absent.

211. Location of vidian sulcus (N 24): (0) along ventral surface of braincase; (1) along lateral surface of braincase.

212. Basipterygoid joint (N 25): (0) epipterygoid comprises entire conus recessus; (1) substantial contribution to conus recessus by pterygoid; (2) conus recessus comprised entirely of pterygoid without epipterygoid participation; (3) pterygoid and parasphenoid broadly sutured without development of a conus recessus

213. Hypophyseal fossa (N 26): (0) single unpaired sulcus; (1) paired sulci divided medially by ridge originating on dorsum sellae.

214. Bone flanking the dorsum sellae (N 27): (0) concurrent with fully ossified lateral braincase; (1) subparallel with sagittal plane ('pleurosphenoid'); (2) strongly oblique to or perpendicular to sagittal plane ('laterosphenoid'); (3) restricted to dorsum sellae only.

215. Basal plate of parasphenoid (HPSA 105): (0) roughly quadrangular, basipterygoid articulations narrowly spaced; (1) rectangular laterally, anteroposteriorly narrow, basipterygoid articulations distant.

216. Sphenethmoid (HPSA 114): (0) ossified; (1) unossified. 
217. Ossification within the synotic tectum (N 28): (0) synotic tectum massively coossified with otic capsules; (1) supraoccipital paired at some point in ontogeny; (2) supraoccipital unpaired throughout ontogeny; (3) no supraoccipital bone; synotic tectum invaded by dorsal processes of exoccipitals.

218. Median ascending process of supraoccipital (N 29): (0) absent; (1) present.

219. Lateral ascending processes of the supraoccipital (N 30): (0) absent; (1) present.

220. Margin of fenestra vestibuli (N 31): (0) parasphenoid excluded by neurocranial elements (basisphenoid and basioccipital); (1) parasphenoid contributes to anteroventral margin of fenestra vestibuli; (2) parasphenoid floors entire fenestra vestibuli; (3) Ossification of otic capsule surrounds entire fenestra vestibuli.

221. Crista intervestibularis (N 32): (0) crista intervestibularis absent; (1) crista intervestibularis present.

222. Morphology of crista parotica (N 33): (0) crista parotica meets exoccipitals only, forming lateral wall of posttemporal fossa but not bracing against dermal skull; (1) crista parotica drawn out dorsolaterally into paroccipital process that contacts the tabular; (2) crista parotica drawn out laterally into paroccipital process that contacts the cheek and/or suspensorium.

223. Dorsal process of stapes (HPSA 111): (0) absent; (1) present.

224. Facets on dorsal surface of supraoccipital (N 34): (0) absent; (1) present.

225. Otoccipital fissure (N 35): (0) present; (1) absent.

226. Crista parotica (N 36): (0) Descends posteriorly; (1) Horizontal along the extent of its length.

227. Position of quadrate with respect to otic capsules (modified from HPSA 82): (0) quadrates ventral and lateral to otic capsules; (1) quadrates mostly lateral to and greater or equal to twice the width of the otic capsules; (2) quadrates mostly ventral to otic capsules; (3) quadrates approaching or abutting lateral wall of otic capsules.

228. Size of otic capsules (N 37): (0) otic capsules comprise less than $2 / 3$ the width of otoccipital region; (1) otic capsules comprise greater than $2 / 3$ total width of otoccipital region.

229. Otic trough (N 38): (0) absent; (1) present.

230. Articulation between the epipterygoid and prootic (N 39): (0) none; (1) elongate facet on anterior surface of prootic for articulation of epipterygoid.

231. Opisthotic obscures occipital in lateral view (N 40): (0) no; (1) yes. 
232. Fenestra vestibularis at end of broad, winglike lateral extension of the otic capsule (N 41): (0) no; (1) yes.

233. Cristae in otoccipital region (N 42): (0) comprised primarily of ascending flanges from braincase; (1) comprised primarily of descending flanges from skull roof

234. Opisthotic excluded from the occipital surface by tabular process of the exoccipital (N 43): (0) no; (1) yes.

235. Insertion of epaxial musculature on occiput (N 44): (0) deep within post-temporal fossae; (1) in broad, shallow fossae along occipital surface of postparietals.

236. Foramen for internal jugular vein (N 45): (0) between supraoccipital and exoccipital; (1) between opisthotic and exoccipital; (2) through exoccipital; (3) Posterior notch of fenestra vestibule.

237. Foramina for hypoglossal nerve (N 46): (0) multiple; (1) single; (2) none.

238. Occipital condyle shape (modified from HPSA 085): (0) round; (1) U-shaped; (2) paired.

239. Ventral process of exoccipital reaches basipterygoid joint along palatal surface $(\mathrm{N}$ 47): (0) absent; (1) present.

240. Occipital condyle shape (HPSA 084): (0) concave; (1) convex.

241. Columella of stapes (modified from HPSA 108): (0) perforate; (1) imperforate.

242. Orientation of stapes (modified from HPSA 109): (0) Dorsal, towards tabular or otic notch; (1) anteroventral, towards quadrate.

243. Stapedial footplate shape (HPSA 110): (0) oval; (1) round; (2) palmate.

244. Dorsal sinus between synotic tectum and skull roof (modified from HPSA 222): (0) absent; (1) present.

245. Ossification within septum internasale (N 48): (0) absent; (1) present, sphenethmoid; (2) present, mesethmoid.

246. Ossification of septum internasale invades nasal tectum (N 49): (0) absent; (1) present.

247. Insertion of hypaxial musculature (N 50): (0) sphenoid; (1) otic; (2) basioccipital.

248. Prootic supported by pedicel extending from basisphenoid lateral to prootic foramen (N 51): (0) no; (1) yes.

249. Position of pineal foramen with respect to hypophyseal foramen (N 52): (0) anterior to; (1) approximately the same; (2) far posterior to. 
250. Pineal foramen or fossa (N 53): (0) well anterior to posterior margin of cerebral fossa; (1) at or behind posterior margin of cerebral fossa.

251. Median wall of otic capsule (N 54): (0) completely unossified; (1) ossification of opisthotic; (2) ossification of supraoccipital and basioccipital.

252. Conical recess in basioccipital (N 55): (0) absent; (1) present.

253. Semicircular canals (N 56): (0) separated from utricular region by bone; (1) not separated from utricular region by bone.

254. Basioccipital (N 57): (0) Robust ossification ventral to foramen magnum present; (1) absent.

255. Accessory articulation processes with proatlantal facet on exoccipitals (N 58): (0) absent; (1) prominent.

256. Exoccipital proatlantal facets incorporated into occipital joint (N 59): (0) no; (1) yes.

257. Anterior tectal (modified from CABF 001): (0) anterior tectal present; (1) absent.

258. Ectopterygoid/palatine exposure (CABF 002): (0) more or less confined to tooth row; (1) broad medial exposure additional to tooth row; (2) reduced to thin sliver.

259. Ectopterygoid: (0) Present; (1) Absent.

260. Ectopterygoid as long or longer than palatines (CABF 003): (0) yes; (1) no.

261. Ectopterygoid reaches subtemporal fossa (CABF 004): (0) no; (1) yes.

262. Frontal (CABF 005): (0) absent; (1) present.

263. Jugal (CABF 007): (0) does not extend anterior to orbit; (1) extends anterior to orbit.

264. Lateral rostral present (CABF 009): (0) yes; (1) no.

265. Maxilla makes interdigitating suture with vomer (CABF 010): (0) no; (1) yes.

266. Maxilla external contact with premaxilla (CABF 011): (0) narrow contact point, not interdigitated; (1) interdigitating suture.

267. Maxilla extends behind level of posterior margin of orbit (CABF 012): (0) yes; (1) no.

268. Median rostral (CABF 013): (0) single; (1) paired; (2) absent.

269. Opercular (CABF 014): (0) present; (1) absent. 
270. Prefrontal (CABF 015): (0) twice as long as broad, or less; (1) three times as long as broad.

271. Prefrontal (CABF 016): (0) transverse anterior suture with tectal; (1) tapers to a point anteriorly.

272. Preopercular (CABF 017): (0) present; (1) absent.

273. Pterygoid quadrate ramus margin in subtemporal vacuity (CABF 018): (0) concave; (1) with some convex component.

274. Vomers separated by parasphenoid > half length (CABF 019): (0) yes; (1) no.

275. Vomers (CABF 022): (0) as broad as long or broader; (1) about twice as long as broad or longer.

276. Basipterygoid process (CABF 023): (0) not strongly projecting with concave anterior face; (1) strongly projecting with flat anterior face.

277. Ethmoid (CABF 024): (0) fully ossified; (1) partly or wholly unossified.

278. Hypophyseal region (CABF 025): (0) solid side wall pierced by small foramina for pituitary vein and other vessels; (1) single large foramen.

279. Lateral commissure of otic capsule bearing hyomandibular facets (CABF 026): (0) present; (1) absent.

280. Parasphenoid (CABF 027): (0) does not overlap basioccipital; (1) overlaps basioccipital.

281. Denticulate field of parasphenoid (CABF 028): (0) present; (1) absent.

282. Sphenoid (CABF 029): (0) fully ossified, terminating posteriorly in intracranial joint or fused to otoccipital; (1) separated from otoccipital by unossified gap.

283. Ectopterygoid fang pairs (CABF 030): (0) present; (1) absent.

284. Ectopterygoid row (3+) of smaller teeth (CABF 031): (0) present; (1) absent.

285. Ectopterygoid/palatine shagreen field (CABF 032): (0) absent; (1) present.

286. Palatine row of smaller teeth (CABF 034): (0) present; (1) absent.

287. Pterygoid shagreen (palatine ramus) (modified from CABF 035): (0) dense; (1) organized radiating rows of denticles; (2) disorganized patches or absent.

288. Dentition of transverse flange of pterygoid (new character): (0) Denticle field indistinct from palatine denticle field; (1) distinct raised denticle field; (2) organized tooth row; (3) absent. 
289. Premaxillary tooth proportions (CABF 036): (0) all approximately same size; (1) posteriormost teeth at least twice height of anteriomost teeth; (2) Anteriormost teeth largest.

290. Vomerine fang pairs (CABF 037): (0) present; (1) absent.

291. Vomerine fang pairs noticeably smaller than other palatal fang pairs (CABF 038): (0) no; (1) yes.

292. Vomer anterior wall forming posterior margin of palatal fossa bears tooth row meeting at midline (CABF 039): (0) yes; (1) no.

293. Vomerine row of teeth (CABF 040): (0) present; (1) absent.

294. Vomerine shagreen field (CABF 041): (0) absent; (1) present.

295. Adductor fossa (CABF 042): (0) faces dorsally; (1) faces medially.

296. Adductor crest (CABF 043): (0) absent; (1) peak anterior to adductor fossa, dorsal margin of fossa concave; (2) peak above anterior part of adductor fossa, dorsal margin of fossa convex.

297. Angular-prearticular contact (CABF 044): (0) prearticular contacts angular edge to edge; (1) absent; (2) medial lamina of angular sutures with prearticular.

298. Coronoid (anterior) contacts splenial (CABF 045): (0) no; (1) yes.

299. Prearticular extends between infradentaries and middle coronoid (modified from CABF 046) (0) Yes; (1) No.

300. Coronoid (middle) contacts postsplenial (CABF 047): (0) no; (1) yes.

301. Coronoid (posterior) posterodorsal process (CABF 048): (0) no; (1) yes.

302. Coronoid (posterior) posterodorsal process visible in lateral view (CABF 049): (0) no; (1) yes.

303. Dentary external to angular \& surangular, with chamfered ventral edge and no interdigitations (CABF 050): (0) no; (1) yes.

304. Dentary ventral edge (CABF 051): (0) smooth continuous line; (1) abruptly tapering or "stepped" margin.

305. Dentary suture with splenial \& postsplenial marked by deep furrow (CABF 052): (0) no; (1) yes.

306. Mandibular sensory canal (CABF 053): (0) present; (1) absent. 
307. Mandibular canal exposure (CABF 054): (0) entirely enclosed, opens through lines of pores; (1) mostly enclosed, short sections of open grooves; (2) mostly open grooves, short sections opening through pores; (3) entirely open.

308. Oral sulcus/surangular pit line of mandible (CABF 055): (0) present; (1) absent.

309. Meckelian bone floors precoronoid sulcus (CABF 056): (0) yes; (1) no.

310. Meckelian bone ossified in middle part of jaw (CABF 057): (0) yes; (1) little or no ossification.

311. Meckelian bone exposure in middle part of jaw (CABF 058): (0) depth much less than prearticular; (1) depth similar to prearticular.

312. Meckelian foramina/fenestrae, dorsal margins (CABF 059): (0) Meckelian bone; (1) prearticular; (2) infradentary

313. Meckelian foramina/fenestrae height (CABF 060): (0) much lower than adjacent prearticular; (1) equal to or greater than depth of adjacent prearticular.

314. Parasymphyseal lateral foramen present (CABF 061): (0) no; (1) yes.

315. Parasymphyseal mesial foramen present (CABF 62): (0) no; (1) yes.

316. Postsplenial with medial lamina (CABF 063): (0) no; (1) small; (2) expanded, contacting precoronoid.

317. Postsplenial pit line present (CABF 064): (0) yes; (1) no.

318. Postsplenial suture with prearticular present (modified from CABF 065): (0) no; (1) yes.

319. Prearticular sutures with surangular (CABF 066): (0) no; (1) yes.

320. Medial lamina of splenial (modified from CABF 067): (0) absent; (1) present.

321. Prearticular with longitudinal ridge below coronoids (CABF 068): (0) no; (1) yes.

322. Prearticular with mesially-projecting flange on dorsal edge along posterior border of adductor fossa (CABF 069): (0) no; (1) yes.

323. Prearticular centre of radiation of striations (CABF 070): (0) level with posterior end of posterior coronoid; (1) level with middle of adductor fossa; (2) level with posterior end of adductor fossa.

324. Splenial has free ventral flange (CABF 071): (0) yes; (1) no. 
325. Splenial, rearmost extension of medial lamina (CABF 072): (0) closer to anterior end of jaw than to adductor fossa; (1) equidistant; (2) closer to anterior margin of adductor fossa than to the anterior end of the jaw.

326. Coronoids; at least one has fang pair recognizable because at least twice the height of coronoid or marginal teeth (CABF 073): (0) yes; (1) no.

327. Coronoids: at least one has fangs recognizable because noticeable lingual to vertical lamina of bone and to all other teeth (CABF 074): (0) yes; (1) no.

328. Coronoids: at least one has organized tooth row (CABF 075): (0) yes; (1) no.

329. Coronoids: at least one carries shagreen (CABF 076): (0) no; (1) yes.

330. Coronoids: size of teeth (excluding fangs) on anterior and middle coronoids relative to dentary tooth size (CABF 077): (0) about the same; (1) half the height or less.

331. Dentary tooth row (CABF 078): (0) homodont; (1) markedly heterodont.

332. Dentary with parasymphyseal fangs internal to marginal tooth row (CABF 079): (0) yes; (1) no.

333. Dentary teeth (CABF 080): (0) same size as maxillary teeth; (1) larger than maxillary teeth; (2) smaller than maxillary teeth

334. Dentary with a row of very small teeth or denticles lateral to tooth row (CABF 081): (0) yes; (1) no.

335. Parasymphyseal tooth plate (CABF 082): (0) present; (1) absent.

336. Parasymphyseal plate dentition (CABF 083): (0) shagreen or irregular tooth field; (1) organized dentition aligned parallel to jaw margin; (2) no dentition.

337. Parasymphyseal plate has fang pair (CABF 084): (0) no; (1) yes.

338. Parasymphyseal plate has tooth row (CABF 085): (0) no; (1) short tooth row, separated from coronoid row by diastema; (2) long tooth row reaching coronoid.

339. Prearticular shagreen field distribution (CABF 086): (0) gradually decreasing from dorsal to ventral; (1) well-defined dorsal longitudinal band; (2) scattered patches or absent.

340. Anterior palatal fenestra (CABF 087): (0) single; (1) double; (2) absent.

341. Dorsal fontanelle on snout (CABF 088): (0) absent; (1) present.

342. Interpterygoid vacuities (CABF 089): (0) absent; (1) at least 2x wider than long; (2) $2 \mathrm{x}$ longer than wide. 
343. Intracranial joint (CABF 090): (0) present in dermal skull roof; (1) absent in dermal skull roof

344. Nature of dermal ornament (CABF 091): (0) tuberculate; (1) fairly regular pit and ridge; (2) irregular; (3) absent or almost absent

345. Nature of ornament: starbursts of radiating ornament on at least some bones (CABF 092): (0) no; (1) yes

346. Anocleithrum (CABF 093): (0) oblong with distinct anterior overlap area; (1) dropshaped with no anterior overlap area; (2) absent.

347. Cleithrum (CABF 094): (0) ornamented; (1) not ornamented.

348. Cleithrum, postbranchial lamina (CABF 095): (0) present; (1) absent.

349. Autopod (modified from CABF 096): (0) radials; (1) digits.

350. Humerus (CABF 097): (0) narrow tapering entepicondyle; (1) square or parallelogram-shaped entepicondyle.

351. Ilium, iliac canal (CABF 098): (0) absent; (1) present.

352. Ilium, posterior process (CABF 099): (0) oriented posterodorsally; (1) oriented approximately horizontally posteriorly.

353. Interclavicle (CABF 100): (0) small and concealed or absent; (1) large and exposed. 354. Interclavicle shape (CABF 101): (0) ovoid; (1) kite shaped; (2) with posterior stem. 355. Lepidotrichia in paired appendages (CABF 102): (0) present; (1) absent. 356. Posttemporal and supracleithrum (CABF 103): (0) present; (1) absent.

357. Radius and ulna (CABF 104): (0) radius much longer than ulna; (1) approximately equal in length.

358. Ribs, trunk (CABF 107): (0) all cylindrical; (1) some or all bear flanges from posterior margin which narrow distally; (2) some or all flare distally.

359. Scapular blade (CABF 108): (0) absent; (1) small with narrow top; (2) large with broad top.

360. Scapulocoracoid (modified from CABF 109): (0) small and tripodal; (1) large plate.

361. Subscapular fossa (CABF 110): (0) broad and shallow; (1) deeply impressed posteriorly. 
362. Squamation (CABF 111): (0) complete body covering of scales, all similar; (1) ventral armour of gastralia.

363. Pectoral process (CABF112): (0) absent; (1) present.

364. Proximal limb of oblique ridge (CABF 113): (0) present, separated from anterior margin of humerus by prepectoral space; (1) absent, replaced by deltopectoral crest.

365. Latissimus dorsi attachment (CABF 114): (0) diffuse ridged area; (1) distinct process.

366. Foramina piercing oblique ventral ridge (CABF 115): (0) many; (1) one moderately large foramen in addition to entepicondylar foramen; (2) entepicondylar foramen is the only large opening, other foramina are pinpricks or absent; (3) none.

367. Humerus with well-developed anterior plate (new character): (0) yes; (1) no.

368. Subclavicular ossifications (new character): (0) Absent; (1) Sometimes present.

369. Radial capitulum (new character, modified from Sigurdsen \& Green, 2011): (0) approximately same size as ulnar facet; (1) greatly enlarged and rounded, $>2 \mathrm{x}$ size of ulnar facet.

370. Lissamphibian inner ear sensu Maddin and Anderson (2012) (MA 220): (0) no; (1) yes.

371. Tabular lateral horn (subdermal unornamented component) (CL 67): (0) absent; (1) button; (2) blade.

372. Tabular prolonged posterolateral ornamented surface (CL 68): (0) absent; (1) present.

373. Tabular emarginated lateral margin (CL 69): (0) absent; (1) present.

374. Tabular occipital flange exposure (CL 70): (0) absent; (1) extends as far ventrally as does postparietal; (2) extends further ventrally than does postparietal.

APPENDIX C: Synapomorphy lists describing nodes of interest in the analyses that added more characters and more stem tetrapod taxa, corresponding to Figures 3.5 and 3.7 , respectively.

Below are the lists of characters describing the placement of embolomeres in their stem tetrapod position in the analyses that added more embolomere taxa, more characters, and 
more stem tetrapod taxa. In all lists, braincase characters are marked with an asterisk (*) and character states are indicated in parentheses.

C1: Characters uniting embolomeres in a stem-tetrapod position in the analyses that added more embolomere taxa and more characters (describing Figure 3.5, Node A):

32. Snout length: less than $1 / 4$ total skull length $(0)$

49. Postparietal size: much smaller than parietals (0)

136. Proatlantes: absent (1)

173. Internal trochanter articulation: continuous (1)

*198. Intermaxillary fossa: absent (1)

*199. Intermaxillary fossa: unpaired (1)

*201. Anterior extent of cultriformis process along palate: cultriform process dramatically shortened, barely reaching the level of the posterior margin of the orbit (1) 273. Pterygoid quadrate ramus margin in suntemporal vacuity: with some convex component (1)

284. Ectopterygoid row (3+) of smaller teeth: present (1)

294. Vomerine shagreen field: present (1)

299. Prearticular extends between infradentaries and middle coronoid: no (1)

306. Mandibular sensory canal: absent (1)

316. Postsplenial with mesial lamina: small (1)

318. Postsplenial suture with prearticular present: yes (1)

331. Dentary tooth row: homodont (0)

333. Dentary teeth: same size as maxillary teeth $(0)$

336. Parasymphyseal plate dentition: shagreen or irregular tooth field (0)

337. Parasymphyseal plate has fang pair: no (0)

340. Anterior palatal fenestra: absent (2)

341. Dorsal fontanelle on snout: absent (0)

359. Scapular blade: large with a broad top (2)

C2: Characters excluding embolomeres from a more derived position within the tetrapod tree in the analyses that added more embolomere taxa and more characters (describing Figure 3.5, Node B):

30. Posterior skull margin: straight (1)

58. Lateral line canal grooves: absent (1)

95. Ventral border of meckel's fossa: angular (1)

107. Number of presacrals: 20-24 (1)

140. Ribs anterior to sacrum: short (0)

166. Olecranon process: unossified (0) 
*207. Path of common internal carotid artery: follows vidian sulcus along posterior surface of basal plate of parasphenoid only (1)

*224. Facets on dorsal surface of supraoccipital: present (1)

*252. Conical recess in basioccipital: present (1)

266. Maxilla external contact with premaxilla: interdigitating suture (1)

285. Ectopterygoid/palatine shagreen field: absent (1)

286. Palatine row of smaller teeth: absent (1)

354. Interclavicle shape: with posterior stem (2)

C3: Characters uniting embolomeres in a more crownward position in the analysis that added more stem tetrapod taxa (describing Figure 3.7, Node A):

30. Posterior skull margin: concave (0)

46. Parietal tabular contact: present (1)

173. Internal trochanter articulation: continuous (1)

294. Vomerine shagreen field: absent (0)

295. Adductor fossa: faces medially (1)

301. Coronoid (posterior) posterodorsal process: yes (1)

313. Meckelian foramina/fenestrae height: equal to or greater than the depth of adjacent prearticular (1)

329: Coronoids - at least one carries shagreen: yes (1)

335: Parasymphyseal tooth plate: absent (1)

337. Parasymphyseal plate has fang pair: yes (1)

C4: Characters uniting Calligenethlon and Tulerpeton in the analysis that added more stem tetrapod taxa (describing Figure 3.7, Node B):

27. External naris shape: posteriorly extended, along lacrimal-prefrontal suture (1)

44. Shape of postorbital: triangular, apex caudal (1)

66. Marginal teeth shape: blunt pegs (1)

109. Caudal processes between depression: present (1)

112. Base of neural spine: smaller than haemal spine (1)

116. Neural spine lateral surface: crenulated (1)

137. Second cervical arch: equal to subsequent (1)

138. Atlas ribs: one pair (0)

139. Cervical rib distal shape: pointed (1)

153. Cleithrum head dorsal extent: posterodorsally enlarged head size and shape (1)

159. Number coracoid foramina: 1 (1)

160. Scapulocoracoid ossification: scapula only (1)

173. Internal trochanter articulation: distinct (0) 


\section{References}

Adams, G.R., Mann, A., Shawwa, N.A., Hebert, B., and Maddin, H.C. A large tetrapod pelvis from the Upper Carboniferous 'Hebert Beds' of the Joggins Formation, Nova Scotia. Unpublished manuscript, in preparation.

Allen, J.P., Fielding, C.R., Rygel, M.C., and Gibling, M.R. 2013. Deconvolving signals of tectonic and climatic controls from continental basins: an example from the late Paleozoic Cumberland Basin, Atlantic Canada. Journal of Sedimentary Research, 83: 847-872.

Anderson, J.S., Reisz, R.R., Scott, D., Frobisch, N.B. and Sumida, S.S. 2008. Nature, 453: 515-518.

Baird, D. 1962. A haplolepid fish fauna in the Early Pennsylvanian of Nova Scotia. Palaeontology, 5: 22-29.

Baird, D. 1978. Studies on Carboniferous freshwater fishes. American Museum Novitates, 2641: 1-22.

Baird, D. 1982. A small temnospondyli amphibian from the Lower Pennsylvanian of Nova Scotia. Journal of Vertebrate Paleontology, 56: 1302-1305.

Bell, W.A. 1913. Excursion in eastern Quebec and the Maritimes Provinces; the Joggins section. Excursion Guide Book 1. XII International Geological Congress, Canada, 326-346.

Bell, W.A. 1943. Carboniferous rocks and fossil floras of northern Nova Scotia. Geological Survey of Canada Memoir, 238.

Berman, D.S., Reisz, R.R., and Eberth, D.A. 1987. Seymouria sanjuanensis (Amphibia, Batrachosauria) from the Lower Permian Cutler Formation of north-central New Mexico and the occurrence of sexual dimorphism in that genus questioned. Canadian Journal of Earth Science, 24: 1769-1784.

Brough, M.C. and Brough, J.C. 1967. Studies on early tetrapods. I. Lower Carboniferous Microsaurs. Philosophical Transactions of the Royal Society of London Series BBiological Sciences, 252(776): 107.

Brown, R. \& Smith, R. 1829. Geology and mineralogy (of Nova Scotia). In (Haliburton, T.C.; ed.) An historical and statistical account of Nova Scotia, 2. Joseph Howe, Halifax, 414-453.

Buchwitz, M., Foth, C., Kogan, I., and Voigt, S. 2012. On the use of osteoderm features in a phylogenetic approach on the internal relationships of the Chroniosuchia (Tetrapoda: Reptiliomorpha). Palaeontology, 55(3): 623-640. 
Calder, J.H. 1998. The Carboniferous evolution of Nova Scotia. In: Blundell, D.J. \& Scott, A.C. (eds) Lyell: the Past is the Key to the Present. Geological Society, London, Special Publications, 143, 261-302.

Calder, J.H. 2012. The Joggins Fossil Cliffs: Coal Age Galapagos. Formac Publishing Company.

Cardini, A., and Elton, S. 2008. Does the skull carry a phylogenetic signal? Evolution and modularity in the guenons. Biological Journal of the Linnean Society, 93: 813-834.

Carroll, R. L. 1970. The ancestry of reptiles. Philosophical Transaction of the Royal Society of London, B, 257: 267-308.

Carroll, R.L. 1964. The earliest reptiles. Journal of the Linnean Society (Zoology), 45(304): 61-83.

Carroll, R.L. 1966. Microsaurs from the Westphalian B of Joggins, Nova Scotia. Proceedings of the Linnean Society of London, 177: 63-97.

Carroll, R.L. 1966. Microsaurs from the Westphalian B of Joggins, Nova Scotia. Proceedings of the Linnean Society of London, 177: 63-97.

Carroll, R.L. 1967. Labyrinthodonts from the Joggins Formation. Journal of Paleontology, 41: 111-142.

Clack, J. A. \& Finney, S. M. 2005. Pederpes finneyae, an articulated tetrapod from the Tournaisian of Western Scotland. Journal of Systematic Palaeontology, 2: 311-46.

Clack, J. A. 2001. Eucritta melanolimnetes from the Early Carboniferous of Scotland, a stem tetrapod showing a mosaic of characteristics. Transactions of the Royal Society of Edinburgh: Earth Sciences, 92: 75-95.

Clack, J.A. 1994. Earliest known tetrapod braincase and the evolution of the stapes and fenestra ovalis. Nature, 369: 392-394.

Clack, J.A. 2011. A Carboniferous embolomere tail with supraneural radials. Journal of Vertebrate Paleontology, 31: 1150-1153.

Clack, J.A. and Holmes, R.B. 1988. The braincase of the anthracosaur Archeria crassidisca with comments on the interrelationships of primitive tetrapods. Paleontology, 31: 85-107.

Clack, J.A. and Milner, A.R. 2015. Basal Tetrapoda. In Handbook of paleoherpetology, part 3A1, ed. H.-D. Sues, pp.1-93. München, Friedrich Pfeil.

Clack, J.A., Bennett, C.E., Carpenter, D.K., Davies, S.J., Fraser, N.C. Kearsey, T.I. Marshall, E.A., Millward, D., Otoo, B.K.A., Reeves, E.J., Ross, A.J., Ruta, M., Smithson, K.Z., Smithson, T.R., and Walsh, S.A. 2016. Phylogenetic and 
environmental context of a Tournaisian tetrapod fauna. Nature, Ecology, \& Evolution, 1: 0002.

Clark, E., 2018. At the roots of limbed vertebrate diversity: new light on patterns and processes of early tetrapod evolution. Doctoral dissertation, University of Lincoln.

Cope, E.D. 1875. On fossil remains from Reptilia and fish remains from Illinois. Proceedings of the Academy of Natural Sciences of Philadelphia, 27: 404-408.

Copeland, M.J. 1957. The arthropod fauna of the Upper Carboniferous rocks of the Maritime Provinces. Geological Survey of Canada, Memoir, 286.

Davies, S. J., \& Gibling, M. R. 2003. Architecture of coastal and alluvial deposits in an extensional basin: the Carboniferous Joggins Formation of eastern Canada. Sedimentology, 50(3): 415-439.

Davies, S.J., Gibling, M.R., Rygel, M.C. \& Calder, J.H. 2005. The Pennsylvanian Joggins Formation of Nova Scotia: sedimentological log and stratigraphic framework of the historic fossil cliffs. Atlantic Geology, 41: 115-141.

Dawson, J.W. 1853. On the Coal-Measures of the South Joggins, Nova Scotia. Quarterly Journal of the Geological Society, London, 10: 1-42.

Dawson, J.W. 1859. On a Terrestrial Mollusk, a Millepede, and new Reptiles, from the Coal Formation of Nova Scotia. Quarterly Journal of the Geological Society, London, 16: 268-277.

Dawson, J.W. 1870. Note on some new animal remains from the Carboniferous and Devonian of Canada. Quarterly Journal of the Geological Society, 26: 166-167.

Falcon-Lang, H.J. 2006. A history of research at the Joggins Fossil Cliffs of Nova Scotia, Canada, the world's finest Pennsylvanian section. Proceedings of the Geologists Association, 117: 377-392.

Falcon-Lang, H.J., Benton, M.L., Braddy, S.J., \& Davies, S.J. 2006. The Pennsylvanian tropical biome reconstructed from the Joggins Formation of Nova Scotia, Canada. Journal of the Geological Society, London, 163: 561-576.

Falcon-Lang, H.J., Rygel, M.C., Calder, J.H., and Gibling, M.R. 2004. An early Pennsylvanian waterhole deposit and its fossil biota in a dryland alluvial plain setting, Joggins, Nova Scotia. Journal of the Geological Society, 161: 209-222.

Godfrey, S., Fiorillo, A.R., and Carroll, R.L. 1987. A newly discovered skull of the temnospondyli amphibian Dendrerpeton acadianum Owen. Canadian Journal of Earth Sciences, 24: 796-805. 
Godfrey, S.J. 1987. The postcranial skeletal anatomy of the Carboniferous tetrapod Greererpeton burkemorani Romer, 1969. Philosophical Transactions of the Royal Society of London B, 323: 75-133.

Godfrey, S.J., Holmes, R.B., and Laurin, M. 1991. Articulated remains of a Pennsylvanian embolomere (amphibian: anthracosauria) from Joggins, Nova Scotia. Journal of Vertebrate Paleontology, 11: 213-219.

Goswami A., and Polly, P.D. 2010. The influence of character correlations on phylogenetic analysis: a case study of the carnivoran skull. In: Goswami A, Friscia A, editors. Carnivoran evolution: new views on phylogeny, form and function. Cambridge: Cambridge University Press. 141-164.

Gregory, J. and Carroll, R. 1965. Microsaurs and the Origin of Captorhinomorph Reptiles [with Comments]. American Zoologist, 5(2): 277-286.

Grey, M. and Finkel, Z.V. 2011. The Joggins Fossil Cliffs UNESCO World Heritage site: a review of recent research. Atlantic Geology, 47: 185-200.

Hebert, B.L. and Calder, J.H. 2011. On the discovery of a unique terrestrial faunal assemblage in the classic Pennsylcanian section at Joggins, Nova Scotia. Canadian Journal of Earth Sciences, 41(3): 247-254.

Holmes, R.B. 1984. The Carboniferous amphibian Proterogyrinus scheelei Romer, and the early evolution of tetrapods. Philosophical Transactions of the Royal Society of London, 306: 431-527.

Holmes, R.B., and Carroll, R.L. 2010. An articulated embolomere skeleton (Amphibia: Anthracosauria), from the Lower Pennsylvanian (Bashkirian) of Nova Scotia. Canadian Journal of Earth Science, 47: 209-219.

Holmes, R.B., Carroll R.L., and Reisz. R.R. 1998. The first articulated skeleton of Dendrerpeton acadianum (Temnospondyli, Dendrerpetontidae) from the Lower Pennsylvanian locality of Joggins, Nova Scotia, and a review of its relationships. Journal of Vertebrate Paleontology, 18(1): 64-79.

Huttenlocker, A. K., Pardo, J. D., Small, B. J., \& Anderson, J. S. 2012. Cranial morphology of recumbirostrans (Lepospondyli) from the Permian of Kansas and Nebraska, and early morphological evolution inferred by micro-computed tomography. Journal of Vertebrate Paleontology, 33: 540-552.

Huxley, T.H. 1863. Description of Anthracosaurus russelli, a new labyrinthodont from the Lanarkshire coal field. Quarterly Journal of the Geological Society of London, 19: $56-68$.

Jaeckel, O. 1902. Über Gephyrostegus bohemicus, n.g. n.sp. Zeitschrift der Deutschen Geologischen Gesellschaft, 54: 127-132. 
Klembara, J. \& Ruta, M. 2004. The seymouriamorph tetrapod Utegenia shpinari from the ?Upper Carboniferous-Lower Permian of Kazakhstan. Part II: Postcranial anatomy and relationships. Transactions of the Royal Society of Edinburgh: Earth Sciences, 94: 75-93.

Lebedev, O.A. and M.I. Coates. 1995. The postcranial skeleton of the Devonian tetrapod Tulerpeton curtum Lebedev. Zoological Journal of the Linnean Society, 114(3): 307-348.

Lemmon, A.R., Brown, J.M., Stanger-Hall, K., and Lemmon, E. 2009. The effect of ambiguous data on phylogenetic estimates obtained by maximum likelihood and Baysian inference. Systematic Biology, 58: 130-145.

Lieberman, D.E., Ross, C.F., and Ravosa, M.J. 2000. The primate cranial base: ontogeny, function, and integration. Yearbook of Physical Anthropology, 43: 117-169.

Lyell, C. 1845. Travels in North America, in the Years 1841-2; With geological observations on the United States, Canada, and Nova Scotia. Murray, London.

Lyell, C. and J. W. Dawson. 1853. On the remains of a reptile (Dendrerpeton acadianum, Wyman and Owen) and of a land shell discovered in the interior of an erect fossil tree in the coal measures of Nova Scotia. Quarterly Journal of the Geological Society of London, 9: 58-63.

Maddin, H.C. 2011. Deciphering morphological variation in the braincase of caecilian amphibians (gymnophiona). Journal of Morphology, 272: 850-871.

Maddin, H.C., Jenkins, F.A. Jr., Anderson, J.S. 2012. The braincase of Eocaecilia micropodia (Lissamphibia, Gymnophiona) and the origin of Caecilians. PLoS ONE, 7(12): e50743. doi:10.1371/journal.pone.0050743.

Maddin, H.C., Olori, J.C., Anderson, J.S. 2011. A redescription of Carrolla craddocki (Lepospondyli: Brachystelechidae) based on high-resolution CT, and the impacts of miniaturization and fossoriality on morphology. Journal of Morphology, 272: 722743.

Matsumoto, R. and Evans, S.E. 2016. The palatal dentition of tetrapods and its functional significance. Journal of Anatomy, 230(1): 47-65.

Matthew, G.F. 1903. On batrachian and other footprints from the Coal Measures of Joggins, N.S. Natural History Society of New Brunswick Bulletin, 21: 103-108.

Matthew, G.F. 1905. New species and a new genus of batrachian footprints of the Carboniferous system in eastern Canada. Royal Society of Canada, Proceedings and Transactions, 10: 77-121. 
Milner, A.C. 1996. A revision of the temnospondyli amphibians from the Upper Carboniferous of Joggins, Nova Scotia. Special Papers in Palaeontology, 52: 81103.

Molnar, J.L., Diogo, R., Hutchinson, J.R., and Pierce, S.E. 2018. Reconstructing pectoral appendicular muscle anatomy in fossil fish and tetrapods over the fish-to-limbs transition. Biological Reviews, 93: 1077-1107.

Mossman, D.J. and Grantham, R.G. 1996. A recently discovered amphibian trackway (Dromillopus quadrifidus) at Joggins, Nova Scotia. Canadian Journal of Earth Sciences, 33: 710-714.

Nabhan, A.R. and Sarkar, I.N. 2011. The impact of taxon sampling on phylogenetic inference: a review of two decades of controversy. Briefings in Bioinformatics, 13: $122-134$.

Olson, E.C. 1965. Relationships of Seymouria, Diadectes, and Chelonia. American Zoologist, 5: 295-307.

Panchen, A.L. 1970. Handbuch der Paläoherpetologie, Pt. 5a. Gustav Fischer Verlag, Stuttgart: Germany.

Panchen, A.L. 1977. On Anthracosaurus russelli Huxley (Amphibia: Labyrinthodontia) and the Family Anthracosauridae. Philosophical Transactions of the Royal Society of London Series B, Biological Sciences, 279: 447-512.

Pardo, J. D., Szostakiwskyj, M., \& Anderson, J. S. 2015. Cranial morphology of the brachystelechid 'microsaur' Quasicaecilia texana Carroll provides new insights into the diversity and evolution of braincase morphology in recumbirostran 'microsaurs'. PLoS ONE 10, e0130359.

Pardo, J.D., and Anderson, J.S. 2016. Cranial morphology of the Carboniferous-Permian tetrapod Brachydectes newberryi (Lepospondyli, Lysorophia): new data from $\mu \mathrm{CT}$. PLOS ONE, 11(8): e0161823.

Pardo, J.D., Szostakiwskyj, M., Ahlberg, P.E., and Anderson, J.S. 2017a. Hidden morphological diversity among early tetrapods. Nature, 546: 642-645.

Pardo, J.D., Small, B.J., and Huttenlocker, A.K. 2017b. Stem caecilian from the Triassic of Colorado sheds light on the origins of Lissamphibia. Proceedings of the National Academy of Sciences, 114(27): 5389-5395.

Paton, R. L., Smithson, T. R. \& Clack, J. A. 1999. An amniote-like skeleton from the Early Carboniferous of Scotland. Nature, 398: 508-13.

Prescott, Z.M., Stimson, M.R., Dafoe, L.T, Gibling, M.R., Macrae, R.A., Calder, J.H., and Hebert, B.L. 2014. Microbial mats and ichnofauna of a fluvial-tidal channel in the Lower Pennsylvanian Joggins Formation, Canada. Palaios, 29(12): 624-645. 
Reisz, R.R., and Modesto, S.P. 1996. Archerpeton anthracos from the Joggins Formation of Nova Scotia: a microsaur, not a reptile. Canadian Journal of Earth Sciences, 33: $703-709$.

Robinson, J., Ahlberg, P.E., and Koentges, G. 2005. The braincase and middle ear region of Dendrerpeton acadianum (Tetrapoda: Temnospondyli). Zoological Journal of the Linnean Society, 143: 577-597.

Romer, A.S. 1947. Review of the Labyrinthodontia. Bulletin of the Museum of Comparative Zoology Harvard, 99: 1-367.

Romer, A.S. 1963. The larger embolomerous amphibians of the America Carboniferous. Harvard College.

Ruta, M. and Clack, J.A. 2007. A review of Silvanerpeton miripedes, a stem amniote from the Lower Carboniferous of East Kirkton, West Lothian, Scotland. Science Transactions of The Royal Society of Edinburgh, 97(1): 31-63.

Ruta, M., Coates, M.I., and Quicke, D.L.J. 2003. Early tetrapod relationships revisited. Biological Reviews, 78(2): 251-345.

Rygel, M. C., \& Gibling, M. R. 2006. Natural Geomorphic Variability Recorded in a High-Accommodation Setting: Fluvial Architecture of the Pennsylvanian Joggins Formation of Atlantic Canada. Journal of Sedimentary Research, 76: 1230-1251.

Sarjeant, W.A.S. and Mossman, D.J. 1978. Vertebrate footprints from Carboniferous sediments of Nova Scotia - historical review and description of newly discovered forms. Palaeogeography Palaeoclimatology Palaeoecology, 23: 279-306.

Säve-Söderbergh, G. 1934. Some points of view concerning the evolution of the vertebrates and the classification of this group. Arkiv fr Zoologi, 26A: 1-20.

Säve-Söderbergh, G. 1935. On the dermal bones of the head in labyrinthodont stegocephalians and primitive Reptilia. Meddr Grønland, 98(3): 1-211.

Schneck, W.M. and Fritz, W.J. 1985. An amphibian trackway (Cincosaurus cobbi) from the Lower Pensylvanian ("Pottsville") of Lookout Mountain, Georgia: a first occurence. Journal of Paleontology, 1243-1250.

Smithson, T. R. 1985. The morphology and relationships of the Carboniferous amphibian Eoherpeton watsoni Panchen. Zoological Journal of the Linnean Society, 85: 317410.

Steen, M.C. 1934. The amphibian fauna from the South Joggins. Nova Scotia. Proceedings of the Zoological Society of London. Vol. 104. No. 3. Oxford, UK: Blackwell Publishing Ltd. 
Sternberg, C.M. 1933. Carboniferous Tracks from Nova Scotia. Geological Society of America Bulletin, 44: 951-964.

Stevenson, J.S. 1967. Note on fossil teeth from Joggins Nova Scotia. Proceedings of the Geological Association of Canada, 18: 109-114.

Stevenson, J.S., and Stevenson, L.S. 1966. Fluorine content of microsaur teeth from Carboniferous rocks of Joggins Nova Scotia. Science, 154: 1548-1550. Anderson, J. S. 2001. The phylogenetic trunk: maximal inclusion of taxa with missing data in an analysis of the Lepospondyli (Vertebrata, Tetrapoda). Systematic Biology, 50: $170-93$.

Stimson, M., G. Spencer, and G. Melanson. 2012. The smallest known tetrapod foortprints: Batrachichnus salamandroides from the Caarboniferous of Joggins, Nova Scotia, Canada. Ichnos, 19: 127-140.

Sumida, S.S. and Lombard, E.R. 1991. The atlas-axis complex in the Late Paleozoic genus Diadectes and the characteristics of the atlas-axis complex across the Amphibian to Amniote transition. Journal of Paleontology, 65: 973-983.

Swofford, D. L. 2002. PAUP*. Phylogenetic Analysis Using Parsimony (*and Other Methods). Version 4. Sinauer Associates, Sunderland, Massachusetts.

Szostakiwskyj, M., Pardo, J. D., and Anderson, J. S. 2015. Micro-CT study of Rhynchonkos stovalli (Lepospondyli, Recumbirostra), with description of two new genera. PLoS ONE, 10, e0127307.

Vallin, G. \& Laurin, M. 2004. Cranial morphology and affinities of Microbrachis, and a reappraisal of the phylogeny and lifestyle of the first amphibians. Journal of Vertebrate Paleontology, 24: 56-72.

Watson, D.M.S. 1926. Croonian lecture. The evolution and origin of the Amphibia. Philosophical Transactions of the Royal Society (B), 214: 189-257.

Witzmann, F. 2016: $\mathrm{CO}^{2}$-metabolism in early tetrapods revisited: inferences fromosteological correlates of gills, skin and lung ventilation in the fossil record. Lethaia, 49: 492-506.

Zittel, K.V. 1888. Handbuch der Palaeontologie. I.Abt. Palaeozoologie. III. Band. Amphibia. Munchen \& Leipzig: Oldenbourg. 